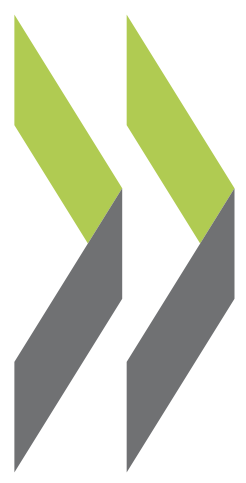

SIGMA Papers No. 47

\title{
Centralised Purchasing Systems in the European Union
} OECD 
Organisation de Coopération et de Développement Économiques

Organisation for Economic Co-operation and Development

PUBLIC GOVERNANCE AND TERRITORIAL DEVELOPMENT DIRECTORATE

English - Or. English

\begin{abstract}
SIGMA - A JOINT INITIATIVE OF THE OECD AND THE EUROPEAN UNION, PRINCIPALLY FINANCED BY THE EU
\end{abstract}

\title{
CENTRALISED PURCHASING SYSTEMS IN THE EUROPEAN UNION
}

SIGMA PAPER No. 47

This study provides a comparative analysis of existing centralised purchasing institutions in selected EU Member States in terms of organisation, coverage, objectives and rationale, financing models, types of framework agreements and call-off systems, as well as the information technology used, and it examines success factors, risks and future challenges.

Piotr-Nils Gorecki, Senior Adviser: piotr-nils.gorecki@oecd.org; Valérie Forges, Project Assistant: valerie.forges@oecd.org 

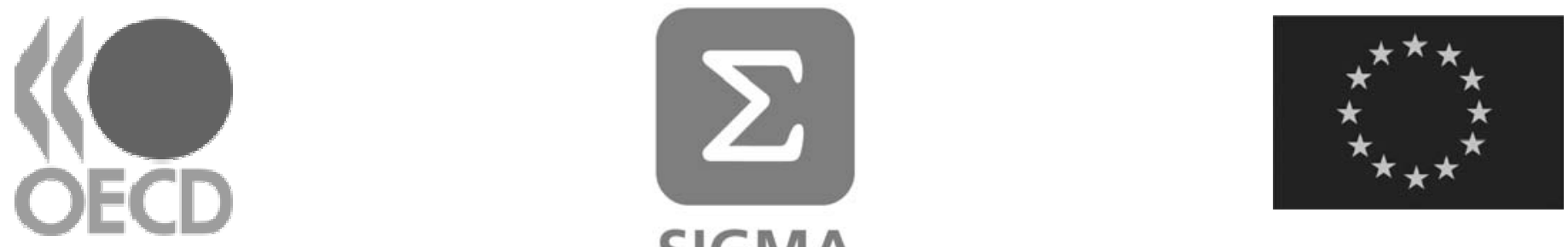

\title{
SIGMA
}

Support for Improvement in Governance and Management

A joint initiative of the OECD and the EU, principally financed by the EU

\section{CENTRALISED PURCHASING SYSTEMS IN THE EUROPEAN UNION}

\author{
A SIGMA STUDY OF CENTRAL PURCHASING BODIES IN SELECTED EU MEMBER STATES \\ AWARDING AND MANAGING FRAMEWORK AGREEMENTS
}

SIGMA PAPER No. 47

This document has been produced with the financial assistance of the European Union. The views expressed herein can in no way be taken to reflect the official opinion of the European Union, and do not necessarily reflect the views of the OECD and its member countries or of the beneficiary countries participating in the Sigma Programme. 


\section{THE SIGMA PROGRAMME}

The Sigma Programme - Support for Improvement in Governance and Management - is a joint initiative of the OECD and the EU, principally financed by the EU.

In 2010, Sigma supports the public governance reform efforts of the following partners:

- $\quad$ EU Candidates and Potential Candidates - Albania, Bosnia and Herzegovina, Croatia, the former Yugoslav Republic of Macedonia, Montenegro, Serbia, Turkey and Kosovo (under UNSCR 1244/99) ${ }^{1}$.

- European Neighbours-Algeria, Armenia, Azerbaijan, Belarus, Egypt, Georgia, Israel, Jordan, Lebanon, Libya, Moldova, Morocco, Occupied Palestinian Territory, Syria, Tunisia and Ukraine, as well as Russia².

Sigma provides assistance in the following areas:

- Legal Framework, Public Service and Justice: Human Resources Management; Public Integrity; General Administrative Law; Organisation of Public Administration.

- Management of Financial Resources: External Audit; Public Expenditure Management; Public Internal Financial Control; Public Procurement.

- $\quad$ Policy-making and Regulatory Systems: Co ordination Structures; Policy and Strategic Capacities; Regulatory Management.

- Design and Implementation of Reform.

Sigma uses a variety of support mechanisms:

- Advice on reforms, design and implementation of strategies and strategic development plans;

- Analysis and assessment of legal frameworks, methodologies, systems and institutions;

- $\quad$ Peer reviews and assistance;

- Drafting of studies, handbooks and other reference material;

- Methodological, technical and strategic input to optimise other Commission assistance;

- Training;

- $\quad$ Support to networks of policy-makers and practitioners.

For further information on Sigma, consult our website: http://www.sigmaweb.org

\section{(C) OECD 2010}

All requests for permission to reproduce or translate this publication for commercial or non-commercial purposes should be submitted to rights@oecd.org.

In accordance with UN Security Council Resolution 1244, since June 1999 Kosovo has been governed by the UN Interim Administration Mission in Kosovo (UNMIK).

As agreed with the European Union, Sigma activities are being undertaken initially in ten prioritised countries: Egypt, Jordan, Lebanon, Morocco and Tunisia (ENPI-South); Armenia, Azerbaijan, Georgia, Moldova and Ukraine (ENPI-East). 


\section{FOREWORD}

The establishment and use of central purchasing bodies, framework agreements and electronic procurement systems - which are closely linked to each other - are areas of growing interest among Sigma's partner countries. EC Directive 2004/18 provides rules and procedures for the application of these instruments, which commonly have been transposed into national legislation of the partner countries, although this is not a mandatory requirement of the Directive. In the past, Sigma has also provided guidance to many of the countries in the form of training and advice so as to support the drafting of primary and secondary legislation on these instruments as well as their practical application and implementation.

The introduction of central purchasing arrangements and the use of framework agreements, including eprocurement, are guided by the ambition of the governments to modernise and improve their procurement systems for the purposes of efficiency and functionality. However, and this is the main challenge, Sigma's partner countries generally lack the experience necessary for the successful use of framework agreements and the operations of central purchasing bodies, especially where these operations are based on the award and management of framework agreements, including within an eprocurement environment. Therefore, Sigma's ongoing dialogue on these instruments with partner countries clearly reveals that there is a strong demand for in-depth information and guidance on how centralised purchasing and framework agreements should best be implemented, based on how such systems are organised and practised in EU Member States.

This study provides a comparative analysis of existing centralised purchasing institutions in selected EU Member States in terms of organisation, coverage, objectives and rationale, financing models, types of framework agreements and call-off systems, as well as the information technology used, and it examines success factors, risks and future challenges. The Member States officially included in the study are Denmark, Finland, France, Hungary and Italy. In addition, brief information on how these systems are set up in Sweden and in the UK is also provided. These countries all have a long experience of central and coordinated purchasing, including the use of framework agreements, and they have established institutional structures for operating such systems.

The study aims to provide guidance to partner countries on the various aspects of the operation of centralised purchasing systems, such as:

- What kind of organisational model can be used for a Central Purchasing Body (CPB); e.g. a department within a line ministry, or an independent agency, or even a separate limited company?

- What are the costs and benefits of a Centralised Purchasing System (CPS) compared with a decentralised one?

- What goods and services are normally covered or not covered by a CPB?

- How are the operations of a CPB financed - through the budget, through transaction fees, through a combination thereof, or in some other way?

- How are the agreements between the CPB and customers usually set up in terms of the elaboration of technical specifications, the estimation of aggregate requirements, payment commitments and procedures, etc.?

- Is the use of the CPB's services and its framework agreements (if any) voluntary or obligatory for the procuring entities? 
- What types of framework agreements are used: single-supplier or multi-supplier agreements; are all terms agreed in advance or not; what is the duration of the contracts; and what are the procedures, if any, for the conduct of mini-competitions?

- How is the participation of SMEs encouraged or ensured, if at all?

The study makes no attempt to evaluate the advantages or disadvantages of different CPS models or to recommend the system of a particular country, but rather aims to provide information and guidance, and it examines various key factors determining the overall attractiveness of a CPS. 


\section{TABLE OF CONTENTS}

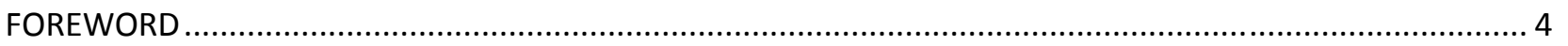

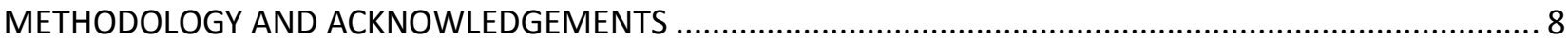

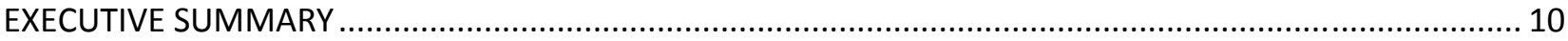

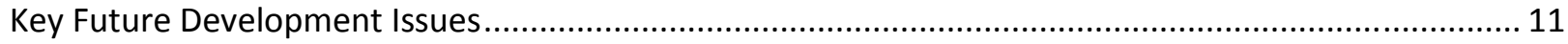

PART I. CONCEPT, RATIONALE AND LEGAL BASE FOR CENTRALISED PURCHASING SYSTEMS IN THE EU14

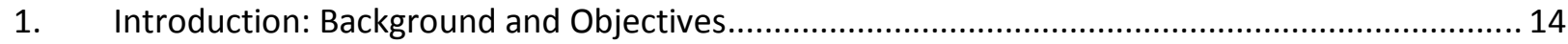

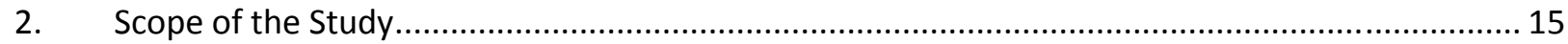

3. The Concept of Centralised Procurement .................................................................. 16

4. The Rationale for Establishing a Centralised Purchasing System (CPS) ................................. 17

5. The Legal Base for Central Purchasing Bodies (CPBs) and Framework Agreements - the EU Public

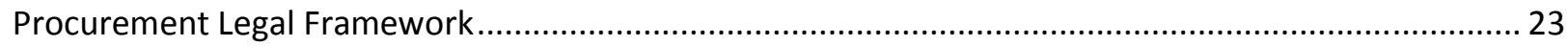

PART II. COMPARATIVE ANALYSIS OF CENTRALISED PURCHASING SYSTEMS IN SELECTED EU MEMBER

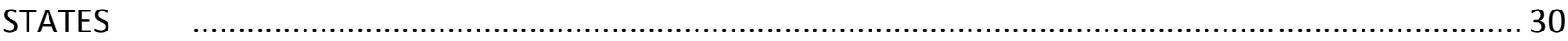

6. An Overview of the respective Centralised Purchasing Systems ..........................................30

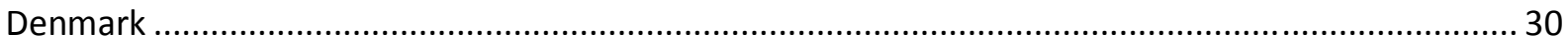

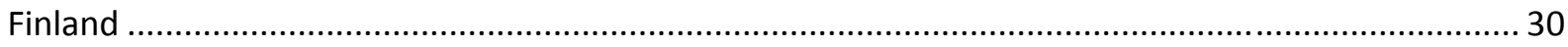

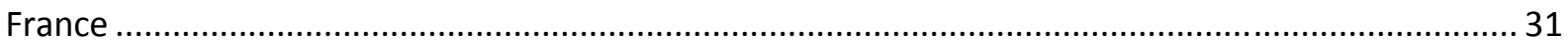

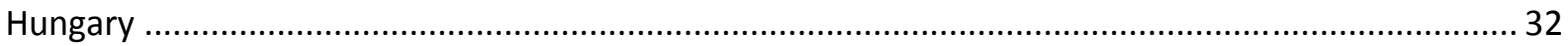

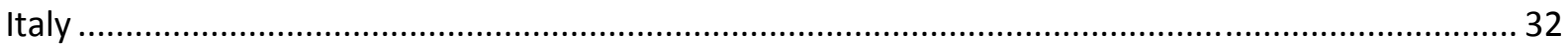

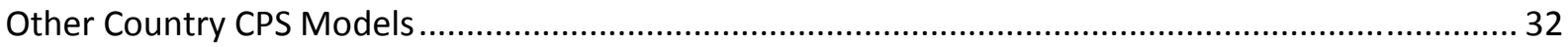

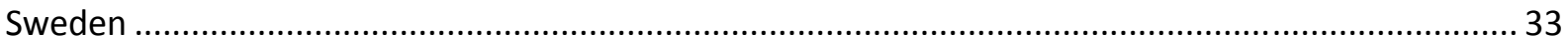

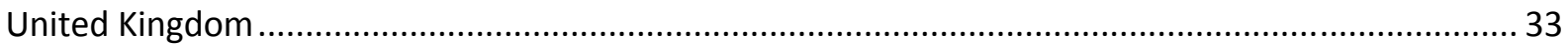

7. Main Features and Characteristics of the Centralised Purchasing System (CPS).........................36

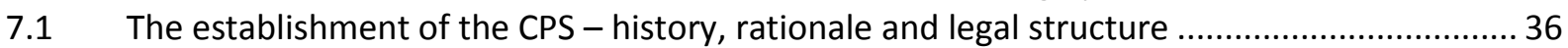

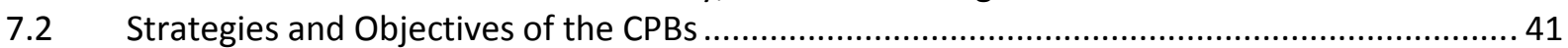

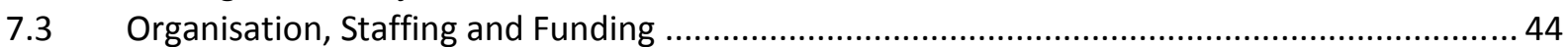

7.4 Procurement and Contracting Strategies ..................................................................47

7.5 Framework Agreements - Models and Conditions …....................................................49

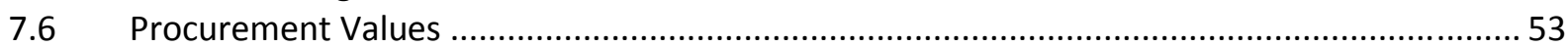

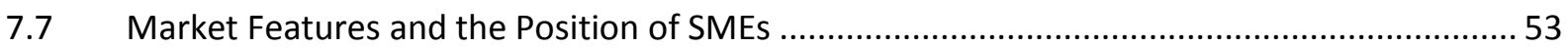

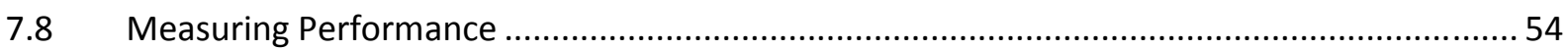

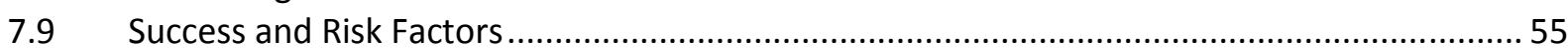


PART III. KEY OBSERVATIONS AND ISSUES, IMPORTANT RISK AND SUCCESS FACTORS - LESSONS LEARNED, AND THE WAY FORWARD - A SUMMARY ............................................................... 56

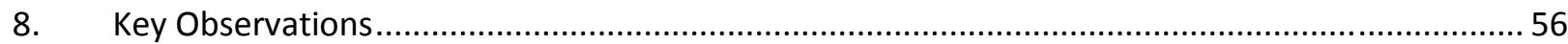

8.1 Centralised Versus Decentralised Procurement? ............................................................ 56

8.2 What Goods and Services Should Normally be Covered or not be Covered by the CPB's

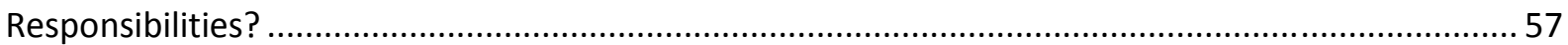

8.3 Should the Use of Central Purchasing Bodies' Services be Compulsory for the Procuring

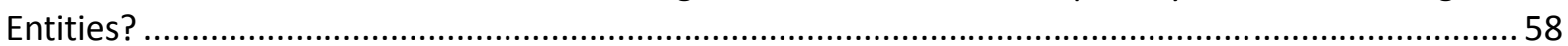

8.4 What is the Best Organisational Form for a Central Purchasing Body? ................................59

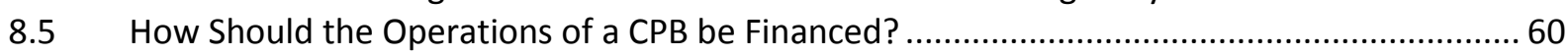

8.6 What is the Importance of Good Customer and Supplier Relationships? .............................61 61

8.7 What Types of Framework Agreements Should be Used? ................................................61

8.8 What Can be Done to Promote Competition and Facilitate the Participation of SMEs? .........63

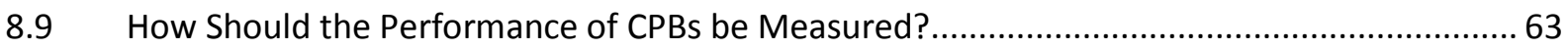

9. Important Risk and Success Factors - Lessons Learned ......................................................64

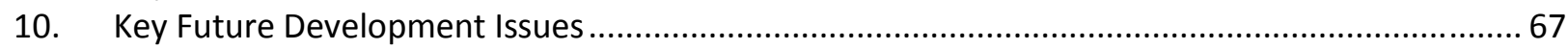

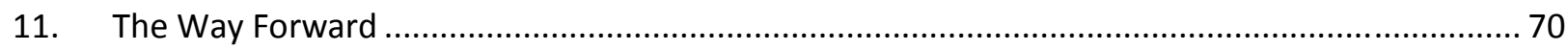

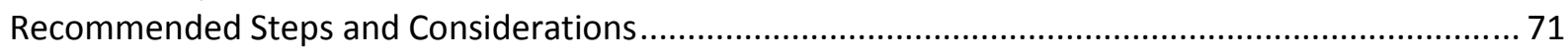

ANNEX 1. DENMARK, SKI A/S (STATENS OG KOMMUNERNES INDKØBS SERVICE A/S) ..........................73

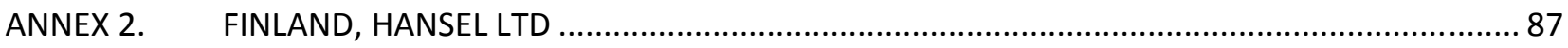

ANNEX 3. FRANCE, UNION DES GROUPEMENTS D'ACHATS PUBLICS (UGAP) AND SERVICE DES ACHATS

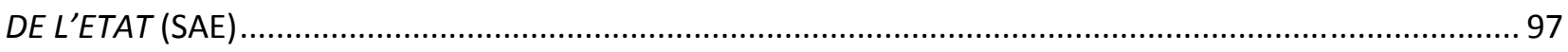

ANNEX 4. HUNGARY, KSZF (CENTRAL SERVICES DIRECTORATE GENERAL) ..................................... 103

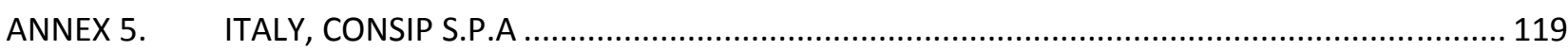




\section{METHODOLOGY AND ACKNOWLEDGEMENTS}

The methodology of the study was based on the following assumptions and methodological approach, namely to:

a) Base the study on a selection of EU Member States willing to participate in the project and to provide the data and information requested. The participating countries should represent different public sector administrative systems and cultures and come from different regions of the EU. Most importantly, each country should have a long experience and a solid background in the operation of a centralised purchasing system (CPS), including the use of framework agreements and preferably also of e-procurement;

b) Agree with the EU Member States selected that each country is to write a detailed description of its national system of centralised purchasing, based on a guidance note prepared by Sigma together with a detailed set of CPS-related questions on history and rationale, strategies and objectives, organisation and finances, goods and services covered, market and supplier approach, customer relations, procurement and contracting, evaluation and performance measurement, important success factors and risks, and future development;

c) Interview the management of the central purchasing body (CPB) in each of the EU Member States selected, i.e. Hansel Ltd in Finland, SKI A/S in Denmark, UGAP and SAE in France, KSzF in Hungary, and Consip S.p.A. in Italy.

Sigma decided to include, in addition to the five countries officially participating in the study, a brief description of the centralised purchasing systems in place in Sweden and in the UK, since knowledge of those systems would add value to the study. However, this description is largely based on data in the public domain and on specific knowledge of the Sigma project team.

A remark needs to be made with regard to certain limitations of this methodological approach. The central purchasing bodies and arrangements in the EU Member States covered in this study all fall under the EU Public Sector Directive. No information is provided in this study on any central purchasing arrangements falling under the Utilities Directive, or as to whether bodies and undertakings falling under the Utilities Directive in any of the countries studied would have the right to use the services of the existing CPB. The study examines central purchasing bodies that mainly serve the central state administration. Other centralised purchasing arrangements may exist in parallel to the CPBs that are covered by this study, in sectors such as health and education or at the municipality level. Furthermore, the study focuses mainly on the overall features of the centralised systems, without examining in depth the practical details of the operations of those systems.

The study uses the concepts of a Centralised Purchasing System (CPS) and a Central Purchasing Body (CPB), where the former covers all types of centralised purchasing arrangements available in the EU Member State while the latter only addresses the central purchasing organisation. The CPBs examined in this study operate primarily by awarding and managing framework agreements in specific product and service areas. 
The term procuring entity is used throughout the study to reflect either of the definitions used in the EC Directives, i.e. contracting authority and contracting entity, and the term usually refers to the customer of the CPB.

In conclusion, Sigma considers that this study will serve as an inspiration and will assist our partner countries in their efforts to establish effective, efficient and attractive centralised purchasing systems, with the use of framework agreements as appropriate, for goods and services of common interest within the public sector. Sigma is convinced that the information and knowledge shared will be very beneficial to its partner countries and will also be of interest to EU Member States themselves and to the international procurement community at large.

The members of the Sigma Project Team were Mr. Peder Blomberg, Sigma (Project Manager) and, as external experts engaged to carry out the study, Mr. Magnus Arnek, Sweden, and Mr. Peter Trepte, UK. Sigma staff supporting the study were: Mr. Yves Allain, Mr. Daniel Ivarsson, Mr. Piotr-Nils Gorecki, Mr. Marian Lemke and Mrs. Valérie Forges (Project Assistant).

Sigma would like to warmly thank the management and staff of the central purchasing bodies studied for all of their support and commitment in the completion of the study, in particular:

SKI A/S, Denmark: Mr. Sören Jakobsen and Mr. William Fellows-Jensen

Hansel Ltd, Finland: Mr. Anssi Pihkala, Mrs. Eija Kontuniemi and their colleagues

UGAP, France: Mr. Alain Borowski

KSzF, Hungary: Mr. László Kétszeri

Consip, Italy: $\quad$ Mr. Gian Luigi Albano 


\section{EXECUTIVE SUMMARY}

The establishment and use of central purchasing bodies, framework agreements and electronic procurement systems are areas of growing interest among Sigma's partner countries. These instruments are regulated in EC Directive 2004/18 and are commonly incorporated into the public procurement laws of the partner countries. However, these countries largely lack their own experience and knowledge about how to most efficiently operate such systems, which is the reason why Sigma decided to conduct this study. The study provides a comparative analysis of centralised purchasing systems (CPS) in selected EU Member States, all of which have a long history of the award and management of framework agreements by central bodies in product and service areas of common interest within the public administration. The EU Member States officially included in the study are Denmark, Finland, France, Hungary and Italy, and their country presentations can be found in the annex section of this document. In addition, brief information on how these systems are set up in Sweden and in the UK is also provided. The study provides guidance on various aspects of the operations of central purchasing bodies (CPB), which principally base their operations on the award and management of framework agreements for use by procuring entities within the public administration at state level, but also very often at regional and local levels.

The study concludes that the rationale for establishing a central purchasing body (CPB) needs to be examined from different angles, including from the perspective of the main stakeholders, which include the owners, users, and suppliers. The efficiency and attractiveness of the CPB's services can only be measured in terms of how well this body satisfies the various needs of the key stakeholders. The study aims to identify the main "attractiveness drivers" behind a central purchasing system and, not surprisingly, it is clear that savings in terms of better prices and lower transaction costs constitute the main rationale for establishing and operating a CPB. However, at the same time it can be concluded that other factors may also play a decisive role in terms of stakeholders' preferences and attitudes towards the usefulness of the CPB's services. The main factors of a non-economic nature are simplicity; legal, technical and contractual certainty; the need for standardisation and for support of important policy goals of the government, such as those concerning the environment and social issues.

The CPBs studied operate in accordance with very different mandates and regulatory instruments. In some countries, the operations of the CPBs are regulated in quite some detail by law or government decrees, while others, in particular in the Nordic countries, are given more freedom to plan and manage their operations. Interestingly, most CPBs are set up as either as publicly-owned limited companies or public bodies with significant economic independence, but with clear restrictions with regard to the level of acceptable profitability. As a matter of fact, they must be contracting authorities according to EU law, and therefore be "established for the specific purpose of meeting needs in the general interest, not having an industrial or commercial character", in line with the meaning of the EC public procurement Directives.

The CPBs generally cover a similar range of products and services of common interest within the public administration. Mostly, they offer standardised products and services of non-strategic importance to the procuring entities, but some CPBs also provide at the same time products and services of significant strategic importance for the procuring entities. In the latter case, the centralised arrangement is often driven by the government's interest in improving administrative efficiency and effectiveness within the public sector as a whole by ensuring interoperability and standardisation of the administrative systems used by the procuring entities. 
The study has analysed centralised purchasing arrangements at the central government level. This does not exclude the possibility that those framework agreements can be used by procuring entities at regional and local levels as well. In some countries, the CPB's mandate gives it the possibility of including also local authorities under the central framework agreements. An important aspect of the coverage is whether centralised purchasing is carried out under compulsory or voluntary conditions, which differs between the countries studied. In a compulsory system where the procuring entities are obliged to use framework agreements, the responsibility for the overall "quality" of the framework agreements rests mainly with the CPB, while in a voluntary system the procuring entities can always refrain from using framework agreements if they are not considered to be sufficiently usable.

The majority of CPBs are financed by service fees paid by the suppliers or, in one case, by the procuring entities. The service fee is based on the invoiced turnover generated under the framework agreement and normally amounts to between $0.6 \%$ and $2 \%$. In one case the CPB is financed from the budget.

Procurement and contracting activities belong naturally to the core functions of all CPBs. Considerable resources and time are dedicated to the preparatory phases, which usually include feasibility studies, decision-making on procurement method as well as selection and award criteria, and the choice of framework agreement and call-off procedure. All procurement methods under the EC Directives are used, but it seems that the restricted procedure is the most common procedure. The most economically advantageous tender (MEAT) is the preferred criterion among the CPBs.

All CPBs subject to this study, except one, carry out their centralised functions by awarding framework agreements to be used by procuring entities through a call-off procedure. The national law implementing the EU Directives is the legal basis for the award and use of these framework agreements. Both singlesupplier and multi-supplier agreements are used and in the latter case, the call-off is carried out by either ranking or a mini-competition, with or without the use of e-auctions. The single-supplier agreement is associated with the least risk, and the call-offs are normally easy to apply for the procuring entities. The multi-supplier agreements, especially when a mini-competition is used as the call-off procedure, offer the most adaptability and usefulness for the procuring entities, but at the same time they are associated with the highest risks and costs. The duration of framework agreements is normally in the range of 2-4 years.

One issue often discussed is the fear that SMEs may be disfavoured in the award of framework agreements, but the conclusion of the study is that SMEs are generally well represented in the framework agreements of all CPBs, with the exception of Consip (Italy).

\section{Key Future Development Issues}

Based on the findings of the study, Sigma has concluded that the main objectives of the CPBs for the future would be to (i) develop and manage efficient and attractive framework agreements and call-off systems for customers and suppliers; (ii) mitigate risk for customers; and (iii) create an organisation with high competence, professionalism and a strong service concept. Sigma considers that the main challenges for the CPBs in the future will be to:

a) Control the flow of business transactions at the call-off level. With better business control, the CPB would have a better chance of designing the financing mechanism, charging the right fees if applicable, communicating with customers and suppliers, adding new services, and improving reporting and statistics systems;

b) Build the business IT infrastructure and the e-procurement platform: the availability of modern, advanced web-based systems for all tendering and business transactions will constitute a strong, 
strategically important competitive factor for the CPB in the future and a foundation for controlling the flow of call-off transactions under the framework agreements;

c) Develop the financing model of the CPB in order to both produce the right incentives and reflect a fair distribution of risk and costs;

d) Manage legal risks that occur under multi-supplier agreements, which have become one of the most challenging issues for CPBs awarding such agreements and where suppliers have the right to file complaints not only during the course of the award of the framework agreement but also during the call-off stage, whether the call-off is done by means of ranking or a mini-competition;

e) Design appropriate call-off systems under framework agreements, which will be decisive for the success of the centralised purchasing system (CPS), not only with respect to legal risks but also, more importantly, to the efficiency and overall attractiveness of the CPB's services;

f) Create and develop the future business and service concept of the CPB beyond the traditional areas of goods and services managed by the CPB;

g) Build strong and lasting partnerships with procuring entities, especially the large ones, in order to strengthen and ensure the sound and efficient development of the CPB's operations;

h) Develop the competence, professionalism and capacity of the CPB organisation, which will constitute a real challenge requiring the support of the owners and a firm anchorage among customers and suppliers.

In conclusion, Sigma elaborates briefly in the study on how centralised purchasing systems could be introduced in its partner countries. The following actions were recommended:

- To elaborate a national strategy and action plan for the establishment of a central purchasing body (CPB);

- To take a step-by-step approach, with realistic objectives and plans;

- To take an integrated approach, where the development of e-procurement, including dynamic purchasing systems, and the use of framework agreements in general are considered;

- To build centralisation on the principles of a decentralised public procurement system, where the owners allow for a differentiated approach, which means that goods and services to be centrally purchased would be carefully reviewed from the perspective of the contracting entities in order to determine whether the use of framework agreements should be compulsory or voluntary;

- $\quad$ To ensure the close involvement of key stakeholders.

A public procurement system can always exist without centralised purchasing arrangements, relying instead on fully decentralised procurement where the individual procuring entities award contracts for goods, services and works. Moreover, this study examines mainly CPBs that serve first of all the state administration at all levels (central, regional and local) and where other sectors (e.g. municipalities and regional authorities) may participate if they so decide. In many countries other centralised purchasing arrangements are in place, such as sector-based CPBs (e.g. health and education) or collaborative or coordinated framework agreements, each with their specific advantages and disadvantages.

As this study shows, the proportion of the purchasing volumes of CPBs is fairly small compared to the total national procurement volume. Therefore, the fundamental question to be answered is to what extent a CPB can generate an "added-value" to the public procurement system in terms of savings, 
GOV/SIGMA(2010)3/REV2

rationalisation, modernisation and other important values. The study clearly indicates that CPBs, under the right conditions, generate such added-value. 


\section{PART I. CONCEPT, RATIONALE AND LEGAL BASE FOR CENTRALISED PURCHASING SYSTEMS IN THE EU}

\section{Introduction: Background and Objectives}

The background for conducting this study is the steadily growing interest that Sigma has noticed among its partner countries in introducing centralised purchasing arrangements, including the use of framework agreements in the stated systems. EC Directives 2004/17 and 2004/18 include provisions and rules regarding the set-up and use of central purchasing bodies, framework agreements and electronic procurement. All of these elements have in large part been transposed into national legislation, although this transposition is not a mandatory requirement under the EC Directives. In general, the introduction of centralised purchasing arrangements and the use of framework agreements are guided by an ambition of governments to modernise and improve their procurement systems for the purposes of efficiency and functionality.

Sigma's ongoing dialogue with partner countries on these instruments clearly reveals that there is an extensive need for in-depth information and guidance on how centralised purchasing and framework agreements should best be implemented.

Among the questions and concerns frequently raised by partner countries regarding centralised purchasing systems, including the use of framework agreements, are the following:

- What kind of organisational model can be used for a Central Purchasing Body (CPB); e.g. a department within a line ministry, or an independent agency, or even a separate limited company?

- What are the costs and benefits of a Centralised Purchasing System (CPS) compared with a decentralised one?

- What goods and services are normally covered or not covered by the CPB's responsibilities?

- How are the operations of the CPB to be financed: through the budget, through a transaction fee, through a combination thereof, or in some other way?

- How are communications organised and agreements concluded between the CPB and the customers on the elaboration of technical specifications and the estimation of aggregate requirements, payment commitments and procedures, etc.?

- Is the use of the CPB's services voluntary or obligatory for the procuring entities?

- What types of framework agreements are used: single-supplier or multi-supplier agreements; with all terms agreed in advance or not; what is the duration of the contracts; what are the procedures, if any, for the conduct of mini-competitions, and who would organise them (the CPB or the customer)?

- What is done to encourage or ensure the participation of SMEs?

There is an obvious need to obtain greater clarity on the above issues. The objective of the study is to review how centralised purchasing systems are managed in selected EU Member States. The approach has been to include those EU Member States with an historical background and experience in operating 
centralised purchasing systems (central bodies or co-ordinated arrangements), preferably with the use of framework agreements and, if possible, e-procurement techniques. The study covers the centralised purchasing systems of Denmark, Finland, France, Hungary and Italy. These countries all have a long experience of these issues and have established institutional structures for operating such systems. They further represent public administrations that differ in terms of the way in which the public sector is structured and governed and that have significant variations in administrative traditions and cultures. Detailed presentations of the country systems are found in the annexes of this study. In addition to these in-depth presentations, the study describes how centralised purchasing is organised in Sweden and in the UK. However, this description is largely based on information available in the public domain or on specific knowledge of these countries of the Sigma project team.

\section{Scope of the Study}

The study refers to the EC Directives for the definitions of central purchasing bodies and framework agreements.

As set out in chapter 5, a Central Purchasing Body (CPB) is defined as a contracting authority that:

- $\quad$ acquires goods or services intended for one or more contracting authorities;

- awards public contracts for works, goods or services intended for one or more contracting authorities; or,

- concludes framework agreements for works, goods or services intended for one or more contracting authorities.

The CPBs covered by this study all fall in one way or another within these defined activities. In addition, all of them base their operations mainly on the conclusion and management of framework agreements. Consequently, the study will essentially examine centralised purchasing systems (CPS) where the CPB awards and operates framework agreements, but other centralised models, such as collaborative or coordinated purchasing, are also examined.

The EC Directives define a framework agreement as:

"...an agreement or other arrangement between one or more contacting authorities and one or more economic operators the purpose of which is to establish the terms governing contracts to be awarded during a given period, in particular the terms as to price and, where appropriate, quantity envisaged."

Within the meaning of the Directive, centralised purchasing would mean the centralisation of activities up to and including the completion of the central framework agreements to be used by the whole or parts of the public sector as well as the management of those agreements.

In this context, it is important to remember that framework agreements can be designed to cover very different situations. Based on information available, this Study focuses on centrally procured framework agreements between a CPB and one or several suppliers that stipulate the terms under which other procuring entities may purchase goods or services. Another popular use of framework agreements, of some interest, concerns an agreement of a procuring entity with one or several suppliers, which sets out the terms for the entity's repeated purchases of particular goods or services. The typical rationale for establishing a framework agreement in this case is that the procuring entity knows that it is likely to have a need for a certain product, but it does not know the extent to which or when it will need the product. With a framework agreement in place, the entity does not need to conduct a formal procurement procedure every time it needs the product. Processing costs are therefore reduced." 
All CPBs covered by the study have been established by the government only, or by the government in co-operation with the municipal sector, to serve procuring entities on either an obligatory or voluntary basis.

\section{The Concept of Centralised Procurement}

Centralised purchasing is not a concept or practice that is unique to the public sector. On the contrary, it is a widely used approach in the private sector, both in manufacturing and retailing as well as in other sectors. Its main objective is to reduce purchase prices and purchasing costs in all phases of production and distribution. Most larger companies have central purchasing units specialising in securing a reliable stream of necessary inputs for the company on favourable terms.

Before examining the CPBs of the study in greater detail, it could be of interest to give an overview of other centralised models in place in EU Member States. However, it needs to be underlined that some of these models were more commonly used in the past and that Sigma has no recent information on the current situation.

\section{Central Purchasing Agencies}

A common centralised procurement model in many EU Member States in the past was the "monopoly" model. Under this model, the central government established a central purchasing office to make bulk purchases directly from suppliers. Government agencies and departments were then obliged to buy goods and services needed from these central purchasing agencies. In other words, the central purchasing units had a wholesaling and very often also a warehousing function.

Over time, some countries have tended to abandon the monopoly model in favour of more decentralised and flexible approaches. Often central purchasing offices still exist, but their legal status has changed and they have been given a greater degree of financial and managerial autonomy. In addition, ministries and government agencies, i.e. the buyers, have usually been given more freedom to buy the goods and services needed from other sources if they consider that this would result in better value-for-money.

Another significant change, as seen in this study, is that many central purchasing offices have tended to focus their efforts on procuring through framework agreements instead of pursuing the earlier wholesale trade function.

\section{Centralised Purchasing at Regional and Local Levels}

Centralised purchasing is commonly practised within regional or local authorities where a municipality or regional authority has created a central purchasing unit in order to serve internal departments with procurement services, including the award of framework agreements and the provision of advisory services to users.

Furthermore, collaborative purchasing arrangements between municipalities in a specific geographical area are not unusual in a number of EU Member States. Such arrangements are feasible for goods and services that are commonly in demand in all types of municipalities, such as food and fuel. These arrangements may be formally and permanently established, but the public bodies concerned may also have a looser relationship in matters of purchasing.

A third approach to centralised purchasing is the use of specialised agencies. Such an agency may specialise in the provision of specific goods or services (e.g. medical equipment or IT products) and may be able to offer better contracts in terms of prices, quality and delivery conditions than would smaller, 
non-specialised entities. For example, as will be seen in this study, the Swedish centralised purchasing system is built on specialised agencies.

In reality, combinations of these different approaches to centralised procurement are likely to exist side by side in various parts of the public sector, together with a large number of decentralised procurement entities.

\section{The Rationale for Establishing a Centralised Purchasing System (CPS)}

Generally, as has been confirmed by the country reports, the rationale for establishing and operating a centralised purchasing system (CPS) needs to be examined from various perspectives. The important stakeholders are:

- $\quad$ the users of the CPB's services - the procuring entities;

- the suppliers of the goods and services under the framework agreements; and

- the owners of the CPBs - usually ministries, associations of local authorities, and other public bodies representing taxpayers' interests.

The efficiency and attractiveness of the CPB can only be measured in terms of how well it satisfies the needs of the external stakeholders. These stakeholders are: first of all, the customers representing the wide spectrum of procuring entities that either purchase goods or services acquired by the CPB or use the framework agreements operated by the CPB; secondly, the private sector market, represented by the suppliers providing the goods or services to the CPB, either directly or under framework agreements; and thirdly, the political system, which may recognise that the CPB contributes to reduced public expenditure, increased value-for-money, and the realisation of certain important policy goals, such as those related to environmental or social issues or to SMEs.

However, these objectives can only be met if the CPB itself has the capacity to serve its clients efficiently and effectively in all key aspects. This capacity is an important factor for all CPBs but in particular for those operating framework agreements that are voluntary and where the financing is solely based on transaction fees, without any budget contributions.

Many of the advantages of centralised procurement are independent of the particular activity carried out by the CPB, i.e. whether the CPB acquires goods or services (the monopoly model), awards public contracts, or concludes framework agreements for goods or services intended for one or several procuring entities. Some differences exist, however, which are indicated below. This being said, the main rationale for establishing a $\mathrm{CPB}$ is often described in the following terms:

\section{"Large procurement volumes generate better prices."}

Under the right conditions, centralised procurement based on an aggregation of the purchasing needs of all of the CPB's customers provides very interesting business opportunities for the private sector. The attractiveness of the public sector market is determined not only by the potential sales volumes but also by other factors, which need to be taken into consideration.

However, with larger procurement volumes, an increasing competition in the market normally follows, affecting prices and other terms in ways that are favourable to the purchaser. An individual procuring entity will seldom have a procurement volume large enough to generate prices that are comparable to those obtained in a situation where an aggregation of needs among many procuring entities has been 
made. The potentially large sales volumes that can be expected under centralised procurement mean that economies of scale can be exploited by economic operators.

In the context of central purchasing based on the award of framework agreements, the purchasing volumes set out in this framework are normally based on estimations and usually do not represent a firm commitment to the supplier(s). The final outcome in terms of contract volume under a framework agreement is uncertain at the time of tendering, especially when the award applies to multi-supplier framework agreements. However, this is usually not the case when a CPB makes bulk purchases directly from suppliers. In that situation, suppliers know for certain the actual sales volume, and this certainty, other factors being equal, should provide more favourable terms. The volume of purchases likely to be made at the end of the process is, of course, a key factor in the attractiveness of the framework agreement for potential suppliers. Where the actual volumes are unknown or where they are uncertain (e.g. when there is a second-stage mini-competition that could be won by others), the suppliers may well be wary of making the initial investments necessary to compete in the framework agreement.

Another difference between direct bulk purchases and centralised purchasing based on framework agreements is that the latter approach is more sensitive to particular details in the procurement process. Specifically, purchasing terms may depend on how the framework agreements are awarded. As found in chapter 5 , where a framework agreement is concluded with several suppliers, the procuring entities are faced with an option. Contracts are awarded either by application of the terms laid down in the framework agreements without reopening any competition or on the basis of a later "mini-tender or mini-competition". Theoretical economic research indicates ${ }^{3}$ that the mini-tender option, which in effect introduces a two-stage competition, may stimulate bidding competition and hence reduce prices. On the other hand, the possibility that a framework supplier may fail to secure a call-off contract at a later stage may discourage participation in the first place. Another important aspect affecting economies of scale is the call-off or order structure under the framework agreement. Economically, it makes a huge difference for a supplier to produce and deliver in large lots under large-volume contracts to a small number of customers compared to a situation where the supplier has to serve a large number of customers with many small orders, even when the total contract volume is equal.

In summary, for a centralised purchasing system (CPS) that is based on the award and management of framework agreements, the aggregation factor and its effect on prices have to be evaluated with respect to the type of framework agreement awarded. Under a single-supplier framework agreement in a compulsory environment, where procuring entities within a certain part of the public sector are obliged to use a specific framework agreement, the aggregation effect on prices is likely to be strong, while at the other end, under a multi-supplier agreement in a voluntary environment, the aggregation effect on prices is likely to be stronger under a single-supplier framework agreement than under a multi-supplier agreement. Under such agreements, when competing for the framework contract, the size of the individual call-off contract could mean more to the suppliers than the potential turnover of the aggregated volume that may be generated by the framework agreement.

3 Albano,G.L. and M. Sparro (2010), Flexible Strategies for Centralised Public Procurement, University of Perugia Electronic Press, Review of Economics and Institutions. 


\section{"Transaction costs are reduced."}

From the perspective of procuring entities, a full competitive procurement process, when compared with a simple call-off exercise, is normally associated with substantial transaction costs ${ }^{4}$, in terms of time and expenditure, of managing the procurement process, from the first stage of defining the needs to the final stage of closing the file. Economic operators have equally significant transaction costs for participating in a tender. With centralised framework agreements, both procuring entities and suppliers can expect a significant reduction of these costs. The transaction costs incurred at the level of the CPB managing the award of a large contract or framework agreement are, naturally, substantially larger than those of an individual case of smaller, decentralised procurement. However, it is very unlikely that the total transaction costs for the centralised procurement alternative are higher than the sum of the transaction costs for the decentralised solution. The positive multiplier effect increases with an increase in the number of customers or users of the framework agreement. Furthermore, with reduced transaction costs within procuring entities and economic operators, resources in terms of staff and time are freed for other more important functions.

However, as in the case of the effect on prices mentioned above, the effect of aggregation on transactions costs incurred by both procuring entities and the private sector cannot be generalised but must be calculated with respect to the type of framework agreement used. A call-off under a singlesupplier framework agreement will not entail any tendering costs, only transaction costs for the placing of the orders, while a multi-supplier framework agreement involving a mini-competition will create substantial tendering costs both for the procuring entity and for the suppliers.

\section{"Other benefits of a significant nature occur."}

Centralised purchasing systems may also offer advantages that cannot be directly expressed in economic terms. Based on earlier Sigma studies and on the country reports annexed to this report, the following arguments in favour of centralised purchasing arrangements should be mentioned:

- The need for standardisation or increased administrative efficiency within the public administration, e.g. in the area of IT systems and software applications, may call for centralised and co-ordinated solutions.

- Many procuring entities may lack sufficient capacity of their own to prepare and carry out complex tenders in areas requiring specific product or market expertise.

- $\quad$ Professional, centralised purchasing provides certainty to procuring entities in many key aspects legal, technical, economic and contractual - thereby reducing the risks that otherwise would have been borne by the procuring entity, such as the risk of complaints, poor or insufficient quality of products, failure of suppliers, and inadequate contract terms.

- Simplicity in the acquisition of goods and services is another relevant argument, as a call-off arrangement gives the procuring entity and its user departments the possibility, even without any professional procurement background, to contract with the framework suppliers. The degree of simplicity is of course dependent on the type of framework agreement in place; single-supplier or multi-supplier agreements, with or without mini-competitions.

4

An investigation of the Swedish system for centralised procurement of framework agreements estimates that transaction costs are reduced by approximately 50 million EUR per year due to centralisation of the central governments procurement. (Statskontoret 2009:12 En effektivare statlig inköpssamordning). 
- Governments may use the CPBs as instruments for the execution of policy goals in specific sectors, such as promoting green procurement, innovations and SME participation in public sector tenders.

Arguments against centralised purchasing arrangements have also been raised.

The first main argument has to do with the risk of market concentration and the development of monopolistic structures. The large volumes often involved in centralised procurement tend to favour large suppliers rather than small, new suppliers. This situation may restrict competition, with a resulting deterioration in terms of sourcing. Over time, this problem may grow if the supplier market becomes more concentrated. There are also more specific objectives related to framework agreements, where purchase volumes are not defined at the moment of signature of the agreements with the suppliers. In these circumstances, some suppliers may refrain from submitting tenders altogether since they cannot be sure of the benefits.

The issue of the opportunities of SMEs to participate in large tenders also falls within this category of arguments against centralised purchasing. This problem has both a political and an operational dimension. Today, in many countries, there is a strong political interest and an explicit policy that measures should be taken by procuring entities, including CPBs, to facilitate the participation of SMEs in public tenders and the award of public contracts to SMEs. As this study will reveal, SMEs seem to be comparatively successful in CPB tenders.

Even in a decentralised procurement regime, there is no guarantee that an SME will be awarded a procurement contract, although the chances are definitely higher, as is indicated by available statistics. In tenders for large contracts, which are the normal case for CPBs, it is unlikely that an SME can participate in its own capacity, since it is probably unable to meet the qualification criteria or to compete with large economic operators. Instead, SMEs may act as subcontractors or participate in consortia or in a tender where the procuring entity has arranged lots of such a nature and size that it would allow SMEs to participate as tenderers in their own capacity.

It is also in the interest of public purchasers in general and CPBs in particular, where this risk is more significant, to prevent monopoly-building in the supply market and instead to ensure a diversified and competitive market structure. However, SME policy cannot be implemented at the expense of a decisive loss of attractiveness of central framework agreements, which in turn would undermine the role of the CPB. Another aspect of course is that the promotion of SMEs and the award of contracts to SMEs must be carried out in a manner in which the fundamental principles of the EC Treaty are respected.

A particular argument raised against centralised purchasing in the form of direct bulk purchasing is that the government may thereby take unnecessary commercial risks. It may happen that a CPB procures goods or services that procuring entities do not consider as meeting their requirements and therefore that they do not want to purchase. This is particularly the case where products are not homogenous and where substitutes exist. Procuring entities may have their own specific requirements and the more standardised requirements of the CPB may not be suitable or acceptable to them. This problem implies the need for a great deal of co-ordination between CPBs and beneficiaries if the system is to satisfy all potential users. The failure to do so could create a financial problem for the CPB, which might be tempted, in order to recover costs, to sell the products at a price below the going market price, creating further problems of unfair competition with private suppliers.

A related critical argument is that framework agreements, due to their long duration (normally 2-4 years), can be relatively unresponsive, unless designed correctly, to ongoing changes in the market, thereby potentially neglecting important developments in market prices and technology. It is therefore important 
that the duration of the framework agreement be realistically set and, when motivated, that competition be maintained by the organisation of mini-tenders.

The uniformity of many framework agreements and the degree of standardisation constitute another concern. Framework agreements sometimes tend to offer a too restrictive approach, in particular on technical grounds, which makes it difficult for procuring entities to fully satisfy their own procurement objectives. The lack of adaptability to individual needs represents, in particular, a problem for procuring entities that are obliged to use a certain framework agreement, but also for procuring entities with no such obligation. They may be forced to conduct their own tenders, which could have negative price and cost implications. This situation would be particularly problematic where the use of a CPB is mandatory but less problematic where parties operate under voluntary agreements.

\section{Concluding Remarks}

It was argued above that the attractiveness of centralised purchasing systems has several drivers, both economic and non-economic, and it may be considered from several different angles. Figure 1 below presents a chart illustrating these drivers.

It should be stressed that, although many of the benefits and potential drawbacks of centralised purchasing are to some extent shared by the various existing approaches, there are also important differences. In order to successfully implement a centralised purchasing system, it is crucial to be aware of both the pros and cons of the different approaches. To maximise the net benefits of centralised procurement, it is important to design a coherent system that suits the surrounding environment. Parts II and III further examine this issue. 
The Attractiveness Drivers of a Centralised Purchasing System

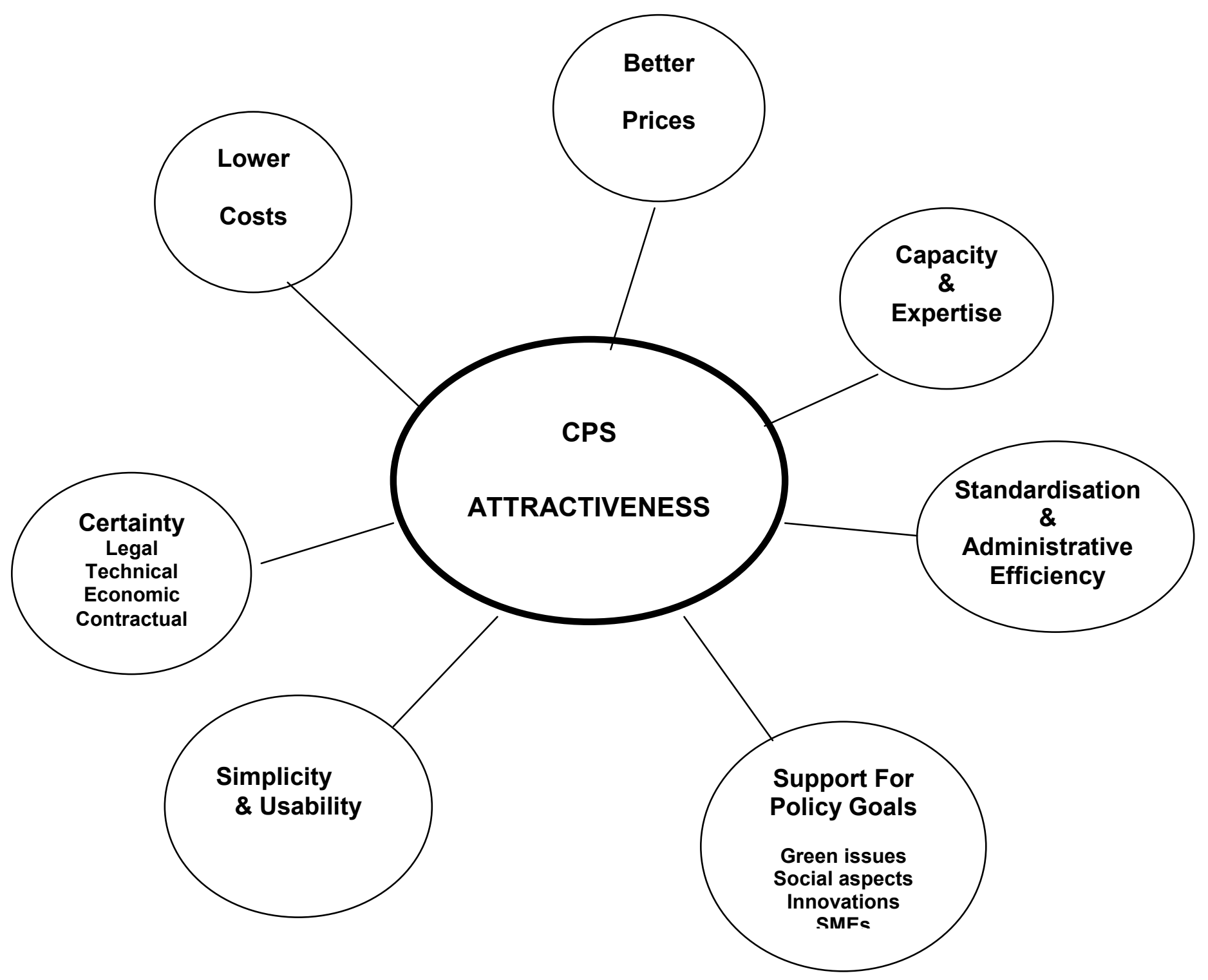




\section{The Legal Base for Central Purchasing Bodies (CPBs) and Framework Agreements - the EU Public Procurement Legal Framework}

\section{Public Procurement in the EU}

Procurement by public authorities is subject to specific Community rules. The EC Treaty itself does not contain any specific provisions on public procurement, but it does establish a number of fundamental principles that are of general application in the European Union. The most relevant in terms of public procurement are the prohibition against discrimination on grounds of nationality; the free movement of goods; the freedom of establishment; and the freedom to provide services. In addition to these fundamental principles in the Treaty, some general principles of law have emerged from the case law of the European Court of Justice, which are applied in the context of public procurement. The most important of these general principles of law in the current context are equality of treatment, legal certainty, transparency, mutual recognition and proportionality.

To underpin the Treaty principles in the field of public procurement and to provide the necessary guidance to EU Member States, the Community adopted a series of Procurement Directives. These were consolidated in 2004 in two new directives, one for the public sector and one for the utilities sector. Directive 2004/18 now provides in a single text the EU procurement provisions applicable to public sector procurement. Under these rules, public sector procurement must follow transparent, open procedures ensuring fair conditions of competition for suppliers.

At the same time, some purchases can be exempt from Community rules under certain conditions. For example, arms, munitions and war materials may be excluded if this is considered to be necessary for the protection of essential security interests, although there is now another directive (Directive 2009/81) that applies to the defence sector in general. Similarly, purchases of a value that is below the financial thresholds triggering the provisions of the Directive will also fall outside the terms of the directives, but they must respect the principles of the EC Treaty.

\section{Facts and Figures on Public Procurement in the EU}

The total value of public procurement in the EU, i.e. the purchase of goods, services and public works by governments and public utilities, is estimated to be about $17 \%$ of the EU's GDP or 1500 billion EUR (2008 figures). Its importance varies significantly between EU Member States but ranges between $11 \%$ and $20 \%$ of GDP. The TED (Tenders Electronic Daily), which is the online version of the Supplement to the Official Journal of the European Union dedicated to European public procurement, is currently updated five times a week, publishing approximately daily 1,500 public procurement notices from the European Union, the European Economic Area and beyond.

According to statistics provided by the European Commission ${ }^{5}$, the opening-up of public procurement within the internal market has increased cross-border competition and improved prices paid by public authorities. There remains a potential for significant further competition in procurement markets and for further savings for taxpayers. Framework agreements are one way of increasing those savings.

According to a recent study, between 2006 and 2008 an estimated $60 \%$ of above-threshold contracts were awarded to SMEs, which in terms of contract value corresponded to a $33 \%$ market share.

5 A report on the functioning of public procurement markets in the EU: benefits from the application of EU Directives and challenges for the future:03/02/2004 


\section{EU Public Procurement Legal Framework - Basic Principles}

As stated above, public sector procurement in the EU is regulated by Directive 2004/18/EC, completed by Directive 89/665/EC revised with regard to reviews and remedies (Directive 2007/66). The Directive regulates procurement by all public sector procuring entities, such as central and local government agencies, county councils and government agencies, as well as "bodies governed by public law" in the meaning of the Directive.

The objective of the Directive is to ensure an EU-level playing field for public procurement, which takes into consideration the EC Treaty as well as European bilateral agreements and plurilateral international commitments (Government Procurement Agreement under WTO). The Directive seeks to co-ordinate national contract award procedures by introducing a minimum body of common procedural rules that reflect the basic Treaty principles rather than to achieve the harmonisation of all national rules on public procurement. In essence, these common rules consist of applying the basic principles, notably nondiscrimination, equal treatment and transparency, in the:

- $\quad$ publicity of proposed procurement contracts;

- design of technical specifications;

- $\quad$ types and use of procedures for the award of public contracts;

- $\quad$ qualification and selection of tenderers;

- $\quad$ award of contracts;

- review procedures related to the award of contracts.

Briefly stated, when a procuring entity wishes to purchase a works, supplies or services contract that is worth more than a stated amount (i.e. above the financial thresholds set out in the Directives), it must put the contract out to tender at the European Union level. The contract is subject to the advertising rules of the Directives, including the required time limits, and the tender notice must be published in the Official Journal of the European Union before it is advertised anywhere else. The selection and award criteria must be objective and non-discriminatory.

\section{The EC Directives on Central Purchasing Bodies}

Both of the EC public procurement Directives on the co-ordination of award procedures (2004/17/EC and 2004/18/EC) include specific provisions on central purchasing bodies, which make it explicitly possible for Member States to enact or maintain provisions in respect of central procurement bodies in their national procurement legislation. Recital 15 of the Public Sector Directive, for example, states:

"Certain centralised purchasing techniques have been developed in Member States. Several procuring entities are responsible for making acquisitions or awarding public contracts/framework agreements for other procuring entities. In view of the large volumes purchased, those techniques help increase competition and streamline public purchasing. Provision should therefore be made for a Community definition of central purchasing bodies dedicated to procuring entities."

A Central Purchasing Body (CPB) is defined in the Public Sector Directive as a contracting authority that:

- $\quad$ acquires goods or services intended for one or more contracting authorities;

- awards public contracts for works, goods or services intended for one or more contracting authorities; or 
- concludes framework agreements for works, goods or services intended for one or more contracting authorities.

EU Member States may prescribe that procuring entities may purchase works, supplies or services from or through a central purchasing body. It is therefore not mandatory to establish CPBs, but an option given to Member States.

Article 11(2) of the Public Sector Directive is of particular importance. It provides that procuring entities that purchase works, supplies or services from or through a central purchasing body, as defined above, shall be deemed to have complied with the Directive insofar as the central purchasing body has complied with it. In the current context, this means, for example, that where a framework agreement is awarded by a central purchasing body in accordance with the provisions of the Directive, procuring entities that purchase under the framework agreement will be deemed to have complied so far with the provisions of the Directive. Subsequent call-offs by other entities will have to comply with the relevant provision in the Directive for the award of contracts subsequent to the framework agreement, without going through the complete process of a standard procedure for the award of a public contract. Without this provision, all call-offs above the threshold values of the Directive might themselves have been subject to award under the Directive.

Similar provisions apply to utilities under the Utilities Directive.

\section{The EU Directives on Framework Agreements}

The Public Sector Directive includes a provision (Article 32) on framework agreements. As with the provision on $\mathrm{CPBs}$, this provision is not part of a mandatory procurement code but is permissive, allowing those EU Member States that wish to do so the possibility of using framework agreements.

\section{The Concepts of "Agreement" and "Contract"}

The notion of framework "agreements" has raised legal difficulties in the past. The problem arises because the definition of framework "agreement" does not necessarily imply binding contractual obligations. It is quite possible, as indicated above, that the parties to the "agreement" do not always undertake binding commitments to buy or sell but merely set out the main terms that would apply to any future contracts they might conclude. These agreements are more like standing offers, binding once accepted, which remain valid for the life of the agreement. They could be based simply on the provision of the general terms and conditions applicable to future contracts or may even include a fee paid by the purchaser in order to have the guarantee of the supply or service required. The degree to which the agreement is binding will, as indicated above, have an effect on the attractiveness of the agreement for suppliers. It also has legal consequences, however.

In all of these examples, there may be no binding contract at the time when the agreement is made. In that case, the actual contract would take effect when orders were placed under the agreement so that, in effect, each agreement call-off would amount to a separate contract. If the value of the call-off was above the threshold value of the Directives, the award would be subject to the procedures of the Directives, and the simple placement of the order with a CPB would be unlawful. Such a situation would of course completely undermine the advantages attributed to framework agreements, as described above.

On the other hand, a framework agreement could be used to establish the binding legal commitment of both parties, even if the precise quantities to be purchased and the timing of their delivery were unspecified. In this case, the agreement would then be a "contract" for the purposes of the Directives and 
should be awarded pursuant to the Directives. In that event, individual call-offs related to this contract would not be contracts: they would simply be orders placed under the existing contract.

The mechanism that has now been explicitly adopted in the Public Sector Directive, although based on the provisions already existing in the Utilities Directive, is very different. Where there are no binding commitments and therefore no "contract" under the Directive (in framework agreements that are concluded with several economic operators and that do not establish all of the terms), individual contracts based on a framework agreement are awarded following the reopening of competition, in accordance with the relevant ad hoc provision.

\section{The Definitions of the Directives}

The Directives define a framework agreement as:

"...an agreement or other arrangement between one or more contacting authorities and one or more economic operators the purpose of which is to establish the terms governing contracts to be awarded during a given period, in particular the terms as to price and, where appropriate, quantity envisaged."

Thus, a framework agreement is a general term for agreements with providers that set out terms and conditions under which specific purchases (call-offs) can be made throughout the duration of the agreement. When awarding call-offs (individual contracts) under framework agreements, procuring entities do not have to once again go through the full procedural steps in the EC Directives, provided that the rules were followed appropriately in the setting up of the framework agreements themselves and that they will be followed as well for all phases up to the award of contracts based on that framework agreement.

\section{Awarding Framework Agreements}

Procuring entities are to follow the rules of a procedure referred to in the Directive (open or restricted procedure in most cases) for all phases up to the award of contracts based on that framework agreement. It is only in the final stage that the procedure differs and where the Directive offers a choice between awarding a framework agreement to a single economic operator or to several.

The procedure is to take place in two steps: the conclusion of the framework agreement to one or more providers, followed by individual call-off contracts awarded to one or more providers. This second step differs depending on whether the framework agreement concerns a single provider or multiple providers.

Call-offs from the framework may only be awarded to economic providers that were originally party to the framework agreement. The conclusion of a framework agreement, unlike for example a utilities qualification system, entails a closed list of potential providers and in that respect is less flexible. The scope of coverage of the framework agreement and the potential customers of the CPB (and therefore the likely volume to be covered) would therefore need to be clearly established at the outset. Of course, a procuring entity may continue to purchase outside the framework agreement, but in that event the benefits of the framework agreement to the procuring entity are lost, as any purchase above the relevant financial threshold would be subject to award under the full procedures of the Directive and would have to be advertised. Of course this would also affect the volume of purchases from the suppliers' perspective, which could impact on their commitment to enter into future framework agreements with the same parties.

In particular where a framework agreement is concluded with a single economic operator but also for any other kind of framework agreement, there is a general and explicit prohibition for parties to make, under any circumstances, substantial amendments to the terms laid down in that framework agreement. This 
prohibition suggests that longer-term frameworks may not be suitable mechanisms for the purchase of products that are subject to frequent changes of specification. These products might be better procured as and when they are needed.

Where a framework agreement is concluded with several providers, there must be at least three operators (to the extent that three providers meeting the conditions are available). Procuring entities are then faced with an option. Contracts based on these framework agreements may be awarded either:

- by application of the terms laid down in the framework agreement, without reopening competition; or

_ $\quad$ on the basis of a subsequent "mini-competition" (mini-tender).

The first possibility effectively applies the same rule as the rule concerning single-provider framework agreements.

The second possibility is available only where "not all the terms are laid down in the framework agreement". Where all of the terms were set out in the first-step agreement, then the call-off contracts must be awarded on the application of those terms (i.e. under the first option above). The mini-tender procedure applies only where the procuring entity envisaged at the outset the need formulate the terms more precisely at a later stage.

Where the mini-tender option is chosen, the parties must compete again "on the basis of the same and, if necessary, more precisely formulated terms, and, where appropriate, other terms referred to in the specifications of the framework agreement". It is clear from the wording of this provision that the essential terms of the original agreement may not be changed. They may be more precisely formulated or they may be supplemented by terms that were at least foreseen in the specifications, but the mini-tender may not take place on the basis of different terms.

For every call-off contract to be awarded, contracting authorities must consult the economic operators capable of performing the contract. The mini-tenders must be solicited in writing, but this also includes solicitation by electronic means of communication. There is no specific time limit set for the competition, but contracting authorities must fix a time limit that is sufficiently long to allow tenders for each specific contract to be submitted. The award is to be made to the tenderer that has submitted the best tender on the basis of the award criteria set out in the specifications of the framework agreement.

\section{Framework Agreements in the Utilities Sector}

Notwithstanding the statement made in the Foreword to the effect that the study did not encounter information relating to the use of framework agreements in conjunction with CPBs in the utilities sector, it is nevertheless worth making some brief comments in respect of the Utilities Directive (Directive 2004/17/EC).

As with the Public Sector Directive, the Utilities Directive also enables a non-binding framework agreement (or arrangement) to be treated in the same way as a binding framework contract. It also foresees the use of CPBs. Thus, if the procuring entity chooses to award the framework agreement under the provisions of the Directive as if it were a binding contract or does so using a CPB, then the subsequent call-off "contracts" may be awarded without a further call for competition.

The framework agreement may be concluded using any of the permitted procedures of the Utilities Directive, namely, the open, restricted or negotiated procedure with a call for competition or when applicable without. A CPB in the utilities sector could therefore award a framework agreement by way of a negotiated procedure. Framework agreements entered into under the terms of the Directive would also 
be subject, as with the award of any other contract subject to the Directive, to the requirement of the publication of a contract-award notice. However, there is no need to publish award notices for each of the individual call-off contracts under the framework agreement.

The greater flexibility afforded to utilities, such as the possibility of awarding framework agreements by way of the negotiated procedure with a call for competition, would provide procuring entities with a greater scope than is permitted in the public sector to conduct and structure the framework agreement. As a matter of fact, utilities are not restricted to the mechanisms foreseen in the Public Sector Directive. While a CPB in the utilities sector might choose to operate a mini-tender within the context of a multiprovider framework, it is also clearly permitted to negotiate directly with those providers and therefore has much more flexibility that a CPB in the public sector.

\section{Risks under Framework Agreements}

The obligation to comply with the Directive in a centralised purchasing scenario rests with the CPB. As indicated above, for the benefits of the Directive to be realised by procuring entities (the ultimate purchasers), the CPB must comply with the rules, and therefore it is considered to be necessary for the procuring entity to also comply with them. As a result, call-offs will not have to follow the full course of an award procedure as set out by the Directive. However, the failure of the CPB to comply will have consequences for the procuring entity. Thus, if the CPB does not comply with the Directive, then a call-off exceeding the appropriate threshold value will itself be a contract subject to the Directive, and the procuring entity would have to comply with the Directive in awarding that contract. If it does not, it would also be in breach of the Directive.

The procuring entity will also have the obligation not to depart from the agreed terms of the framework agreement and the facility provided by the Directive. As indicated above, the call-off is subject to conditions under the Directive. In any case, and in particular in the case of a single-provider framework, the call-off must be awarded on the originally agreed terms, without any substantial amendment and if necessary completed by more precisely formulated terms and, where appropriate, additional terms, provided that such an amendment was announced and referred to in the specifications of the framework agreement. If that is not the case (e.g. the procuring entity changes the terms of the contract during the call-off stage), the procuring entity will be in breach of the Directive. In the latter case (where the terms of the call-off may be more precisely formulated at the call-off stage), the procuring entity does not have the possibility of renegotiating the terms of the framework agreement. To do so would place the procuring entity in breach of the Directive. The procuring entity must therefore, even at the call-off stage, respect the terms which constituted the basis on which the award of the original framework agreement was made and on which the entity's compliance with the Directive was determined.

Liability for breaches of the procurement rules is also dealt with differently, depending on the stage reached and the entity concerned. For example, the standstill period introduced by the amendment to the Remedies Directive by Directive 2007/66/EC (which essentially requires a period of at least 10 days to elapse between the decision to award a contract and its conclusion so as to allow time for any aggrieved tenderers to make any challenge they consider to be appropriate) applies in the first instance to the award of the original framework agreement. As a result, the CPB must respect this standstill period. It is during this period that the terms of the agreement are agreed and that any potential breaches in the contract award procedure are likely to be identified.

Where there is a mini-tender in a multi-provider framework that might be concluded on more precisely formulated terms, and, where appropriate, on other terms than those contained in the original agreement, and provided that such a change was foreseen and referred to in the specifications of the 
framework agreement, it is conceivable that the change could lead to a potential challenge, i.e. there may be a question as to whether the conditions of the agreement and of the Directive have been respected. However, it would be impractical to apply a standstill period at that stage, as it would re-open the original contract award procedure (for which the original standstill period will probably have lapsed) and could negatively affect the efficiency gains of having opted for this route (see Recital 9 of Directive 2007/66).

This does not mean that breaches at the mini-tender stage will go unchallenged, however. Directive 2007/66 does allow Member States to apply a standstill period at this stage (and thus cause efficiency loss, as foreseen in the Recital), but it also allows them, as an alternative, to opt for the newly introduced remedy of contract ineffectiveness, i.e. it would be possible to declare the offending call-off null and void in the event that it was awarded contrary to the terms of the Directive. This remedy is a serious consequence of non-compliance (which creates its own legal and practical difficulties), but it would allow the efficiency gains of the call-off system to be maintained, thereby allowing compliant call-offs to benefit from the speed of the process without having to hold up the award of a call-off under a mandatory standstill period.

The risk of a challenge therefore has to be taken into consideration by both the CPB and the procuring entities.

\section{Concluding Remarks}

It needs to be underlined that the provisions on framework agreements apply equally to all procuring entities falling under the Public Sector Directive, irrespective of their operational differences. A CPB setting up a framework agreement for wide cross-public sector implementation, thereby enabling other procuring entities to make call-offs, has to apply the same rules and procedures as an individual procuring entity, which only has the purpose of serving its internal users and clients. The possible implications of this equal application of these provisions to all procuring entities will be examined further on in the study. 


\section{PART II. COMPARATIVE ANALYSIS OF CENTRALISED PURCHASING SYSTEMS IN SELECTED EU MEMBER STATES}

In Part I, the concept, rationale and legal base for centralised purchasing systems (CPS) was presented and examined from various angles, but mainly at a theoretical level. The study deals in large part with central purchasing bodies (CPBs), which have as their main function the award and management of framework agreements to be used on a wide basis within the public administration. Part II aims to describe the main characteristics and features, including similarities and differences, of the CPBs in the EU Member States covered by the study. The structure follows closely the composition of the country reports presented in the Annex section. For in-depth descriptions of the country systems, reference is made to the annexes. The comparative review covers first of all the five EU Member States that submitted country reports: Denmark, Finland, France, Hungary and Italy. In addition, the study presents and examines briefly the centralised purchasing systems of Sweden and the UK.

\section{An Overview of the respective Centralised Purchasing Systems}

\section{Denmark}

The Statens og Kommunernes Indkøbs Service A/S (SKI) was established in 1994 as a 100\% publicly-owned company falling under private law. The Danish Ministry of Finance owns $55 \%$ of the shares in SKI, while the remaining $45 \%$ are owned by the Association of Local Authorities of Denmark (Kommunernes Landsforening), which is the interest group and member authority of Danish municipalities. SKI is a nonprofit organisation.

The regulatory instrument governing the operations of SKI is the shareholder's agreement between the state and the Association of Local Authorities on the establishment of SKI, which falls under the definition of a central purchasing body in accordance with the relevant EC Directive.

SKI is financed almost entirely by a service fee - usually $1 \%$ - on the turnover invoiced by framework agreement suppliers.

SKI currently administers approximately 50 framework agreements involving more than 850 suppliers in about 15 different product categories. The total annual turnover of the framework agreements administered by SKI amounted in 2009 to 1.3 billion EUR.

The use of framework agreements is voluntary for SKI's customers.

The number of SKI staff exceeds 85 persons.

\section{Finland}

Hansel Ltd, the central procurement unit of the Finnish State, was established in its current form in 2003. Its previous operations (wholesale trade, etc.) were closed down in 2004, and the company's new activities were directed towards fulfilling the role of a central procurement unit in line with the European Union's procurement directives. Hansel is a limited, non-profit company under private law, owned by the State of Finland under the control of the Ministry of Finance. 
Hansel's main function is the establishment and management of framework agreements.

Its tasks and roles are defined in the Act on Hansel, the Public Procurement Act, and the State Procurement Strategy.

It is primarily financed by a service fee (maximum $1.5 \%$ ) paid by the suppliers.

Today, Hansel maintains 70 framework agreements covering goods and services required by most government entities. Municipalities are not covered. In 2009 the total value of the purchases made by the state sector under these agreements amounted to 534 million EUR.

The use of framework agreements is primarily voluntary, but some framework agreements are obligatory for the central government administration.

The number of Hansel staff at the end of 2009 was 57 persons.

\section{France}

\section{$\underline{\text { UGAP }}$}

The Union des Groupements d'Achats publics - UGAP (Union of Public Purchasing Groups) was established in 1985 as a public body with legal personality. It has no share capital and is committed to balancing its revenues and expenditures. Any surplus is either distributed to the state or contributes to the reduction of the gross margin rate in the following year. UGAP acquires goods and services for the state, local authorities and hospitals. To that end, it awards multi-purchase order contracts directly (calloffs awarded by CPBs for subsequent purchases from public entities), whereby the flow of documents, purchase orders from public entities to suppliers, invoices from suppliers, and bills to public entities passes through its accounting system, whereas goods are delivered directly and services are rendered directly to each of the public entities having utilised UGAP.

The statute of UGAP is defined by Decree $n^{\circ} 85-801$ of 30 July 1985 and by article 9 of the Code des Marchés publics (Public Procurement Code). UGAP falls under the definition of a central purchasing body in accordance with Directive 2004/18/EC.

In 2009 the total value of UGAP's procurement activities amounted to 1.58 billion EUR.

The financing of UGAP originates from the gross margin on the turnover invoiced by UGAP to its customers.

The use of UGAP's services is not mandatory.

The number of UGAP staff exceeds 875 persons.

\section{$\underline{\mathrm{SAE}}$}

A new entity, the Service des Achats de l'Etat - SAE (State Procurement Office), was set up by Decree $n^{\circ}$ 2009-300 of 17 March 2009. SAE's mission is to co-ordinate the common purchases of the state (amounting to approximately 10 million EUR per year) and to ensure the professionalisation of state procurement officers. SAE may award framework agreements and procurement contracts, but in general it requests a ministry or UGAP to award framework agreements on behalf of the public authorities whose needs have been grouped.

The services of SAE are mandatory for state administrations in defined areas and voluntary for agencies or bodies under the supervision of the state.

SAE's operations are financed by the state budget. 
SAE is a state administration located within the Ministry of the Budget.

\section{Hungary}

In 2003 KSzF (Central Services Directorate General), a budgetary entity with significant economic independency, was established by Government Decree 2722003 (XII.24.) The state's control of KSzF is at the time of the preparation of the study represented by the Minister of the Prime Minister's Office. The Public Procurement Act (PPA) establishes two kinds of collaborative public procurement tools: (i) for central government entities (KSzF); and (ii) for local governments. The central system is regulated by the government decree establishing $\mathrm{KSzF}$, which is the contracting agency for centralised public procurement. The local system is regulated in greater depth by the PPA, leaving less room for detailed regulation by local governments.

This centralised system has introduced mandatory, collaborative procurement in specific, predetermined categories for central government entities. The general areas of centralised public procurement activities are listed in the government decree, while further details are provided by a ministerial guideline (State Normative).

The services of KSZF in the defined product categories are mandatory for procuring entities covered by the centralised procurement system, mainly the state administration, and voluntary for entities outside the state administration.

The operations of KSzF are financed by both the budget and a service fee, amounting to a maximum of $2 \%$, paid by the customers.

The number of KSzF staff is 26 .

In 2009 the total turnover of all framework contracts amounted to 72 billion HUF ( 260 million EUR).

\section{Italy}

Consip S.p.A. - acronym for Concessionaria Servizi Informatici Pubblici - operates exclusively on behalf of the state, with the aim of engaging in information technology, consultancy, and support of public administration activities. The company was established in 1998, initially as an operative tool to radically change IT management. With the 2000 Budget Law, Consip was identified as the service structure for the provision of goods and services on behalf of public administrations. Consip is a joint-stock company owned by the Ministry of Economy and Finance.

The operations of Consip are financed by the Ministry of Economy and Finance through a three-year framework agreement, which is partly incentivised.

The central government is mandated to use Consip's framework contracts, while other agencies are free to use them.

The number of staff working in the procurement division (DAPA) of Consip exceeds 140 persons. In 2009 the total turnover of Consip's framework agreements amounted to 1.7 billion EUR.

\section{Other Country CPS Models}

The five EU Member States above are officially part of the study and their operations are described in detail in the annexes. Sigma has also been able to examine information received from the administrations of Sweden and the UK on the way in which their centralised purchasing systems are organised. 


\section{Sweden}

In contrast to its neighbours, Denmark and Finland, Sweden has not yet established a central purchasing body but instead relies on a system for the central award of framework agreements with call-off arrangements for procuring entities within the government sector. The system was originally based on a mechanism through which the government agency with the best prerequisites for the award and management of a framework agreement within a specific range of products or services of common interest to other central agencies assumed the responsibility for awarding and establishing that framework agreement. This system was created under the assumption that an aggregation of needs within the central administration, with the responsibility of awarding a framework agreement assigned to a specific authority, would help to purchase supplies or services on better terms than each authority would have been able to obtain individually.

This centralised purchasing system was reinforced in 1998, when the Swedish Government established a co-ordination function for government procurement, with the objective of increasing efficiency in public spending. The scope of activities for the co-ordination function is to develop, co-ordinate and follow-up procurement activities within the central government. This function includes the establishment, development and deployment of a framework agreement, and also the provision of methods and support aimed at increasing procurement competence and practice. The co-ordination function is a strategic function, consisting of a small group (three to four persons) currently placed in the Swedish National Financial Management Authority, which is the authority responsible for the system for the co-ordination of government procurement.

Today 11 government agencies responsible for government procurement are working together to exercise the co-ordination function within the central system for the award and management of framework agreements.

The system in Sweden currently includes some 50 product areas with 90 sub-areas, e.g. for stationery, vehicles, IT supplies and services, furniture, and flight services. The annual turnover in 2009 amounted to 1 billion EUR.

According to government policy, the system should in principle be mandatory for entities within the state administration that have made pre-commitments to use the framework agreements concerned, unless a procuring entity has justifiable reasons for awarding a contract outside the framework agreement. Regional and local authorities may also use central framework agreements, and their share of the turnover is approximately $25 \%$.

The system in Sweden is financed mainly by a service fee paid by the framework suppliers.

\section{United Kingdom}

Centralisation of public procurement is a fairly recent trend in the UK. Until the late 1990s, the approach to procurement in the UK was best described as decentralised. Departments and government agencies were responsible and accountable for obtaining value-for-money from their expenditures on goods and services, and most departments had procurement units with staff having had procurement training. Central buying agencies existed, but there was no obligation to use them. As a result of a review conducted in 1999 to consider whether the structure of procurement was suitable for future needs, the Office of Government Commerce (OGC) was set up to provide greater co-ordination of the government's procurement activities.

OGC is an independent office of the Treasury, established to help the government deliver "best value" from its spending. OGC, among other functions, provides policy standards and guidance on best practice 


\section{GOV/SIGMA(2010)3/REV2}

in procurement, projects and estate management, and it monitors and challenges the performance of departments against those standards on the basis of information supported by verified evidence. It also promotes and fosters collaborative procurement across the public sector to deliver better value-formoney and better public services.

Buying Solutions, the executive branch of OGC, is the largest of over 40 Professional Buying Organisations (PBOs) in the wider public sector. The primary role of Buying Solutions is to maximise the value-formoney obtained by government departments and other public bodies through the procurement and supply of goods and services. The company provides easy access to more than 500,000 products and services, through a range of framework agreements as well as a number of managed services, including telecommunications, e-mail and Internet services, energy and e-commerce.

The main product and service areas cover ICT and Telecare, Energy, Property and Office Solutions, Professional Services, Travel and Fleet.

Buying Solutions is mainly financed by a commission (average of $0.6 \%$ ) charged on the turnover of the suppliers but also to a certain extent by a managed service fee charged when it acts as a "procurement agent" for its customers.

The number of staff of Buying Solutions exceeds 300 people.

In 2009 the total value of public sector transactions with Buying Solutions suppliers, through framework agreements and enabling contracts, was 5 billion EUR. 
Summary Table

\begin{tabular}{|c|c|c|c|c|c|c|}
\hline CPB & Legal Status & Funding & Coverage & $\begin{array}{l}\text { Mandatory or } \\
\text { Voluntary }\end{array}$ & $\begin{array}{l}\text { Framework } \\
\text { Model }\end{array}$ & $\begin{array}{l}\text { Call-off } \\
\text { Method }\end{array}$ \\
\hline $\begin{array}{l}\text { Hansel } \\
\text { (Finland) }\end{array}$ & Limited company & $\begin{array}{l}\text { User fees } \\
\text { (paid by } \\
\text { suppliers) }\end{array}$ & $\begin{array}{l}\text { The state (at } \\
\text { all levels) and } \\
\text { entities owned } \\
\text { or controlled } \\
\text { by the state }\end{array}$ & $\begin{array}{l}\text { Mainly (80\%) } \\
\text { voluntary }\end{array}$ & $\begin{array}{l}\text { Both single- } \\
\text { supplier and } \\
\text { multi-supplier }\end{array}$ & $\begin{array}{l}\text { Both ranking } \\
\text { and mini- } \\
\text { tender }\end{array}$ \\
\hline $\begin{array}{l}\text { Consip } \\
\text { (Italy) }\end{array}$ & Limited company & State budget & $\begin{array}{l}\text { Whole public } \\
\text { sector }\end{array}$ & $\begin{array}{l}\text { Mandatory } \\
\text { (central } \\
\text { government) }\end{array}$ & $\begin{array}{l}\text { Single- } \\
\text { supplier }\end{array}$ & \\
\hline $\begin{array}{l}\text { SKI } \\
\text { (Denmark) }\end{array}$ & Limited company & $\begin{array}{l}\text { User fees } \\
\text { (paid by } \\
\text { suppliers) }\end{array}$ & $\begin{array}{l}\text { Whole public } \\
\text { sector }\end{array}$ & Voluntary & Multi-supplier & $\begin{array}{l}\text { Ranking and } \\
\text { mini-tender }\end{array}$ \\
\hline $\begin{array}{l}\text { UGAP } \\
\text { (France) }\end{array}$ & $\begin{array}{l}\text { Public body with } \\
\text { legal personality }\end{array}$ & \begin{tabular}{|l} 
Sales \\
revenues
\end{tabular} & $\begin{array}{l}\text { Whole public } \\
\text { sector }\end{array}$ & Voluntary & & \\
\hline $\begin{array}{l}\text { KSzF } \\
\text { (Hungary) }\end{array}$ & $\begin{array}{l}\text { Non-profit making } \\
\text { body with } \\
\text { economic } \\
\text { independence }\end{array}$ & $\begin{array}{l}\text { User fees } \\
\text { (paid by } \\
\text { contracting } \\
\text { authorities) } \\
\end{array}$ & $\begin{array}{l}\text { Whole public } \\
\text { sector }\end{array}$ & $\begin{array}{l}\text { Mandatory } \\
\text { (central } \\
\text { government) }\end{array}$ & Multi-supplier & $\begin{array}{l}\text { e-auction and } \\
\text { mini-tender }\end{array}$ \\
\hline $\begin{array}{l}\text { Buying } \\
\text { Solutions } \\
\text { (UK) }\end{array}$ & $\begin{array}{l}\text { Non-profit making } \\
\text { body, run on } \\
\text { commercial lines }\end{array}$ & $\begin{array}{l}\text { User fees } \\
\text { (paid by } \\
\text { suppliers) }\end{array}$ & $\begin{array}{l}\text { Whole public } \\
\text { sector }\end{array}$ & Voluntary & & \\
\hline Sweden* & $\begin{array}{l}\text { Government } \\
\text { Agencies }\end{array}$ & $\begin{array}{l}\text { User fees } \\
\text { (paid by } \\
\text { suppliers) }\end{array}$ & $\begin{array}{l}\text { Mainly central } \\
\text { government }\end{array}$ & $\begin{array}{l}\text { Semi- } \\
\text { mandatory }\end{array}$ & \begin{tabular}{|l|} 
Single- \\
supplier and \\
multi-supplier
\end{tabular} & $\begin{array}{l}\text { Ranking and } \\
\text { mini-tender }\end{array}$ \\
\hline
\end{tabular}

The Swedish central purchasing system consists of 11 specialised agencies, each of which is a form of CPB. 


\section{Main Features and Characteristics of the Centralised Purchasing System (CPS)}

\subsection{The establishment of the CPS - history, rationale and legal structure}

\section{History}

Centralised procurement in the public sector is nothing new. For example, the Nordic countries included in the study (Denmark, Finland and Sweden) all have a long history of centralised procurement systems. Finland established a central procurement system for central government as early as 1941. It was a public agency and worked in line with the above-mentioned monopoly model. ${ }^{6}$ In 1995, it was transformed into a limited company, Hansel, but maintained the focus on wholesaling until 2003, when it gave up this line of business and began to concentrate its efforts on the establishment of framework agreements for the Finnish State sector. The reason for this radical change of scope was a growing dissatisfaction among ministries and agencies with the products and services offered by the central purchasing body (CPB).

Denmark created a central procurement body for the state in 1976. Its main task since its start has been to award framework agreements in specific product and service areas to be used throughout the government sector. In 1995, this CPB was merged with a similar municipal entity to create a national procurement body - SKI, a publicly-owned limited company - with the objective of serving the entire public sector with central framework agreements.

In contrast to the other Nordic countries with established central purchasing bodies, Sweden has since the 1970s relied on a system for the co-ordination of central framework agreements with simple call-off procedures, mainly designed for procuring entities within the central government. This system was built around 10-15 government agencies, each of which was given responsibility for a particular product or service area and normally with a large own need for the same goods or services. Since these authorities possessed the necessary product and market knowledge for the efficient procurement of these items, they were considered to be in the best position to manage the procurement process. However, in 2011 a central procurement body will be established within one of the government agencies. The legal form for the organisation was discussed, including the formation of a limited company, but eventually it was decided that the CPB should be established within an existing agency.

France has also had a long history of centralised public procurement. In 1949 the Ministry of Education established a central purchasing unit for goods and school furniture. In 1968 this entity was named the Union des Groupements d'Achats Publics (UGAP). In 1985 it obtained legal status as a public body with legal personality. Throughout its history, UGAP has acted as a CPB, procuring products and services on behalf of the public sector. Last year, the French Government established another CPB, which awards framework agreements in areas commonly required within the state administration, or it entrusts UGAP or another procuring entity with this task.

The three other countries included in the study - Hungary, Italy and the UK - have a more recent history of centralised procurement units. Consip, the central purchasing body in Italy established in 1997, was given the responsibility for running the new "Programme to Rationalise Public Spending on Goods and Services" in 2000, where the aggregation of demand through framework contracts was a key feature. In Hungary, KSzF - established in 1995 - was given the task of setting up a system for the centralisation of the procurement of certain goods and services. In the UK, the government initiated a more co-ordinated approach in the area of public procurement in the late 1990s, first with the creation of OGC and then of its operative branch, Buying Solutions.

$6 \quad$ See chapter 3 below. 
This short historical overview of the CPBs studied reveals several interesting aspects. First, several of the current CPBs were originally organised as government agencies but, for various reasons, were transformed into publicly-owned limited companies later on. The preferences for this legal form may indicate that this organisational form is considered to be suitable for a CPB. Secondly, none of the CPBs, except UGAP, included in this study deal with the physical distribution of goods by acting as procurement agents, including undertaking warehousing functions. The centralised purchasing functions are nowadays generally based on the award of framework agreements.

\title{
Rationale
}

As examined above in chapter 4, the "CPS Attractiveness Model" used by Sigma identifies a number of key drivers and justifications for a centralised purchasing system based on the award of framework agreements:

\author{
$>\quad$ Better prices of goods and services \\ $>\quad$ Lower transaction costs \\ $>$ Increased certainty - legal, technical, economic and contractual \\ $>\quad$ Greater simplicity and usability \\ $>\quad$ Improved capacity and expertise \\ $>\quad$ Higher level of standardisation and greater administrative efficiency
}

$>\quad$ Stronger support for policy goals

These drivers are both explicitly and implicitly described in the country presentations. Overall, the CPBs agree that the main rationale for setting up a centralised purchasing system is the desire to increase savings in the public procurement system by obtaining lower prices and reduced transaction costs. It is generally believed that by consolidating the government's purchases of widely-used goods and services in large contracts, considerable quantity discounts will be generated, resulting in reduced acquisition costs for the public sector which, in turn, will favourably affects overall public expenditure. The other economic justification for centralised purchasing, namely, reduced transaction costs at the level of procuring entities and economic operators, is also important but is not stressed to the same extent as price reductions.

Among other strong arguments in favour of centralised procurement, the modernisation rationale is mentioned by several CPBs. Centralised procurement should function as a tool for modernising the public sector administratively in order to enhance efficiency and effectiveness in the operation and delivery of public services. Modernisation was the explicit reason behind the decision to create Consip where, it was believed, considerable process savings could be generated by developing and promoting new Internetbased purchasing tools and procedures. The creation of Consip thus paved the way for the broader use of these efficient tools within the government sector. Through the creation of centralised purchasing arrangements in the area of information and communication technology (ICT), it would be possible to achieve a higher degree of technical standardisation throughout the public sector. This objective is an important factor in the Swedish system for centralised framework agreements. One government agency is specialised in the award of framework agreements concerning ICT products for the whole public sector, including municipalities. Standardisation and interoperability of administrative systems - based on modern technology - within the public administration is a key argument and a driving policy behind a government's decision to establish centralised purchasing solutions in this area. 
Another rationale - of a non-economic nature - for centralised purchasing, as found in this study, is the mitigation of risks, especially the increasing legal risk of dealing with potential complaints during both the award of framework agreements and the procedure for call-offs. The high requirements of professionalism in correctly applying the rules and procedures laid down in the public procurement legislation of EU Member States constitute a major problem for many procuring entities, especially among small and medium-sized authorities, which furthermore may lack their own permanent procurement staff. For many procuring entities, centralised purchasing arrangements may offer enhanced legal certainty along with other important assurances, such as the assurance of technical feasibility and contractual standards.

However, the rationale for centralised purchasing systems should not be examined only from the perspectives of the government as the owner and the CPB itself, but needs to be analysed from the viewpoint of all important stakeholders of the CPS as well. The following chart illustrates the relationships and the variety of possible interests of the stakeholders, that is, the owner of the CPB, the procuring entities, and the economic operators, as well as how this affects the CPB's ability to satisfy the multitude of different priorities. The CPB will need to consider these various interests and priorities for the success of its operations, as they have implications for operational strategy and planning. 


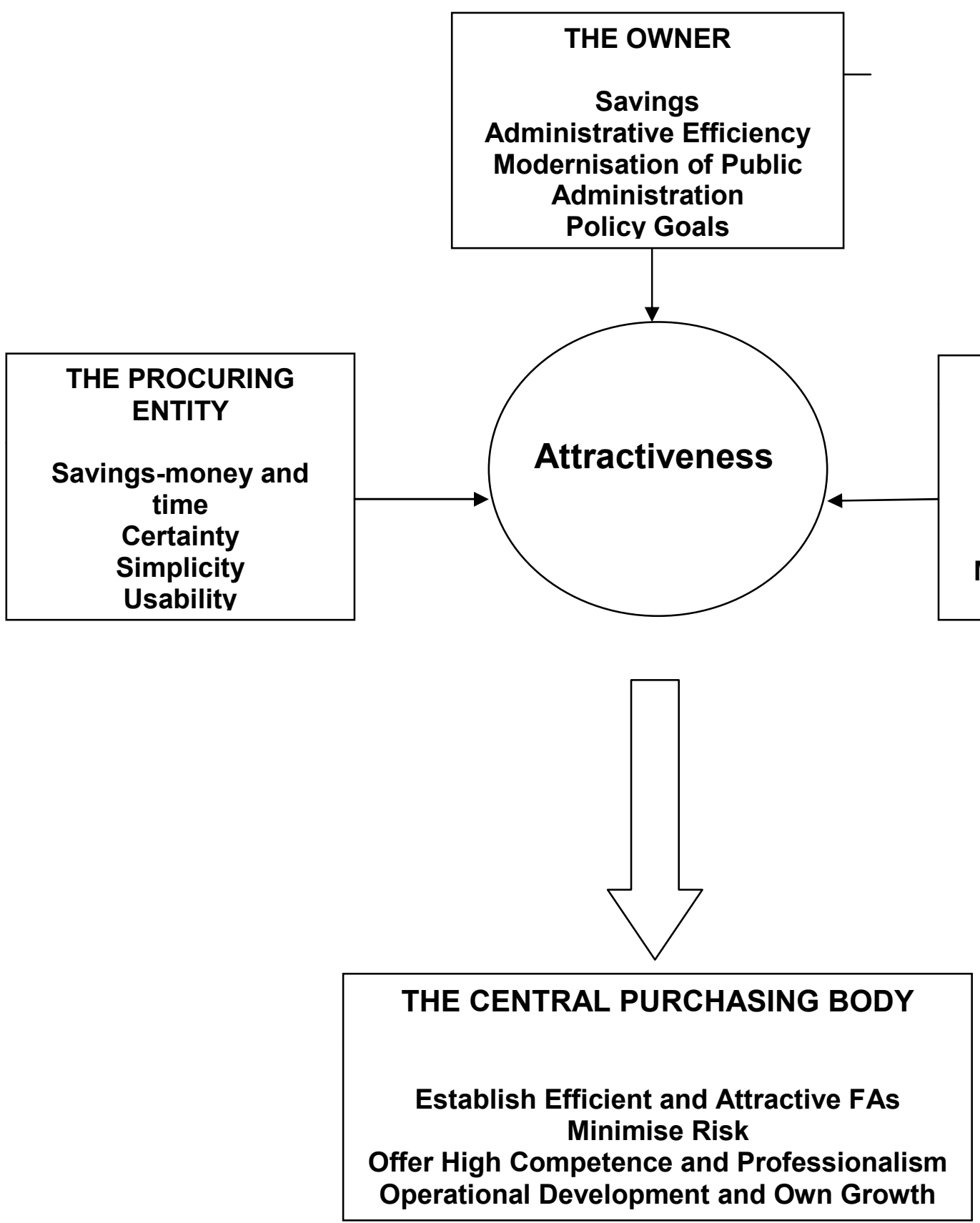




\section{Legal Status of CPBs}

Some of the central purchasing bodies studied have the legal status of a publicly-owned limited company. Hansel, Consip, and SKI are all non-profit limited companies that are owned and controlled by the Ministry of Finance in each country, partially or totally. Others are public bodies with considerable economic independence. SKI (Denmark) has, in addition, a second owner, Kommunernes Landsforening, the Association of Local Authorities, that owns $45 \%$ of the company. UGAP (France) is a public body with legal personality and no share capital, fully controlled by the state. As already mentioned above, until now the Swedish centralised purchasing system has differed in many respects from those of the other countries studied. The system has been characterised by a mechanism for co-ordinated purchasing, where individual authorities have been given the responsibility for awarding framework agreements for a particular product or service area, which can or should be used not only by the state administration as a whole but also by municipalities and regional authorities, although at those levels always on a voluntary basis. A consequence of this dispersed arrangement makes it difficult to identify a single "owner" of the Swedish system. However, a centralised purchasing body will also be established in Sweden in 2011, but with the difference that this body will be located within an existing authority and will not be formed as a limited company.

The instruments for establishing and regulating the operations of the CPBs also differ between the countries. Not only are the instruments themselves different, but the mandates given to the CPBs by the owners also vary in many key respects. In Italy, the Budget Law identifies Consip as the service structure for the provision of goods and services for the benefit of public administrations. This law also defines the regulations to be followed by the company in the implementation of the major rationalisation programme covering the public sector in Italy. In Hungary, centralised public procurement is regulated by a government decree, which prescribes in detail the responsibilities and tasks of the CPB and indicates that mandatory, collaborative procurement should be established in specific, predetermined product categories. In Finland, the tasks of the CPB (Hansel) and its roles are defined in the Public Procurement Act and in the State Procurement Strategy. The objective of the central procurement unit is to promote open competition and to organise tendering processes in a way that fosters efficient market operations. Moreover, Hansel is requested to evaluate the market effects of its operations. The same legal instruments further define the procuring entities covered by Hansel's framework agreements and specify whether these agreements are mandatory or voluntary for the procuring entities.

In Sweden, the system for co-ordination of government procurement is regulated in a government regulation (1998:796), which applies to government agencies directly under the government, i.e. about 400 agencies. Other government-related organisations can, under certain conditions, be included in the system.

SKI in Denmark is the only CPB that is not regulated by a legal instrument. Its establishment, responsibilities and functions are governed by the owners' agreement establishing the company. It is a publicly-owned company operating under private law.

In summary, the CPBs studied operate under very different mandates. These differences probably find their origin in the differences between the countries in terms of legal and administrative structures, traditions and cultures. It appears that the operations of Consip (Italy) and KSzF (Hungary) are regulated quite in detail, while the CPBs in the Nordic countries are given more freedom to plan and manage their operations. As an example, the regulatory instrument in Hungary governing the operations of $\mathrm{KSzF}$ prescribes in detail the product areas and public sector bodies covered and specifies whether the framework agreements are mandatory or voluntary as well as the financing mechanism. No similarly detailed regulations exist in countries such as Denmark, Finland and Sweden. There, CPBs may basically 
decide for themselves on the products and service areas that are subject to framework agreements, the financing models, the type of framework agreements to use including call-off systems and, in particular, the organisation, staffing, market relationships and design of all of the steps in the procurement process.

\subsection{Strategies and Objectives of the CPBS}

In order to be successful, it is important that CPBs elaborate strategies with long-term goals and a clearlydefined scope for their operations (the services that the CPB will offer, the products and services for which it will establish framework agreements, the parts of the public sector that it will target, etc.).

\section{Objectives}

As examined above, since the main rationale for establishing a centralised purchasing system is to improve cost-efficiency in public procurement, the CPBs studied generally state as their primary goal the achievement of cost savings. For instance, Hansel explicitly states that the objective of its operations is to provide savings for the Finnish Government. Buying Solutions' ultimate goal is clearly formulated in its vision, "Savings for the Nation". More specifically, its objective is to achieve the best possible value for the taxpayer through effective, sustainable procurement, thereby releasing savings that are to be recycled into frontline public services, as further formulated in the target to deliver at least 1 billion EUR of savings to its customers each year as from 2010/11. To meet this overall objective, several CPBs have adopted sub-goals, such as the streamlining of procurement processes, the aggregation of demand through the use of framework agreements, and the identification of new areas and ways of achieving savings in public procurement. In addition, some CPBs also have goals that point more indirectly to savings for the public sector. For example, SKI formulates long-term goals regarding growth, trust and qualifications.

As summarised in the stakeholders' chart above, a CPB has to consider a wide number of interests - of both a coinciding and conflicting nature - seen from the stakeholders'perspectives. Although the overarching objective of the CPBs is to contribute to cost-efficiency and savings, they further seem to adopt objectives that serve as prerequisites for the success of their operations.

In brief, the main objectives of a CPB should be to:

$>\quad$ Establish efficient and attractive framework agreements and call-off systems for users and suppliers

D Minimise risks by providing legal, technical, economic and contractual certainty to users

O Offer high-level competence and professionalism in all key aspects of the CPB's operations

$>\quad$ Ensure sound and stable operational development and own growth

These objectives form the foundation for the strategic development and direction of the CPB, which will be further examined in this report.

\section{Main Functions}

The CPBs included in the study award and manage centralised framework agreements in product and service areas of common interest within the public administration, but there are both similarities and differences in the way in which this main function is carried out. The study further reveals that other functions may be part of the CPBs' operations. The CPBs consider that a natural and necessary function is to provide guidance and advice to users on how to plan and conduct the call-off procedures under the framework agreements. A more complicated function discussed with the CPBs was the provision to 
procuring entities of procurement consultancy services in general, i.e. not linked to the use of framework agreements. There is generally a strong reluctance to add such services to the CPBs' operations, for two reasons: (i) the risk of a negative market impact on private procurement consultancy firms; and (ii) the risk that such contracts with procuring entities may be subject to the public procurement legislation and that the CPB may become a contracting party for such services. Whatever the reason, it should be noted that even where such services exist, this activity is very small in relation to the CPB's main function.

An interesting function is the Electronic Marketplace of the Public Administration (MEPA) run by Consip. MEPA is designed for the purchase of goods with a contract value that falls below the EU thresholds, and it aims to encourage the participation of small and medium-sized enterprises in Consip's purchasing programme.

As part of its core business, the operational functions of a CPB normally include the following main activities:

$>\quad$ Procurement management and support

$>\quad$ Market analysis and relationships - customers and suppliers

$>\quad$ Development and operation of the business architecture (electronic platform)

$>\quad$ Administration and reporting

\section{Goods and Services}

A general observation is that the goods and services covered by the framework agreements awarded by the CPBs studied are to be of common interest to and frequently purchased throughout the public administration. With a few exceptions, the range of items covered by the CPBs' operations includes the following goods and services:

- ICT products and services (computers, photocopiers, printers, servers, software);

- Telecommunications (TCL) products (networks, mobile phones, landline phones, telephone exchanges);

- $\quad$ Office furniture;

- $\quad$ Travel services;

- $\quad$ Office equipment and supplies;

- Vehicle and transport services;

- $\quad$ Fuel (for heating and transport) and electricity;

- $\quad$ Food (foodstuffs, meal tickets);

- Organisational and human resources development services.

In terms of purchasing volumes, generally the largest product area is ICT products. An interesting observation is that, although many of the products and services could be considered technically to be comparatively uncomplicated and standardised, there are also areas of high technical and commercial complexity, such as advanced IT systems, that are under the responsibility of some CPBs. However, highly complex products and services can normally not be awarded through the use of single-supplier agreements or fixed ranking call-off procedures but instead require multi-supplier frameworks with mini- 
competitions to ensure their necessary adaptation to the specific requirements of the individual procuring entity.

The conclusion is that a CPB may very well offer both standardised products and services of non-strategic importance and products and services of significant strategic importance. In the latter case, the centralised arrangement is often driven by the government's objective to improve administrative efficiency and effectiveness within the public sector as a whole by ensuring interoperability and standardisation of the administrative systems used by procuring entities.

\section{Public Sector Entities Covered by the CPS}

The study has analysed centralised purchasing arrangements at the central government level. This focus does not exclude the possibility of those framework agreements being used by procuring entities at regional and local levels as well. Generally, regional and local authorities/municipalities have an independent position within the public administration and are regulated by other acts than those regulating state authorities. This means that the state cannot impose the use of central purchasing arrangements outside its own jurisdiction. The participation of non-state level procuring entities and their use of centrally managed framework agreements, if allowed, are always voluntary. In three of the countries studied - France (as concerns the SAE), Sweden and Finland - the CPBs only serve central government entities, while in other countries the CPBs also target other parts of the public sector, mainly municipalities, but on a voluntary basis. SKI (Denmark) and UGAP (France) serve both the state administration and municipalities. It is further important to keep in mind that in several of the countries there are other CPBs, besides those covered by the study. For instance, in both Finland and Sweden there are CPBs that serve municipalities. In the UK, besides Buying Solutions, there are approximately 40 public organisations helping the public sector in its procurement efforts. In several countries, the CPBs studied face competition from other CPBs, especially at regional and local levels.

\section{Compulsory or Voluntary Coverage}

The extent to which it is compulsory for procuring entities to use the services offered by the CPBs differs significantly between the countries studied. In two countries, Italy and Hungary, it is mandatory for the central government, i.e. ministries, departments and central government agencies, to use the framework agreements established by Consip and KSzF, while for sub-national public sector entities, such as municipalities, it is voluntary. Every year in Italy, the Ministry of Economy and Finance drafts a list of framework agreements that procuring entities in the central government should use. Although it is not mandatory for other parts of the Italian public sector to use Consip's framework agreements, they serve as a benchmark for these authorities (normally upper-bound purchasing prices) so as to determine whether a procuring entity should use the central framework agreement or not (unless other sources do not provide better prices).

Sweden has a kind of semi-compulsory system. There is a regulation for procuring entities under the state (ministries and central government agencies) stating that they should use the framework agreements that have been signed. However, it is possible for these entities to purchase from other sources if the products offered do not fulfil their needs or if better terms may be obtained elsewhere. Swedish municipalities may use framework agreements for ICT products, but this is completely voluntary. In Denmark, no public sector entity, at either the central or local level, is forced to use SKI's framework agreements; their use is completely voluntary. In order to use them, however, public sector entities must be members of SKI. In Finland, Hansel's customers consist of ministries, their subordinate bureaus and other government agencies, which have the authority to make acquisitions without separate tendering 
processes by joining the framework agreements administered by Hansel. Of Hansel's 80 framework agreements, the use of approximately 15 is mandatory.

The issue of compulsory or voluntary use of centralised framework agreements is interesting from various angles. In a compulsory system, where procuring entities are obliged to use the framework agreement, responsibility for the overall "quality" of the framework agreement rests very much with the CPB, whether this "quality" is considered positively or negatively by the procuring entities. Call-off contracts leading to poor supplier performance, inadequate product quality and incorrect prices emanating from poorly designed and awarded framework agreements by the CPB may lead to serious dissatisfaction among the procuring entities. In a voluntary system, the procuring entities can always refrain from using the framework agreements if these agreements are not considered to be sufficiently usable. The attractiveness of a framework agreement is always dependent on the extent to which it will satisfy the individual needs of the procuring entities.

\section{The Problem of Maverick Buying Behaviour}

A potential problem for CPBs is non-loyal behaviour on the part of procuring entities. If these entities do not call-off from the framework agreements or do not buy the products acquired by the CPB, the public sector's purchasing expenditures may increase. Moreover, if suppliers believe that many procuring entities will not make their purchases through the framework agreements established by the CPB, the interest in participating may decrease, which in turn may affect competition in a negative way. The country reports do not present a conclusive picture on this topic. Strictly speaking, maverick buying is a problem only for the CPBs with services that are mandatory for procuring entities. However, it may also, in principle, be a problem in countries with voluntary agreements where procuring entities have made more or less firm commitments to use the framework agreements. Indicative purchasing volumes may never be fulfilled which, as mentioned above, may affect the attractiveness of the framework agreement from the suppliers' point of view, but may also affect CPB revenues by way of lower transaction fees.

Several CPBs reveal that maverick buying most certainly occurs but that the extent of this practice is unclear. In general, no actions are taken by CPBs if they suspect maverick buying. Instead, the various countries rely on competition authorities or inspection agencies to watch over procuring entities' procurement practices.

In summary, a common objective for the CPBs studied is to achieve cost savings for the public sector through centralised purchasing. To this end, the main function carried out by the CPBs is the establishment of framework agreements within product areas that are commonly used by many procuring entities. The parts of the public sector covered by the CPBs differ between countries, although the main target for all CPBs is the central government. Another difference is the extent to which procuring entities must use the CPB's services.

\subsection{Organisation, Staffing and Funding}

\section{Organisation}

As indicated above, a CPB in this study could generally be seen as exercising a wholesale function without the physical distribution of goods and services, only the establishment of business relationships between customers (procuring entities) and economic operators (suppliers under the framework agreements). This wholesale function of a CPB, as the business centre for procurement and contracting, market and product competence, business transactions, and communication between suppliers and customers, is normally organised from a product and market perspective. 
A typical organisational chart of a CPB contains the following main functions, which summarise well the organisational models presented in the annexes:

$>\quad$ CPB management
$>\quad$ Product/category management
$>\quad$ Customer/client market management
$>\quad$ Procurement/contracting
$>\quad$ IT/electronic systems development
$>\quad$ Legal services management
$>\quad$ Financing and accounting

Although the CPBs in the study are of different size and have somewhat different scopes, their internal organisations share many common features. First of all, the CPBs are organised in divisions, with specific skills and roles. ${ }^{7}$ Naturally, the department of procurement fills an important role in these organisations. It is usually divided into several sub-divisions, specialising, for instance, in ICT procurement and procurement of administrative services. Marketing and service to public entities play a prominent role in several CPBs, but not in all. Secondly, all CPBs have a department of human resources, finance and administrative support. The number of legal staff differs somewhat between the CPBs studied. For instance, Hansel (Finland) has had legal experts in the organisation for several years, while SKI (Denmark) only recently hired its first legal expert on procurement. Consip (Italy) is the only CPB with a research department that analyses various practices. However, several other CPBs maintain close collaboration with academic institutions, in particular regarding performance evaluation. One observation is that the CPBs' demand for legal support seems to have increased over time.

The study has found that although the main functional departments of the CPBs have many common features, there are also differences, depending on the nature of the CPB's operations. CPBs operating with voluntary framework agreements seem to allocate more resources to marketing and customer relations than those in a compulsory environment. It is also apparent that CPBs managing multi-supplier agreements, with the right to file complaints in the call-off stage, engage more legal service expertise. Another dividing line can be seen in contexts where all transactions are carried out through the CPB's electronic business portal, including e-auctions (e.g. KSzF), leading to a much stronger resource allocation to the IT function of the CPB.

\section{Staffing}

Procurement is more and more becoming a profession in its own right. In order to buy the goods and services needed by the public sector in a cost-efficient way, many different skills are required. For example, because of the highly complex public procurement regulations, good legal skills are needed. It also necessary to have a thorough knowledge of the markets from which purchases are made, which requires sector-specific skills in addition to economic and financial competences. These skills are necessary for both decentralised and centralised procurement. With regard to centralised procurement, even more skills are needed. The key competences needed in a CPB are:

- $\quad$ Experienced and business-oriented senior management;

$7 \quad$ Consip recently changed from a divisional structure to a functional structure. See the Annex for more detailed information. 
- $\quad$ Specialised product and market skills;

- $\quad$ Professional procurement and contracting staff;

- Qualified legal staff;

- IT and systems analysts;

- $\quad$ Financing and accounting skills.

In general, the CPBs studied have staff with various competences, reflecting the needs above.

UGAP (France) and Buying Solutions (UK) are by far the largest CPBs in terms of staff numbers. Respectively, nearly 930 and 300 persons worked in these two companies in 2009. Consip (Italy) is also one of the larger CPBs, with a procurement staff of 140 persons. SKI (Denmark) and Hansel (Finland) currently have a staff 85 and 60 , respectively. The Swedish centralised procurement system altogether employs about 50 persons. The Hungarian CPB, KSzF, is by far the smallest, with a staff of fewer than 30 .

\section{Financing Models}

A central procurement body must be financed, and this can be done in several ways. One possibility is to finance the CPB directly from the government budget, as for ordinary government agencies, which usually receive a lump sum every year that is intended to cover all of their costs. Another funding possibility is to have service fees. These fees may be levied either on the various government entities that use the services provided by the CPB or on the suppliers to the CPB.

Of the CPBs studied, all but two, Consip (Italy) and SAE (France), are mainly funded by service fees, whereby the CPB charges a percentage (usually in the range of $0.6-2.0 \%$ ) of the suppliers' invoiced turnover under the framework agreement. In Hungary and in the case of UGAP (France), the fee is paid by the buyers, while in Sweden, Finland, Denmark and the UK it is paid by the suppliers. Consip and SAE are financed directly from the government budget.

All of the CPBs financed by means of user fees seem to appreciate the arrangement because it provides them with an incentive to establish popular framework agreements: no sales, no revenues. This points to a potential weakness in the arrangement, however, due to the fact that revenues are based on suppliers' reported sales. The problem lies in the fact that the suppliers have an incentive to misreport the true turnover: the higher the turnover reported, the more they must pay to the CPB and hence the lower their own profits. KSzF in Hungary states that this is not a problem in their case because all of their sales are made through an electronic purchasing system, which records every single call-off. Consip's revenues consist of two components: a fixed amount and a variable amount that depends on the extent to which certain objectives are met. The funds are provided by Consip's owner, the Ministry of Economy and Finance. Others CPBs funded directly from the government budget are the French SAE and the Swedish National Debt Office (Riksgälden), which is also responsible for establishing framework agreements for the state's payment transactions, banking services, etc. Both Consip and the Swedish National Debt Office feel comfortable with the current funding systems.

The summary table above (under section 6) presents information on how the six countries studied have chosen to organise their CPBs, their way of funding, etc.

The financing mechanisms of the CPBs constitute an important area and are the focus of considerable attention from owners, procuring entities, suppliers and of course the CPBs themselves. This topic will be examined in greater depth in the next chapter. 


\subsection{Procurement and Contracting Strategies}

Procurement and contracting constitute the core functions of any CPB. They involve a number of clearly identifiable steps, in each of which the CPB needs to make many difficult decisions of a strategic nature, up until the point of conclusion of a framework agreement. Any procurement activity, which is further determined by the size of the contract, is likely to be governed by the rules and procedures of the EC Directive.

The steps listed below are normally part of the procurement process for the award of a new framework agreement, but they are also followed when renewing an existing agreement.

1. Conduct a (pre)-feasibility study to determine the feasibility and appropriateness of a specific product or service area;

2. Obtain a management decision to approve or recommend the inclusion of a specific product or service area;

3. Decide on the type and content of the framework agreement and call-off system that should be used (when this is possible) in terms of single-supplier or multi-supplier agreements (and their duration), with ranking or mini-competition as call-off procedures, including the use of e-auctions;

4. Decide on the procurement methods to be used - open, restricted or negotiated procedures;

5. Decide on the selection and award criteria and the maximum/minimum number of suppliers under each framework agreement;

6. Issue notifications and invitations, respond to queries, receive and evaluate tenders, and identify the best-placed supplier(s);

7. Conclude the framework agreement(s) with the supplier(s) and inform and advise the customers concerning the new framework agreement.

The above actions are all important steps and decisions of a strategic nature that a CPB must take during the procurement process.

The first step consists of the feasibility study, which provides a demand and supply analysis. The purpose of this analysis is to estimate the relevant public sector's needs and likely purchases of a product in the coming years and to get a better idea about what the supply market for that product or service looks like. A demand analysis can be triggered in several ways. It can, as in Hansel's case, be triggered by a customer request, a supplier initiative, or experience gained from an existing framework arrangement that needs to be renewed. For the CPBs investigated, the demand analysis to a large extent consists of various types of information-gathering activities (interviews with public procurement officials, questionnaires disseminated to government departments, etc.). The information for the supply market analysis is gathered through interviews with suppliers and with various associations and organisations representing companies and suppliers. As a general rule, the preliminary demand and supply analysis is usually carried out by a project group within the CPB and often results in a pre-study report. The project group, in addition to CPB staff, is often composed of technical and procurement experts from among the customers, especially the large customers. The success of a framework agreement is highly dependent on the involvement of the large customers early on in the procurement process.

If the first step indicates the feasibility of a centralised procurement action, the process usually moves to the second step. This second step differs from the first in several ways. First of all, it usually consists of a much deeper market analysis. Available statistical market data is often collected. External consultants with specific market knowledge are sometimes brought in to help. Secondly, this step usually involves 
more staff within the organisation. For instance, at Consip, accountants, legal and sourcing experts, and analysts from the research unit, together with marketing experts, are involved at this stage. The outcome of this second step is usually the decision as to whether or not to go forward with the procurement of a framework agreement.

This decision is made, as a general rule, by the CPB's top management. In Hungary, for example, the decision is taken by the General Director of KSzF in the form of a recommendation to the ministry, which will issue - if in agreement - a regulation. The study has identified a slight difference between the CPBs concerning the basis for the "Go/No go" decision. The more commercially-oriented CPBs seem to place a heavier weight on market potential than the less commercially-oriented ones. SKI, which belongs to the former category, follows a general rule of thumb according to which it will only enter a new framework agreement area if there is an expected framework agreement turnover of at least 10 million EUR. Other decision criteria are the relevant public sector's procurement volume of the goods or services in question, the number of procuring entities, and the level of standardisation of the product in the supplier market.

Several CPBs indicated that the owner, usually the Ministry of Finance, was regularly informed or consulted with regard to the procurement unit's tendering plans.

The CPBs seem to take great care during the tender preparation stage to take into account existing product standards, whether they be technical, environmental or of another nature. The same consideration applies to standards regarding delivery and payment policies.

Regarding procurement procedures, no clear picture emerges. Some CPBs stated that they nearly always used the restricted procedure, while others seemed to prefer the open procedure. CPBs in the latter category stated that a restricted procedure might be used for a complicated tender. The negotiated procedure is also used, when justifiable, especially for complex service contracts.

The award criterion most used, by far, by the CPBs is that of the most economically advantageous tender (MEAT). In fact, SKI, Hansel, the Swedish CPBs and KSzF all stated that this was the only award criterion used. Consip sometimes uses the criterion of the lowest price, but only in a minority of cases, less than 10 percent; for the remaining tenders the award criterion is the economically most advantageous tender. This means that the CPBs use both price and quality factors in the evaluation and award of framework agreements.

However, in the event that e-auctions are also used for the award of framework agreements, all factors are usually expressed in quantifiable or monetary terms, although the latter is not a legal requirement. Moreover, a procuring entity can use the MEAT criterion for the call-off, which should be based on the original terms but the terms do not necessarily have to be identical. Furthermore, the call-off procedure under a multi-supplier agreement may also designate the price as the only factor for the call-off award, even if the framework agreement was based on the MEAT criterion. For determining the most economically advantageous tender, price and various qualitative criteria are used, such as delivery time, technical performance, environmental aspects, or coverage of services, as suited to the particular product tendered. The weight of price is usually considerable; Hansel, for instance, places a weight of $60-80 \%$ on the price.

The call-off phase, including contract management, should be based on the specifications, conditions and terms set out in the framework agreement. Routines for ordering, deliveries, invoicing and payments, as well as for the preparation of purchase statistics are to a large extent outlined and agreed in detail in the framework agreement and follow a standard format. They are then usually handled directly by the purchasers and suppliers. CPBs often provide comprehensive guidance to the users of framework agreements on how to conduct the call-off process in all its steps. The importance of the call-off guidance element depends on the type and complexity of the framework agreement. 
As a general rule, suppliers are obliged to report purchasing statistics to the CPB. For those CPBs that are funded by user charges these statistics provide the basis for the billing of the suppliers.

All CPBs have introduced electronic means in their operations, but the extent to which they use electronic tools differs considerably. Generally, electronic, Internet-based platforms are in place for the publication of procurement notices, tender documentation, and award results. However, there are differences in the extent to which CPBs have developed electronic systems for the call-off process and the subsequent contract management phase. The publication of electronic catalogues of the goods and services that they provide seems to be common among all CPBs. Electronic purchasing management systems have also been developed by some CPBs to facilitate and make the procurement process more efficient. Other countries are implementing such systems or planning to introduce them. KSzF offers, in accordance with legal requirements, a complete electronic call-off system for all transactions, except payments, under the call-off contract.

\subsection{Framework Agreements - Models and Conditions}

All CPBs included in this study, except two, carry out their centralised functions by awarding framework agreements that are to be used by procuring entities through a call-off procedure. UGAP (France) also awards framework agreements, but with itself as the only user of the subsequent multi-purchase contract in order to resell the products to the customers, the procuring entities.

The study has described the legal basis for awarding framework agreements and the various conditions that must be in place during the call-off process. The study has further concluded that the CPBs studied have both similarities and differences in the way in which framework agreements have been introduced and are used, depending on the national context. Some CPBs practise both single-supplier and multisupplier agreements, while others - for example, Consip - have so far basically used only single-supplier frameworks. There are also differences in the way in which the call-off procedure can be used, through ranking or mini-competition, with or without the use of an e-auction, etc.

In brief, the following variants concerning framework agreements have been found among the CPBs studied.

\section{Single-supplier Framework Agreements}

Although it is not a legal requirement, the single-supplier type of agreement usually implies that all conditions are decided at the level of the framework agreement, including prices and delivery conditions, which procuring entities then use for placing orders. Most of the time, the only open part of this agreement is the quantity, which is not guaranteed to the framework agreement supplier. KSzF (Hungary) is the exception, where the value or quantity of the framework agreement is determined at the point of conclusion of the agreement.

It should be noted that a CPB using single-supplier agreements may have to award parallel agreements in order to cover different geographical areas or to meet different quality requirements among its customers. Other important considerations are the duration of the agreement and the method of capturing price developments. For such agreements there is always a risk of monopolistic consequences and other negative implications.

The main advantages of single-supplier agreements are:

$>$ Competitive prices;

$>\quad$ Low transaction costs; 
$>\quad$ Simple use;
$>\quad$ Legal certainty.

The main disadvantages of single-supplier agreements are:

- $\quad$ Risk of low adaptability to individual needs, which can be a major problem in a compulsory system;

- Difficulties for SMEs to participate.

\section{Multi-supplier Framework Agreements}

The multi-supplier framework agreement normally leads to more complexity, both in the award of the agreement and in the design of the call-off system. The award of a multi-supplier agreement is completed only upon conclusion of the call-off procedure, whether this procedure is carried out by a ranking or a mini-tender. This means that the responsibility for completing a multi-supplier framework agreement in general is shared between the CPB and the procuring entities, affecting the distribution of risk between the two parties for the final completion of the framework agreement.

The award procedure for a multi-supplier agreement must pay greater attention to the applicability of the agreement than is required in the context of a single-supplier agreement. A multi-supplier agreement must correctly reflect the variation of needs among the procuring entities in terms of differences in technical requirements, geographical location, the size and demands of the procuring entity, and the procurement competence at hand, to give some examples. For the award of a framework agreement, the CPB makes a pre-selection of suppliers as well as an indicative evaluation of the tenders submitted. The pre-selection of suppliers under the award of multi-supplier framework agreement has much in common with the restricted procedure, but the selection criteria need to be set with reference to the type of calloff procedure to be used. In the case of a mini-tender, the CPB needs to ensure that the variation of needs among the procuring entities is taken into account; as a result it is not unusual to find both large and small suppliers among the framework suppliers. The tender evaluation may include prices, and this is considered necessary when a ranking procedure is used. In the case of a mini-tender, quality factors may be the only grounds for the award of the framework agreement.

Multi-supplier framework agreements thus require important decisions on the following points:

\section{Number of providers under the framework agreement}

The number of providers needs to be at least three, but usually the CPBs include more suppliers to ensure technical and customer adaptability, sufficient competition and a sound supplier structure, including SMEs.

\section{Duration of the agreement}

The duration of framework agreements is normally between 2-4 years, with a possibility of extension where justified for technical or commercial reasons.

\section{Design of the call-off system}

The two main call-off procedures used by CPBs under a multi-supplier framework agreement are ranking and mini-competition (mini-tender).

However, the ranking procedure is not practised in exactly the same way by the CPBs. The following methods can be distinguished: 


\section{a) Fixed ranking}

The order of the framework suppliers is determined by their ranking in the evaluation following the award of the framework agreement. The best-placed supplier has the first option to accept a call-off by the procuring entity. If it cannot accept the call-off for any justifiable reason, the order can be placed with the second best in the ranking, etc.

This procedure seems to have in common with a single-supplier agreement the determination of prices under the call-off by the framework agreement.

\section{b) Dynamic ranking}

The CPB arranges a price competition at certain moments during the lifetime of the framework agreement, which may change the ranking between the suppliers.

\section{c) Indicative ranking}

This is a call-off procedure whereby the CPB leaves it to the procuring entity to determine the final ranking of the suppliers based on the parameters used in the original ranking at the time of the award of the framework agreement. The final ranking is set by taking into consideration factors of importance to the individual procuring entity, such as transportation costs, local availability, and technical requirements that are specific to the procuring entity.

The main advantages of multi-supplier agreements with a fixed ranking procedure appear to be:

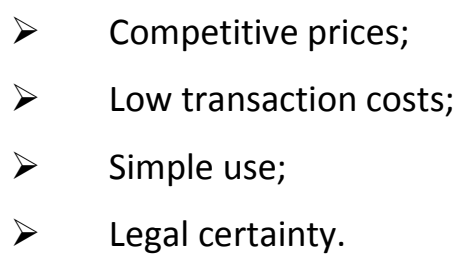

It should be noted that a single-supplier agreement would normally offer stronger price competition since it is a winner-takes-all situation.

The main disadvantages of multi-supplier agreements with a fixed ranking procedure:

- Unless there is a mechanism for price fluctuations, the framework agreement has to be of short duration;

- $\quad$ Risk of low adaptability to individual needs, which can be a major problem in a compulsory system;

- $\quad$ Difficulties for SMEs to participate.

The main advantages and disadvantages of multi-supplier agreements with an indicative ranking procedure, compared with the fixed ranking system, appear to be:

- Greater adaptability to the individual needs of the procuring entity and the local context;

- $\quad$ Higher legal risk for procuring entities.

The study reveals that both Hansel (Finland) and the Swedish CPBs seem to strictly follow a fixed ranking procedure, whereby procuring entities first contact the supplier with the tender for the award of the framework agreement that was considered the best and turn to the second supplier only if the first is not capable or willing to provide the goods or services in question, and so on. The actual ranking of the suppliers is made by the CPB on the basis of the evaluation criteria. SKI (Denmark) uses the indicative ranking model, whereby the final ranking is made by the individual procuring entities. 
A dynamic ranking procedure also exists and is used by KSzF (Hungary), for which it is the standard procedure, and Hansel also uses it sometimes. For these tenders, the ranking of the suppliers changes during the contract period. The criterion for these changes is usually the price.

\section{d) Mini-tender}

As mentioned in the section on the legal basis, where the mini-tender (mini-competition) option is chosen, the parties must compete again "on the basis of the same and, if necessary, more precisely formulated terms, and, where appropriate, other terms referred to in the specifications of the framework agreement". The terms may be more precisely formulated or may be supplemented by terms that were at least foreseen in the specifications, but the mini-tender cannot take place on the basis of different terms.

For every call-off contract to be awarded, procuring entities must consult the economic operators that are capable of performing the contract. The mini-tenders must be solicited in writing, but this also includes solicitation by electronic means of communication. There is no specific time limit set for the mini-competition, but procuring entities must fix a time limit that is sufficiently long to allow tenders for each specific contract to be submitted. The award will be made to the tenderer who has submitted the best tender on the basis of the award criteria set out in the specifications of the framework agreement.

If the mini-tender is arranged without any change of the specifications and general contract terms, but only to determine the lowest price or the criteria that are usually directly expressed in monetary terms, the call-off procedure is fairly simple and may also allow the use of e-auctions.

However, in contract situations where significant but acceptable adaptations of the technical specifications and of the evaluation criteria to meet the specific requirements of the individual procuring entity are needed, the call-off process may be very similar to and as demanding as normal tendering in terms of preparing the final specifications, setting the contract terms and evaluation criteria, issuing the tender invitations, and carrying out the tender evaluation. Such demanding call-off procedures are not uncommon under framework agreements for complex IT systems.

\section{Findings Specific to Some CPBs}

Among the CPBs, several different models exist, often in parallel. Consip has so far chosen to employ a model where the framework agreement is concluded with a single economic operator and all of the terms are fixed. According to this arrangement, a provider undertakes to accept - at the conditions and prices established - orders from public administrations until the expiry date of the agreement, although sometimes only up to a predetermined monetary amount or quantity of goods. Public entities send their orders for supplies (by fax or online) directly to the supplier. SKI and KSzF have both chosen to employ models where framework agreements are generally concluded with several providers. In this case, they are both adhering to the EU rules of having at least three different providers under each framework agreement. Additional suppliers are often chosen, however. Hansel and the Swedish CPBs represent a third model, using both single-supplier and multiple-supplier framework agreements. Regardless of whether single-supplier framework agreements or multiple-supplier framework agreements are used, the period of validity of these contracts is usually between two and four years.

\section{Call-off Procedures}

As already pointed out, the EC Directives allow call-offs to be made in two different ways if the framework agreement is concluded with several providers: a "ranking-method" or a mini-tender, depending on whether all of the terms are laid down in the framework agreement or not. The study 
reveals that both methods are used. Interesting differences exist, however. One difference is the extent to which the call-off procedure is laid out in the invitation to tender. In Sweden and Finland, it is always the case that the call-off procedure and its selection and award criteria are presented in the invitation to tender. In other words, potential providers know beforehand whether call-offs will be made through a mini-tender or through a ranking.

To sum up, several models of framework agreements are used by the CPBs studied. This finding indicates that it is possible to have different opinions on which types of framework agreements are the best to use and to use in different ways the set of options offered by the provisions in the relevant EC Directive.

\section{Issues of Particular Interest}

Sigma has found that the choice and application of the framework agreements among the CPBs studied give rise to a number of interesting observations, which will be further examined in the next chapter.

\subsection{Procurement Values}

The value of CPB purchases in the countries studied is substantial, usually between 0.5 and 1.5 billion EUR, either by awarding public contracts or concluding framework agreements for works, supplies or services intended for contracting authorities or by acquiring supplies and/or services intended for contracting authorities. Interestingly, the values do not differ very much depending on the size of the country. For instance, the value of centralised purchases in Denmark, a relatively small country, is about the same as the value of centralised procurement in Italy and France, both much larger countries.

One factor that affects the total sales value is the extent to which the public sector is covered by CPB services. This is clearly seen by comparing Denmark and Finland. In Denmark, the central procurement body makes purchases for the whole of the public sector, while in Finland only the central government is served. This explains why the volume in Denmark ( 1.3 billion EUR) is so much larger than in Finland (0.6 billion EUR).

Although purchasing made through CPBs amounts to considerable values, it is generally small in comparison to the overall value of public procurement. Any exact figures regarding the "market shares" of CPBs are hard to find. In Sweden, the public sector's annual purchases of goods and services are estimated to be somewhere in the region of 40-50 billion EUR, of which the central government's purchases amount to 15 billion EUR. Of these 15 billion EUR, about two thirds, or 10 billion EUR, relate to purchases that potentially may be centralised. In comparison, the 700 million EUR of purchases actually made through centralised purchasing systems amount to less than $10 \%$ of the potential amount. Similar proportions are found in the other countries studied. In some product segments, however, such as IT products, the market share of CPBs may be considerably higher.

\subsection{Market Features and the Position of SMEs}

An important policy aspect of centralised procurement and the use of framework agreements is the access of small and medium sized-enterprises (SMEs) to public procurement. This issue has several components, such as the existence of a specific policy towards SMEs and the structure of supply markets.

\section{SME Participation}

It has been difficult to obtain an exact overall picture of SME participation among the CPB suppliers studied, but the general impression is that SMEs are well represented. Recently, the CPBs in Finland and Sweden conducted detailed investigations of their suppliers. In Sweden, out of nearly 700 firms with 
framework agreements, approximately 500, or 70\%, were SMEs (fewer than 200 employees). In fact, nearly 100 were "micro-firms", with fewer than 10 employees. Moreover, SME participation differs significantly between the various framework agreements and product areas. For some products, most suppliers are SMEs, while for others most suppliers are large firms. In Finland, approximately $40 \%$ of the sales made through Hansel's framework agreements were by SMEs. In France, around 70\% of UGAP's suppliers are SMEs: $13.6 \%$ for services and fuel products; $72 \%$ for medical equipment; and $82.8 \%$ for furniture, general equipment and logistics (68.4 \% in value).

Data for the other countries are less detailed. SKI (Denmark), for instance, argues that many of its suppliers are SMEs, although exact figures are missing. The picture is the same in the UK and Hungary. In Italy, the picture is totally different. Although Italy is one of the countries with the highest SME share overall, none of Consip's framework contracts is with an SME. On the other hand, Consip has developed an electronic marketplace for purchases of small value (below the EC thresholds), specifically aimed at facilitating the participation of SMEs.

\section{SME strategies}

In general, most of the CPBs seem to have SMEs in mind when they establish their framework agreements. In Sweden, the government policy requires that opportunities be given for small and medium-sized enterprises to participate in framework agreements, e.g. by allowing subcontracting and setting qualification criteria at an appropriate level. In Finland the project plans of tender competitions are required to contain an analysis of the situation for SMEs.

Measures used by CPBs to facilitate the participation of SMEs include the division of contracts into lots. For example, the procurement of accommodation and conference services is often divided into several lots, by geographical area, in order to enable SMEs to participate. Specialised consulting services, for instance IT services, are another product category for which this technique has been used. Several CPBs also stress the importance of not putting too strict and rigid demands on technical and capacity requirements, which smaller firms may find it difficult to meet. For instance, Consip aims to facilitate for SMEs the formation of consortia and to thereby be able to bid on the large framework agreements of the CPB.

\subsection{Measuring Performance}

The ultimate purpose of centralised procurement is to achieve savings for the government. The CPBs and their owners have chosen various methods to evaluate and measure performance in this respect. A general observation, however, is that all CPBs point to the problem of achieving reliable results.

Several CPBs have tried to estimate the extent to which prices are lower due to the centralisation of procurement. To that end, prices obtained under framework agreements are compared to the suppliers' "ordinary" prices, which could correspond to the list prices for certain products. These comparisons usually reveal significant savings of between 20 and 50 percent. A few CPBs have also tried to estimate the process savings, i.e. to what extent transaction costs are reduced with centralised procurement and the use of framework agreements. These calculations show considerable savings. For example, recent evaluations in Sweden and Finland indicate savings in each country in the range of 100-150 million EUR per year. These estimated savings consist of both price reductions and process savings.

One indication of CPB performance used by some CPBs is how turnover develops under the framework agreements. For instance, SKI views the development of turnover as an important indicator of how competitive its agreements are. 
Customer satisfaction studies are also conducted by some CPBs. These studies are of particular importance for those operating a compulsory system of framework agreements.

\subsection{Success and Risk Factors}

The country reports point to a number of factors that are considered to be important for successful centralised purchasing where savings are obtained. First, it is important in terms of support from the owners. The CPB must have a clear mandate to operate. The mandate may be broad or narrow, but it must be clear. Second, good relations with both customers and suppliers are important for building confidence in the operations of CPBs, which in turn are important for preventing maverick buying practices, stimulating tender participation, etc. Third, and related to the second factor, it is important to actually obtain favourable purchasing terms and products, thereby creating legitimacy and loyalty towards the centralised purchasing systems that have been established. Specifically, the more inclined procuring entities are to use the CPB's services, the more attractive it is for potential suppliers to compete for framework agreements. In other words, there is a set of complementary factors that will facilitate the success of a CPB. Clearly, the CPB's competence and behaviour are important success drivers.

On the risk side, the most obvious risk is that a CPB will fail to deliver on its promises, that is, by not being responsive to the various stakeholders involved (customers, suppliers, and owners) and not delivering attractive terms, etc. This is a type of risk, however, that a CPB may learn how to manage, at least to some extent. Another important risk mentioned by several CPBs, but more or less outside their control, is that the procedural rules in the public procurement legislation will be more important than the economic aspect of procurement, thereby making a CPB difficult and expensive for its customers to use. The possibility of filing a complaint and, in countries where it applies, the need to respect standstill periods also during the call-off stage have led to a transfer of risk from the CPBs to the procuring entities, which has changed the CPBs' risk situation. 


\section{PART III. KEY OBSERVATIONS AND ISSUES, IMPORTANT RISK AND SUCCESS FACTORS - LESSONS LEARNED, AND THE WAY FORWARD - A SUMMARY}

So far, this study has examined various conceptual, legal, economic and practical aspects of centralised purchasing systems, including a description and comparison of the main characteristics, features, etc. of the workings of central purchasing bodies in a selected number of EU Member States. This final Part III, which is more normative than descriptive, aims to provide guidance on key aspects related to the management and operation of centralised purchasing systems. The focus is centred on the questions posed at the beginning of the study. In addition, Part III examines main challenges and lessons learned for Sigma partner countries and suggests possible ways forward.

\section{Key Observations}

\subsection{Centralised Versus Decentralised Procurement?}

Public sector procurement in the EU is regulated by Directive 2004/18/EC, which means that all public sector procuring entities must follow a minimum set of common procedures as implemented in their national law. Member States, however, remain free to decide on certain practical matters, such as whether to implement in their national procurement regulation specific provisions in the EC Directive concerning central purchasing bodies (CPBs) and framework agreements. By using the services offered by $\mathrm{CPBs}$, it is possible for procuring entities to buy certain goods and services by placing an order directly with the CPB, such as with UGAP (France), or to use framework agreements provided by the CPBs. In other words, procuring entities do not need to conduct formal procurement procedures on their own. This study has examined the possible benefits and costs of such a centralised purchasing approach compared to a more decentralised approach, where each procuring entity is responsible for its own purchases. The result of that comparison may be summarised in the following points:

- $\quad$ From a theoretical point of view, there are both economic and non-economic arguments to explain why, under certain conditions, a centralised purchasing strategy may lead to higher efficiency and better products, lower prices due to economies of scale, process cost savings, lower legal risks, etc. than decentralised purchasing.

- $\quad$ Centralised purchasing also involves risks. For instance, it may create barriers to entry for small and medium-sized firms and lead to a selection of products that are insufficiently responsive to the majority of the procuring entities' needs. However, under the right conditions, centralised systems may also offer risk mitigation in terms of improved legal, technical and contractual certainty, as well as fair access to public procurement by any kind of economic operator.

- It is therefore important to realise that centralised purchasing has the potential to achieve gains. However, these gains will not occur with certainty, irrespective of the type of system that is implemented and how it is implemented. The design of the centralised purchasing system is crucial.

- Moreover, it is important to realise that there are many possible ways of designing a centralised purchasing system in accordance with the EC Directives, and this fact is underscored by this study. 
Bulk purchasing of certain goods is an option, for instance, used by the French CPB, UGAP. Establishing framework agreements for these goods is another model used by several CPBs. The outcomes in terms of efficiency and cost savings of these different models are likely to differ, and it is difficult to argue that one model dominates another.

- $\quad$ Centralised purchasing builds on the idea of demand aggregation and therefore works better the more standardised the products in question are. Hence, centralised purchasing is not beneficial in the case where procuring entities have specific and unique demands. This means that for many goods and services, procuring entities need decentralised purchasing, which should then be the preferred method. However, the study has also demonstrated that centralised solutions may also be clearly advantageous in areas of a highly complex nature, such as contracts for IT and administrative systems that are of common interest to the public administration.

- Centralised purchasing of certain goods and services is likely to benefit mostly small and mediumsized procuring entities. Large procuring entities, such as ministries or large government agencies, probably have sufficient procurement competence and sufficiently large purchase volumes to reap most of the gains that a centralised purchasing system can produce. This is not the case of many small or medium-sized procuring entities. One implication of this situation is that a country with a public sector consisting of many small procuring entities may have more to gain from establishing a centralised purchasing system than a country with mostly large procuring entities. However, the study confirms that, even in a voluntary environment, large procuring entities tend to use CPB framework agreements covering products and services of non-strategic importance to them. Furthermore, it is usually vital for a CPB to have large procuring entities as customers and users of framework agreements, for economic as well as other reasons, such as increased credibility.

\subsection{What Goods and Services Should Normally be Covered or not be Covered by the CPB's Responsibilities?}

One important issue is the product scope of a CPB, i.e. what goods and services should normally be covered by the CPB's responsibilities? This issue has several dimensions. One issue concerns the products that the CPBs should acquire or establish framework agreements for. Another is whether the CPB should take on other roles, such as helping individual procuring entities with procurement support.

To answer the first question one needs to remember the main rationale for establishing a centralised purchasing system. The public sector needs a large number of different goods and services in order to perform its various tasks in society. Some of these goods and services are common to many or to most procuring entities, such as office supplies and ICT products. Others are specific to individual authorities, such as police cars or advanced medical equipment. For the former category of products, it might be rational to aggregate demand and centralise purchasing, thereby achieving lower prices and transaction costs. For the latter category, these advantages are usually non-existent. In other words, from a theoretical perspective, it is clear that only a subset of all of the products that the public sector needs is suitable for centralised purchasing.

This study has revealed that this logic also has empirical support. The country reports show that the participating CPBs more or less focus on the same type of products. Framework agreements are generally put in place for goods and services that all procuring entities need (the common interest principle). Some variation in the range of products exists, but it is surprisingly small. An interesting observation regarding this issue is that the different mandates given to the CPBs do not seem to have any significant impact on the choice of products and services. Consip (Italy) and KSzF (Hungary) are more heavily regulated by their 
respective owners than, for instance, SKI (Denmark), but all three make approximately the same product choices.

The second question - to what extent a CPB should offer services to individual procuring entities - is more difficult to answer. The study reveals that, from time to time, several CPBs are asked by procuring entities to assist by providing procurement expertise. There thus seems to be a demand for procurement assistance, and the CPBs obviously have the necessary competence to be of help. The CPBs are ambivalent concerning this issue, however. It seems that only Hansel provides individual consulting services and then only on a very small scale. Others, like SKI, which are otherwise commercially oriented, has so far chosen to stay out of the consulting business altogether, despite the fact that there is most likely a profitable market in procurement consulting. One reason for this choice is that CPBs fear criticism from the private sector if they were to start offering this kind of service. Another is their legal status as contracting authorities in the meaning of EU law, which requires them to be established for the specific purpose of meeting needs in the general interest, without having an industrial or commercial character. In contrast to the bulk purchases or framework agreements offered by CPBs, where the services are provided to many procuring entities at the same time, individually tailored procurement consulting services would need to be tailored to specific needs, and it is precisely those kinds of services that are offered by the private sector. In other words, if CPBs were to start offering individual consulting services, they would start competing with the private consulting sector, which is a sensitive issue in many Member States. The issue of competition neutrality and the risk of cross-subsidisation would immediately be raised. There is a risk that this issue would create legitimacy problems for the CPBs, which might negatively affect their core activities of creating value for the public sector through the establishment of framework agreements.

\subsection{Should the Use of Central Purchasing Bodies' Services be Compulsory for the Procuring Entities?}

One difference between the CPBs studied is the extent to which procuring entities are obliged to use the services offered by the CPBs. In some countries, governments have made it mandatory for procuring entities to buy certain goods or services through or from a CPB. In other countries, it is up to the procuring entities to use whichever source produces the most "value-for-money". One country, Sweden, has chosen a "middle-way" model, where procuring entities are recommended to use CPBs' services but are free to choose other sources if they are considered to offer more "value-for-money". Finally, a fourth model, applied by the Finnish Government, makes it mandatory for procuring entities to use a subset of the CPB's framework agreements, but allows the use of other agreements to be voluntary.

What can be said about the attractiveness of these regulatory differences? Proponents of a system whereby procuring entities should be forced, in principle, to use the CPB's services argue that this ensures a cost-efficient public sourcing and increases standardisation among authorities. It may further improve tender prices and terms and would make it easier for the CPB to estimate the expected demand. It would also create a greater degree of certainty for potential suppliers regarding the actual sales. Both of these factors are likely to strengthen competition for the contracts and produce better prices and other terms. Others argue that such a requirement weakens the incentive of CPBs to be user-friendly and creates a risk of monopolistic behaviour.

One of the benefits of having a voluntary system, they argue, is that it provides an incentive for CPBs to offer attractive services on competitive terms. If CPBs fail to do so, there will be no demand for their services and their own existence may be at risk. This is especially so if the revenue of the CPB is tied to the extent to which its services are used by procuring entities. As mentioned in section 7.2, several of the CPBs operating under those conditions, i.e. where services are voluntary and revenues are directly linked to sales under framework agreements, consider these incentives as positive and important. They argue 
that the main benefit of a voluntary system is that it exposes the CPB to a form of competition, which stimulates it to offer attractive products whereby it creates the most value-for-money.

In other words, there are arguments both for and against making CPB services mandatory. However, the study does not result in a firm conclusion as to whether a voluntary or a compulsory system is best suited to generating savings and economic benefits. However, a voluntary system should provide better opportunities to properly reflect customer satisfaction or dissatisfaction with the services of the CPB. Also, a voluntary system would in principle coincide more closely with the concept of a decentralised public procurement system, where it is the role of the procuring entity to take procurement decisions and to be held accountable for them.

\subsection{What is the Best Organisational Form for a Central Purchasing Body?}

This study has documented the different ways of organising centralised procurement. By far, the most common organisational form for CPBs among the countries studied is the limited company. However, it is important to point out that, contrary to the normal case with limited companies, the objective of these CPBs is not to maximise profits. Instead, they are - without exception - non-profit companies. The CPBs studied favour this organisational form mainly because it provides them with flexibility and a certain degree of freedom compared to being part of the government administration, within a ministry or as an independent agency. It is also argued that being a corporation makes it easier to attract competent and specialised staff. In addition, it is argued that this organisational form enables the CPBs to focus solely on creating value for their customers, without taking unnecessary political considerations into account.

Others argue that because the limited company form is ultimately an organisational model that is meant to be used for profit-seeking firms, it is not ideal for CPBs, which do not have the objective of maximising profits but of creating savings for the public sector. Instead, they argue, a CPB is best organised as a government agency or a division within a ministry. Of these two models, only the former is used by any of the CPBs studied.

The Swedish central purchasing system currently consists of a set of specialised CPBs, all of which are organised as divisions within government agencies. This way of organising the system has a long history and is considered, by and large, to have worked well over the years and produced significant savings for the government. A recent evaluation of the system, however, pointed to a number of weaknesses of the system and proposed a switch to another organisational model - a single, independent government agency.

Some of the weaknesses identified in the evaluation of the Swedish system were directly linked to the organisational model. Being part of an agency that has other tasks than centralised purchasing, tasks that are core activities of the "mother" agencies, has created problems with non-transparency, a risk of crosssubsidisation, and downgrading of the purchasing function. Moreover, several of the specialised CPBs argued that this organisational model was a hindrance to developing relations with suppliers and customers, promoting framework agreements, and developing e-procurement tools. It is considered that the proposal to aggregate the framework agreements of these 10-12 specialised CPBs and place them under the responsibility of a single, new procurement agency would eliminate many of these weaknesses. The evaluation also discusses the possibility of organising this new procurement agency specialising in the establishment of framework agreements as an independent company, as is the case in Denmark and Finland. It was clearly pointed out by a Swedish study that this would most likely be a good model, but would not easily fit into the Swedish public sector organisational model. In addition, it was argued that, with an independent agency, most of the benefits associated with a CPB in the form of a limited agency would be achieved. 


\subsection{How Should the Operations of a CPB be Financed?}

An issue that has been debated in some countries is how CPBs should be funded. The study again shows that several different models exist. Most of the CPBs studied are funded through service charges. Two different variants are used: either procuring entities pay a fee when call-offs are made or the fees are paid by suppliers when they invoice through the framework agreements. Generally, service charges have been criticised on several accounts. First, critics argue that this arrangement enables CPBs to make profits, which is not their objective. A second line of criticism is that user charges provide CPBs with weak incentives to reduce costs; if costs increase they can just raise the fees. Third, another potential weakness from the point of view of procuring entities is having the central purchasing body's income dependent on turnover, which might not be an incentive for price optimisation. However, interestingly, funding by service charges remains the dominant financing method. Fourth, it is argued that if user charges are to be used, the procuring entities should pay the charges, not the suppliers. This point of criticism is sometimes emphasised by suppliers. Finally, as the system is practised in several countries (Sweden, Finland and Denmark), with suppliers reporting their invoiced sales under the framework agreements, there is a risk of under-reporting of the actual sales volume.

Proponents of user charges argue that CPBs usually do not make large profits. They argue that user charges are set with the aim of breaking even, i.e. fees should be set so that revenues cover costs, including necessary investments. Furthermore, they argue that it is a well-functioning model that has existed and has been proven to work over a long time. Finally, and most importantly, it is argued that user charges provide CPBs with incentives to establish attractive framework agreements that are actually used. If the procuring entities did not use framework agreements to buy the goods and services they needed, the CPBs would not receive any revenues.

Regarding the issue of whether user fees should be paid by procuring entities or by suppliers, it is important to understand that, from a basic economic perspective, it does not matter. The "statutory incidence" of a fee indicates who is legally responsible for paying the fee. Where the user charge is paid by the procuring entities, the statutory incidence is on those entities, and vice versa when the fee is paid by the suppliers. It is well known from microeconomic theory that the statutory incidence generally indicates very little about who really bears the economic burden of a fee. The economic burden is instead determined by how market prices are affected by the introduction of the fee. This is in turn affected by factors of demand and supply in the market, factors that generally differ between markets. In other words, from an economic point of view, whether the fee is paid by procuring entities or suppliers does not matter. This does not mean, however, that the issue might not be important from other aspects, such as whether the procuring entity will actually need to pay service charges that may be debited from its account. There is also another important aspect to be considered, namely, whether the service charge is seen by the procuring entity as being fair or not. Such a fee has the objective of covering the costs of the CPB for awarding and managing framework agreements, which could be seen as a reasonable argument in favour of its fairness. However, if the procuring entity needs to carry out a complicated mini-tender procedure, which is not uncommon, it could argue that it should also receive a part of the service fee charged.

An alternative funding model is when CPBs are financed directly from government funds. Proponents of this model argue that it eliminates the profit risk and provides better incentives for cost-efficiency. Those who do not like this model argue that it removes the incentive to find the most attractive product areas and framework agreements. Moreover, it runs the risk of under-investment in new technology due to a lack of funds.

In summary, several financing models are practised, each with pros and cons, and they all seem to work. 


\subsection{What is the Importance of Good Customer and Supplier Relationships?}

All CPBs have established organisations that closely reflect their main functions and services. The main objective, i.e. to provide in all aspects attractive framework agreements, implies a strong involvement of the customers in the whole procurement process: determining the appropriateness of a specific product or service area; design of technical specifications, tender selection and evaluation criteria; choice of the type of framework agreement and call-off system; and award of the framework agreement.

The inclusion of the customers, especially large purchasers, early on in the procurement process is a key to the success of a framework agreement. This is of particular importance to CPBs operating in a voluntary environment, but also of great importance to CPBs acting in a compulsory context. Even if no firm commitments can be made by the customers (in a voluntary environment) to use the framework agreement, the likelihood of success increases significantly with their strong involvement. This is equally true for CPBs operating in compulsory contexts. The benefits of a CPB's services in terms of providing certainty and simplicity to the procuring entities are highly dependent on the way in which the framework agreement system has been designed and "pre-agreed" with the customers.

The effective execution of the main functions of the CPB is based on its capacity and ability to "understand and manage" the supply market efficiently, in terms of knowing who are the main suppliers of a specific product or service segment of the market, as well as their size and market presence. Preinformation and dialogue with the suppliers at an early stage of the procurement process, as long as this is carried out transparently and in accordance with applicable procurement rules, are valuable in order to determine the various options for the best design of contracting and procurement strategies for the framework agreements and attached call-off systems. It appears clearly that all CPBs studied pay the necessary attention to supplier markets in order to optimise the possible responsiveness to the invitation to tender for framework agreements as well as for the call-off system in place for the duration of the framework agreement.

\subsection{What Types of Framework Agreements Should be Used?}

A striking observation in this study is the considerable variation that exists with regard to how framework agreements are used. The EC Directive allows CPBs considerable freedom regarding the type of agreement and procedures to use. CPBs take advantage of this freedom, and as a result both singlesupplier and multiple-supplier framework agreements are used, as well as various call-off procedures. This mix of practices is interesting and is an indication that there is no single best practice to follow. Still, it is of interest to identify principles that may guide CPBs in making these choices.

Single-supplier framework agreements have the advantage that the award of such a contract is likely to be very valuable for the supplier chosen. This has to do with "the winner takes all" characteristics of these contracts. A supplier receiving such a framework agreement can with certainty count on selling a considerable volume during the lifespan of the contract, thereby producing a stable turnover. The competition among potential suppliers for this winning position will most likely be fierce and force prices down to very competitive levels. This is of course valuable for both the CPB and its customers.

The experience of Consip (Italy), which practices a single-supplier approach to centralised purchasing and argues that its prices and other terms in general are very competitive, is in line with this reasoning. On the other hand, a potential drawback of this approach is that it may hinder SMEs from participating because they lack sufficient production capacity. This may be true even if the agreement is divided into several regional lots. The fact that Consip has few SMEs as suppliers under its framework agreements is consistent with this theory. Moreover, it is a strategy that may create problems in the long run if it leads to concentration in the supplier markets and hence to less competition. This may happen if suppliers that 
do not receive contracts have problems surviving in the market until the next time a framework agreement is up for tender. Finally, it may be a risky strategy if the winning supplier for some reason finds itself having delivery problems and is unable to fulfil its obligations.

Framework agreements with multiple suppliers have the advantage of providing a more reliable sourcing than single-supplier agreements. If one supplier has delivery problems, there are others to turn to. It also provides a greater product variety due to the fact that the suppliers' products are not completely homogeneous - this is a value-enhancing factor, given the fact that procuring entities may have diversified preferences. Another advantage is that the risk of a successive market concentration is smaller. Several CPBs also argue that for certain products, such as some ICT products, it is not viable to use only one supplier, as no single firm will have sufficient production and distribution capacity to serve the whole public sector or even parts of it. A potential disadvantage of a multiple-supplier arrangement is that, in most national laws, suppliers have no guarantees of selling anything under their framework agreements. This is especially so if the CPB has many framework suppliers within the same product area under a specific framework agreement. The reason for this is the uncertainty regarding the value of receiving a framework agreement, which is not present in the case of a single-supplier agreement. This may have the effect of making the bidding competition less fierce.

There are also pros and cons concerning the two options for call-offs that exist with multiple-supplier framework agreements. The option whereby procuring entities make call-offs through a mini-tender has the advantage of introducing a kind of ongoing competition between the suppliers during the lifespan of the framework agreement. In other words, it has the feature of being both a competition for the market receiving a framework agreement - and a competition in the market - actually selling to procuring entities under the agreement. This feature is likely to be pro-competitive. On the other hand, the minitender option may involve substantial transaction costs. Several CPBs are worried that the mini-tender process might become too formalised, so that it would resemble a new procurement procedure in its own right, which would make this form of centralised procurement less attractive.

The other call-off option, known as the ranking method, applying the terms laid down in the framework agreement without reopening, also has its pros and cons. As pointed out in section 7.5, several CPBs apply a ranking procedure, whereby suppliers are first ranked in the evaluation of tenders - from the best to the worst - and this ranking must then be strictly followed by the procuring entities when making calloffs.

This procedure has the same characteristic as the single-supplier framework agreements - the winner takes all - making it very valuable to win the tender, which may have a pro-competitive effect. It is not as strong as in the single-supplier case, however, because one supplier is not likely to have the capacity to supply to all procuring entities (if such a capacity were to be at hand, there would be less advantage in having several suppliers in the first place). Another advantage is that the procedure assumes that the supplier considered to be the best in the evaluation is also the one that will actually deliver the goods or services. In other words, it pays off to deliver the best offer.

The procedure also has potential drawbacks. First, it is more static that the mini-tender approach. Terms are determined at the time of the tender competition and are not allowed to be fine-tuned or complemented during the lifespan of the contract. Second, a potential disadvantage with the ranking procedure is that the interest in participating in the tender competition may be weaker than with minitenders, due to the fact that firms that are not ranked as the best may not sell anything and that the minitender offers many more chances to actually sell under a framework agreement. Third, there is a risk of co-operative behaviour among the suppliers. For instance, the first few tenderers (in terms of ranking) may collude so that a more expensive deal may be concluded, with the least-cost supplier then 
nevertheless producing the goods (at least if these goods are of standard issue) and the price difference being shared among the suppliers involved.

\subsection{What Can be Done to Promote Competition and Facilitate the Participation of SMEs?}

Competition authorities are sometimes sceptical towards attempts to centralise public procurement because of a fear that competition in the marketplace may be weakened, especially in the long run. The argument is that centralised procurement runs the risk of creating situations where the government will be in the hands of a few very large suppliers, which will be in a position to dictate prices and other terms. It is implicit in this criticism that centralised framework agreement procurement creates a risk of generating an entirely different supplier market structure than the highly decentralised model in which authorities procure for their own use.

Simplifying slightly, one can say that with the centralised procurement model, the result is assumed to be supplier markets comprising a small number of large firms and few, if any, SMEs, while the decentralised model creates supplier markets with firms of all sizes. This is a risk with centralised purchasing that it is important to be aware of and to actively work to reduce.

The CPBs participating in this study are clearly aware of this risk. In general, they express satisfaction with the competitive situation in their respective supplier markets. They also work actively to facilitate the participation of SMEs, for instance by dividing contracts into smaller lots. The empirical data in section 7.7 indicates that these efforts by SMEs are quite successful: SMEs are fairly well represented among the suppliers of the CPBs studied.

At the same time, it is important to remember that it is not always efficient to have too many small suppliers. Procuring entities generally appreciate smooth and efficient buying procedures, which means that they often like to have suppliers that can deliver large packages of goods and services within a specific product area. Small firms may have difficulties in meeting such a requirement. In addition, it is a fact that economies of scale exist in many activities (production, distribution, etc.), which means that large firms that can exploit these conditions will, by definition, be more cost-efficient than smaller ones.

In summary, it is a difficult but highly important balancing act for a CPB to manage these competing demands in a competent way.

\subsection{How Should the Performance of CPBs be Measured?}

Several CPBs report that they generate large savings for their owners, savings that have been calculated in more or less elaborate ways. Some argue that these calculations cannot be trusted because the methods used are usually not reliable. For instance, they point to the fact that list prices and standard conditions are not a relevant basis for comparing prices and other terms obtained under centralised purchasing.

Generally speaking, it is important to understand that it is difficult to estimate the savings that are generated through centralised procurement. The fundamental reason for this is that it is not possible to observe the counterfactual outcome of centralised procurement of goods or services and the different prices and other terms generated by an alternative procurement method. This means that an alternative outcome needs in some way to be constructed.

Several difficulties are involved in constructing an alternative outcome. First, it is not obvious what the alternative method should be. Second, data concerning outcomes generated by the chosen alternative must be available, which is usually not the case. Third, other variables, such as quality and service conditions must be held constant so that it is not apples and pears that are being compared. Because of 
these difficulties, it is important to understand that any savings reported can, at best, only be an indication of a true gain.

The fact that it is difficult to evaluate the performance of CPBs in terms of outcomes (prices, process savings, etc.) should of course not be taken as an excuse for not trying to measure performance. In cooperation with universities, several CPBs have developed methods that are used to measure performance. These evaluations provide valuable information regarding performance, especially if they are conducted on a regular basis so that trends and patterns that develop over time may be observed. Also, these evaluations have the important function of putting a certain pressure on CPBs, which are aware that their performance is under review.

Another type of information that might be useful in evaluating the performance of a CPB is how actual sales develop. For CPBs with services that are voluntary for procuring entities, the development of sales is perhaps the best indication of how attractive a CPB's services are. It is a form of market test. If procuring entities that are free to buy from whatever source they find to be the most suitable increasingly choose to source from a CPB, this indicates that the services offered by the CPB are considered to be more competitive. Customer satisfaction surveys are another method used for determining the performance of CPBs.

\section{Important Risk and Success Factors - Lessons Learned}

To successfully set up and implement a modern and value-creating centralised purchasing system, several challenges need to be taken up. This study points to the following lessons learned and challenges for Sigma's partner countries:

\section{Main Lessons:}

\section{$>$ Centralised purchasing systems can be organised and managed in several different ways - there} is no single best model.

One of the main conclusions of this study is that centralised purchasing is carried out in many different ways in the EU Member States studied. Differences exist with respect to:

- the legal status of the central purchasing bodies (CPBs) and the sectors/levels of the public administration that they cover;

- $\quad$ the way in which the mandates of the CPBs have been given by the owner(s);

- $\quad$ the types of framework agreements and call-off systems used; and

- the organisation and financing of the CPBs.

These various choices usually have both advantages and disadvantages in terms of the key factors affecting the attractiveness of a centralised purchasing system - CPS (see the Attractiveness Model). For this reason, it is not possible to single out one model as the best one for organising and managing centralised purchasing.

\section{$>\quad$ The areas most suitable for centralised purchasing are goods and services of common interest to} the majority of public sector entities.

Despite the considerable differences that exist between CPBs, their centralised purchasing focuses on goods and services of common interest, such as office and furniture supplies, ICT products, and travel and transport services. The study did not find any CPB that awarded framework agreements for works 
contracts. For the products mentioned above, centralised purchasing is obviously seen as a good way of reducing government spending and increasing cost-efficiency. In other words, there is a core of goods and services that is suited to centralised purchasing, most often those that are not of strategic importance to the procuring entities. However, there is a growing trend to alo include products and systems of strategic importance to the owners, such as complex IT and administrative systems that need to be implemented throughout the public administration.

\section{$>\quad$ It is most likely that the CPBs studied create savings for their governments, but solid proof is difficult to provide.}

The main rationale for centralised purchasing is to satisfy the public sector's need for certain goods and services in the most cost-efficient way. There are both theoretical arguments and empirical evidence indicating that the CPBs studied produce savings for their governments. Comparisons of terms obtained under centralised purchasing and decentralised purchasing, conducted by the CPBs themselves or by external evaluators, indicate that considerable savings are made by the CPBs. The savings consist of both lower prices and reduced transaction costs. It is important to realise, however, that the savings reported only constitute indications of the real savings, which may be lower or higher than the estimated savings. To obtain objective and reliable measures of savings is generally very difficult.

\section{Success Factors for Centralised Purchasing}

This study has identified a number of factors that are likely to determine whether a centralised purchasing attempt will be successful or not. Some of the most important factors are:

\section{- Sensitivity to the needs of the key stakeholders}

The success of a CPB is likely to depend on the extent to which trust and confidence can be strengthened and maintained in its relations with major stakeholders - owners, procuring entities and suppliers. Owners must trust the CPB to develop and offer attractive framework agreements and call-off systems that generate substantial savings for the public sector in the procurement of goods and services in compliance with legal requirements, while fulfilling important environmental and social policy goals. Procuring entities must trust the CPB to be competent and capable of providing high-quality services at competitive prices while offering certainty and simplicity in the use of framework agreements. Suppliers must first of all consider that the framework agreements offer the business opportunities expected, at profitable price and cost levels and with fair treatment. Further, it is of vital importance that the government provide the CPB with a clear objective and mandate to operate. In addition, it is equally important that the various procuring entities in the government are provided with incentives to purchase goods and services needed for their operation in a cost-efficient way. Such incentives require the support of the top management in the procuring entities. The support of the procuring entities may vary depending on whether the use of the CPB's services is compulsory or voluntary. It is really a challenge for a CPB to meet all of these high expectations.

\section{- "Competitive" framework agreements with user-friendly and low-risk call-off systems}

The success of a CPB is, of course, highly dependent on its ability to offer technically and commercially attractive framework agreements to a large proportion of the potential "customers" in the public sector served by the CPB. This ability is decisive for a CPB in a voluntary environment but is almost equally important for a CPB operating in a compulsory situation. A key success factor for meeting such a goal is to get the incentives right for the major stakeholders. The CPB should have incentives to provide centralised purchasing services in product areas where the greatest value and savings can be achieved. Procuring entities should have incentives to purchase goods and services from the source that provides the best 
value-for-money. Suppliers should have incentives to participate in the CPB`s various tenders and incentives to deliver products in demand on competitive terms. In other words, the centralised purchasing system should be designed in such a way that it provides these various stakeholders with the correct incentives. The study has tried to identify these incentives and to examine the factors making the centralised purchasing system attractive from the perspectives of the key stakeholders.

\section{- Appropriate identification of contract scope and value}

All of the CPBs studied have put in place mechanisms for the identification not only of the products to be purchased through centralised procurement but also of the value of those contracts, usually based on an in-depth supply and demand analysis or on feasibility studies. Indeed, as indicated in section 7.4, SKI (Denmark) will only enter new agreements where there is an expected turnover of at least 10 million EUR. This is important for a number of reasons. Identifying the scope and value of the contracts to be awarded under a framework agreement provides potential tenderers with the information they need to decide whether or not to participate. The promise of valuable contracts will make participation attractive, but the chance of obtaining fewer or smaller orders will lead to greater concentration on the level of the transaction costs involved. Similarly, the type of framework agreement (single-supplier or multiplesupplier) will alter, from the tenderers' perspective, the potential success rate of participation and, in effect, alter the scope and value of the agreement. The choice of call-off mechanisms is thus a factor to be taken into account in terms of the attractiveness of the framework agreement. In mandatory systems covering the whole public sector, the task of identifying the value of the contracts may be relatively straightforward, but in voluntary systems covering potentially smaller segments of the public sector, maintaining the attractiveness of the scheme may be more challenging. It should be recalled, as mentioned in section 2.5 , that framework agreements may be used only by those participants that were party to the original agreement. This means that the identity of the ultimate purchasers and, by implication, the scope and potential value of the contracts to be awarded will be finite (even if the contracting entities are defined broadly). It is thus important to identify correctly the scope and value of the contract at the outset, with a view to maximising the attractiveness of the framework agreement to potential tenderers and, clearly, its utility to users of the agreement.

\section{- An efficient organisation with competent staff}

The design of the CPB's organisation is vital to its success and should reflect the specific characteristics according to which it works, but its main functions are usually centred around market and customer relations, product management, procurement, and contract management, together with key support functions, such as IT, legal services and administration, including accounting. Another crucial factor is the availability of competent staff. In general, efficient public procurement operations require a broad variety of competences covering the procurement process from its start to its completion. These competences, which may involve procedural, technical, contractual and financial skills, are of course also important and necessary in a centralised public procurement context, but they are not sufficient for a CPB. A successful centralised purchasing operation also requires strong competence in marketing and IT and, not the least, skilled and experienced management, together with a thorough understanding of commercial realities.

\section{- Good overall conditions}

Apart from support from key stakeholders and competent staff, it is important that the overall conditions for the CPBs are good. These conditions include sufficient financial resources to perform all of the various activities required for efficient centralised purchasing, including resources to make the necessary investments in physical and human capital. The fact that all CPBs are non-profit organisations should not 
limit their possibilities to generate revenues large enough to ensure their development and growth ("it is not- for-profit and it is not-for-loss").

\section{Main Risks of Centralised Purchasing}

Among the risks of centralised purchasing, the failure to satisfy the above requirements for success should be mentioned first of all. If any of these requirements is not fulfilled, the result is likely to be negative. In addition, two other very significant risks may be added, namely:

\section{- $\quad$ Failure to effectively manage the legal risk}

Several CPBs have witnessed an increase in the number of complaints concerning not only the tenders for the award of framework agreements but also - which further complicates the position of the CPBs - the proceedings during the call-off stage. The increasing number of complaints under multi-supplier agreements implies a transfer of risk from the CPB to the procuring entities, which creates a situation of legal uncertainty to which the parties involved need to find a solution. Otherwise, there is an obvious risk that procuring entities may choose to award the framework agreements themselves, which thus constitutes a significant strategic risk for the CPB (and a loss of the efficiency brought about by centralised purchasing). Strengthening the legal expertise of CPBs is probably necessary, but it would be very unfortunate if the mitigation of risk led to a situation where CPBs would have to "compromise" their main objective of offering highly attractive and "value-for-money" framework agreements.

\section{- $\quad$ Lack of focus}

Another risk is that the CPB will start to lose focus and try to expand the boundaries of its operations into areas where it either lacks a competitive advantage or is not able to respond correctly to the needs of the procuring entities, thereby offering services or framework agreements that are potentially unattractive to the procuring entities. The provision of individual consultancy services to procuring entities may be one such area where the CPB does not necessarily have a competitive advantage and also faces competition from the consulting industry. However, if these consultancy services are a natural part of or a close complement to the award and management of framework agreements, they may not only be advisable but even required to ensure the competiveness of the CPB. At the same time, the CPB must constantly develop its operations and service concepts in order to meet the requirements and expectations of the owners and the customers (procuring entities). This should be done in close partnership with the main stakeholders.

\section{Key Future Development Issues}

The Sigma study examines how purchasing systems are set up and operated by the CPBs. There are similarities between these systems but also significant differences, which may affect the kinds of problems and challenges that the CPBs will need to resolve and adjust to in the future. Based on the findings of the study, Sigma has concluded that the main objectives of CPBs for the future would be to:

Establish and manage efficient and attractive framework agreements and call-off systems for customers and suppliers

Mitigate risks for customers

Offer high competence, professionalism and a strong service concept - market, product and procurement

Ensure growth and development of the CPB 
All CPBs studied find in general that they have experienced very positive development in recent years, and they are overall optimistic about the future prospects of their operations. However, at the same time, they all admit that they experience problems and feel uncertainty about the future strategic direction of the CPB, for example in terms of the need to change the business model and service concept, to reconsider the type of framework agreements and call-off systems used, to find new and more appropriate financing models, and to develop the future IT infrastructure.

As a conclusion of the analysis of the country reports and the meetings held with the CPBs studied, Sigma considers that the main challenges for the CPBs in the future will be to:

\section{- $\quad$ Control the flow of business transactions at the call-off level}

Only KSzF (Hungary) has a business model with full control of the business (call-off) transactions that are made under the framework agreements. The main reason is that all of its framework contracts have either a fixed deadline for making call-offs or ceilings for quantities or value, which in practice requires that all transactions are conducted with the use of the IT platform. Such control of transaction flows is likely to generate strong benefits for all CPBs, including for reasons other than those put forward in the case of KSzF. It should be in the interest of CPBs to have a clear picture of the final outcome of their framework agreements through procuring entities' call-offs, rather than simply through the feedback from suppliers. Good standards for management monitoring and internal control require CPBs to be able to evaluate their own performance on the basis of the turnover generated under the framework agreements, which has also been expressed by the CPBs themselves (see Annex). With better business control, the CPB would have a better chance of designing the financing mechanism, charging the right fees, if applicable, communicating with customers and suppliers, adding new services, and improving the reporting and statistics systems. Moreover, improvement in this area is in the interests of the procuring entities as customers and all the more so as shareholders.

\section{- $\quad$ Build the business IT infrastructure and the e-procurement platform}

All CPBs intend to develop their IT systems and electronic platforms for tendering and call-off actions. The availability of modern, advanced Internet-based systems for all tendering and business transactions will constitute a strong, strategically important competitive factor for CPBs in the future and a basis for controlling the flow of call-off transactions under framework agreements (as indicated above). It will also serve to develop electronic procurement in general and to expand the service package on offer by the $\mathrm{CPB}$.

- $\quad$ Develop the financing model of the CPB in order to both produce the right incentives and reflect a fair distribution of risks and costs

As the study reveals, the majority of CPBs have a financing model that is based on transaction fees, which in most cases are paid by the suppliers and in one case by the procuring entities. These service fees aim to compensate the CPB for the costs of awarding and managing the framework agreements. The financing model may need to be developed in the future to reflect new service areas and to achieve a fairer distribution of risks and costs incurred in the system. This is especially the case of the arrangement of mini-tenders under multi-supplier agreements, where the procuring entity needs to assume a much greater involvement than under single-supplier agreements.

\section{- $\quad$ Manage legal risks that occur under multi-supplier agreements}

Legal risks have become one of the most challenging issues for CPBs awarding multi-supplier agreements, under which suppliers have the right to file complaints not only in the course of the award of the 
framework agreement but also in the call-off stage, whether the call-off is carried out by means of ranking or a mini-tender. The CPB takes the full risk for the conclusion of a single-supplier framework agreement, but the risk is shared between the CPB and the procuring entity for the final conclusion of a multi-supplier agreement with the use of a mini-tender. This shared risk is a dilemma for the CPB, since it may negatively affect its competitive situation or attractiveness as a partner whenever it cannot offer the necessary degree of certainty to customers.

Another aspect is that if the conditions under which complaints were made during the call-off process do not refer mainly to the way in which the procuring entity has acted but instead to the design of the original framework agreement, then there is a risk that the framework agreement itself could be endangered. It is important both to clarify the appropriate distribution of responsibilities and risks between the CPB and its customers and to agree on how the CPB should best act in order to support the procuring entity during the call-off process so as to minimise the risks. Of course, the consideration of legal risks will also affect the choice of the framework agreement and the call-off system, with a view to removing as much as possible any undesirable risks from the procurement process.

\section{- Design appropriate call-off systems under framework agreements}

The design of call-off systems under framework agreements will be decisive for the success of the centralised purchasing system, not only with respect to legal risks but also, and more importantly, to the efficiency and overall attractiveness of the CPB's services, which should be based on simplicity, usability and certainty, both technically and contractually.

The award of a multi-supplier agreement through the use of a fixed-ranking methodology seems to be more complicated and its advantages even questionable compared with the award of a single-supplier agreement with all terms fixed. A fixed ranking call-off procedure, where the first-ranked supplier has the right to refuse a call-off from a procuring entity, seems to give rise to uncertainty among procuring entities and suppliers as to how to correctly arrange the call-off so as to satisfy both legal and commercial requirements; it may even offer an opportunity for collusive practices. A fixed-ranking system may also have a negative impact on prices, since all tenderers may wish to calculate the risk of being ranked lower than number one, which in turn may lead to the submission of a tender under the main framework agreement that needs to include conditions on the pricing and the application of volume discounts since prices tendered are normally based on certain delivery volumes. The attractiveness of such a system is thereby lost. A single-supplier agreement, where firm contractual obligations to accept and deliver under a call-off are made, should reduce uncertainty. In the case of a multi-supplier agreement, the alternative would be to use dynamic ranking or indicative ranking (see above) and to let the procuring entity determine the final ranking based on its specific requirements, as long as they are in accordance with the conditions for the award of the framework agreement. The mini-tender provides the highest degree of adaptability and the most numerous commercial advantages, but at the same time it exposes the procuring entity to the highest risks and costs. It is crucial for the CPB, in close co-operation with the main stakeholders, to determine how best to arrange the call-off system in the future so as to offer an optimum level of simplicity and certainty as well as to ensure a fair distribution of risks and costs between the parties. It should of course also include the use of e-auctions and dynamic purchasing systems.

\section{- $\quad$ Create and develop the future business concept of the $C P B$}

There are discussions on how to possibly expand the operations of the CPBs beyond the traditional areas of goods and services managed by the CPBs. A CPB is not only a provider of framework agreements but, with its extensive experience and knowledge of public procurement, constitutes a knowledge centre of expertise within the government administration on framework agreements and e-procurement, and this 
expertise of course could and should be exploited. The owners of the CPB may use it as a tool for the modernisation of the public administration and the implementation of important policy goals.

Sigma has found that the main attention of the CPBs themselves is placed on the possible development of their advisory functions, as long as this activity does not negatively affect the private consultancy industry. Another conclusion of the study is that complex products, systems and contracts requiring highly specialised staff also constitute an important and suitable area to be developed, provided that it is of common interest to the public administration. Further expansion would probably emerge as a result of the development and establishment of IT systems and electronic platforms, which may offer opportunities to organise e-auctions and to "host" framework agreements and call-off systems on behalf of individual procuring entities in return for a service fee. Another potential service area could be the provision of contract management services through a common e-procurement platform covering ordering, deliveries and payments.

\section{- $\quad$ Build strong and lasting partnerships with procuring entities}

A CPB will likely need to more closely involve its customers in its operations in the future, since investments and operations will become more costly and risky. This will become a clear problem for all $\mathrm{CPBs}$, in particular for those operating in a voluntary context. There must be pre-commitments from the customers to use the services developed as well as a willingness to pay for those services, to the extent that these costs cannot be borne by the suppliers through transaction fees. The large procuring entities are of particular importance for the CPBs.

\section{- $\quad$ Develop the competence and capacity of the CPB organisation}

Finally, the design of the future organisation of the CPBs will constitute a real challenge, which will require the support of the owners. It must also be well anchored among the customers and suppliers. CPBs will need to strengthen their organisation in terms of technical, legal and IT capacities and to ensure the sufficient adaptation to the changing needs of the customers and to the supplier markets.

\section{The Way Forward}

In conclusion of this study, Sigma would like to elaborate briefly on how a centralised purchasing system (CPS) could be introduced in each of its partner countries that have no or very limited experience of central purchasing bodies (CPBs) for the award and management of framework agreements. However, Sigma realises that conditions vary extensively between these countries and that the concept of a CPS might not fit some countries at all or would need, at the least, to be extensively adapted to the national context. Under EU law, there is no legal obligation for Member States to introduce CPBs; decisions on the matter are left entirely to the governments. A public procurement system can always exist without centralised purchasing arrangements, instead relying on fully decentralised procurement through which individual procuring entities award contracts for goods, services and works. All kind of centralised and decentralised structures may also exist in parallel. Moreover, this study discusses mainly CPBs that serve, first of all, the state administration at all levels (central, regional and local) and where other sectors (e.g. municipalities and regional authorities) may participate if they so decide. As mentioned in the introduction of the study, in many countries there are other centralised purchasing arrangements in place, such as sector-based CPBs (e.g. health and education) or collaborative or co-ordinated framework agreements, with their specific advantages and disadvantages.

As this study shows, the proportion of the purchasing volumes of CPBs is fairly small compared to the total national procurement volume, but they nevertheless belong to the category of main purchasers in all countries studied. Therefore, the fundamental question concerns the extent to which a CPB can 
generate an "added-value" to the public procurement system in terms of savings, rationalisation, modernisation and other important values. The study clearly indicates that CPBs, under the right conditions, generate such added-value.

\section{Recommended Steps and Considerations}

1. Elaborate a strategy and an action plan for the establishment of a central purchasing body (CPB), if considered appropriate

Many countries are already in the process of elaborating national strategies and action plans for the overall reform and modernisation of their national public procurement systems. Sigma proposes to include in this planning the possibility of introducing CPBs. Countries need to carefully analyse the preconditions for the creation of centralised purchasing arrangements before going ahead with such an important decision.

\section{Take a step-by-step approach}

If the decision to establish a CPB is taken by the government, Sigma would recommend a step-by-step approach in terms of goods and services to be covered at the start-up, organisation and staffing, etc. so as to provide the CPB management with realistic possibilities for successfully building the organisation's capacity, infrastructure and performance without risking its credibility. The most sensitive stage of a CPB's operations is the start-up phase, since procuring entities may regard the CPB only as a "competitor" and not as a partner. Building confidence, which is essential for the success of a CPB, takes time, but the initial period is often decisive in ensuring a good outcome. It is important to agree not only on the right steps but also on the right order of these steps. The main risks are:

- Over-ambitious or even unrealistic goals set by the owners, which will jeopardise the chances for the successful introduction of the new CPB;

- Insufficient time, discretion and financial means for the management to build the organisation, the infrastructure, the operational models, the system for framework agreements and, not least, the partnerships with the customers.

\section{Take an integrated approach}

Within the strategy and action plan for a new CPB it is important not only to address the establishment of the CPB but also to integrate the development of e-procurement, including dynamic purchasing systems if they are implemented in national legislation, and the use of framework agreements in general. The operations of the future CPB will be firmly based on such instruments.

\section{Build centralisation on the principles of a decentralised public procurement system}

Public procurement legislation is built on the idea of decentralisation, where procuring entities are responsible for all steps in the procurement process, including the award decision and the signing of contracts, for which they are held accountable. A CPB is also a contracting authority with the same responsibilities, but at the same time it might be able to make decisions that other procuring entities may be obliged to accept in the event that they need to acquire a product or service covered by a framework agreement. In a fully voluntary system this is not a major issue, since a procuring entity may always refrain from using the framework agreement and instead make its own purchases. In a fully compulsory system this set-up becomes a real issue, since the procuring entity has no choice other than to use the framework agreement. Sigma recommends that countries apply instead a differentiated approach, which means that goods and services to be centrally purchased would be carefully reviewed from the point of 
view of the procuring entity's interests (the client's perspective) in order to determine whether the use of a framework agreement should be compulsory or voluntary. Some products may be well suited to compulsory use while others would be much better suited to voluntary use. As an example, compulsory conditions might be fully acceptable to procuring entities for the award of a framework agreement on fuel, which normally is a non-strategic commodity for which aggregation gains on prices and discount structures are probably important, whereas any intention to establish a compulsory framework agreement on office furniture would run the risk of being received very negatively, since procuring entities are likely to have different preferences. A compulsory application in the latter case could lead to dissatisfaction, maverick behaviour and low commitment on the part of the procuring entities.

\section{Closely involve key stakeholders}

A CPB cannot exist without strong support from its key stakeholders, that is, the owners, the procuring entities and the private sector, but there are also other stakeholders of importance. The study has emphasised the importance of involving the stakeholders in the CPB's operations in order to obtain their support and commitment. This is particularly important for newly started CPBs. The CPBs should elaborate a communication strategy. The CPB should give its attention to the media and civil society at large, in addition to the core stakeholders.

\section{Take strategic operational decisions}

As demonstrated by the study, there are a number of crucial decisions to be taken by governments as part of the process of establishing a CPB. The most important decisions concern the following issues:

- Legal status of the CPB - limited company or public agency?

- Which goods and services should be covered, initially and in the medium term?

- A voluntary or compulsory system, or a mixed solution?

- Types of framework agreements and call-off systems to be used

- What kind of electronic platform should be developed?

- How are the CPB's operations to be financed?

- Organisation and staffing

- $\quad$ Capacity-building of staff and also of customers and suppliers

The study has examined these issues in some detail and hopefully has provided guidance concerning possible solutions.

The Annex provides the country descriptions, which were prepared and approved by the CPBs included in this study and subsequently edited by Sigma for the purposes of ensuring a consistent structure and language. 


\section{ANNEX 1. DENMARK, SKI A/S (STATENS OG KOMMUNERNES INDKØBS SERVICE A/S)}

\section{The Establishment of CPS - History and Rationale}

Statens og Kommunernes Indkøbs Service A/S (SKI) was established in 1994 as a 100\% publicly-owned company falling under private law. Before SKI was established, the central government had Statens Indkøb (central government procurement), and the Danish municipalities had Kommunernes Vareformidling (municipalities' supplies). The plan was that SKI would be a central procurement body that would benefit all parts - whether central, regional or local - of the Danish public sector. SKI would therefore be able to pool the procurement volumes across all public sectors and thereby secure lower prices for the public sectors' total procurement volume.

The regulatory instrument governing the operations of SKI is the shareholder's agreement between the state and the association of local authorities for the establishment of SKI, which also falls under the definition of a centralised purchasing body in accordance with the relevant EU directive. There is no separate government regulation or inclusion of SKI in the procurement legal acts.

In general the public procurement area in Denmark is regulated by the national competition authority (Konkurrencestyrelsen), which is responsible for implementing the EU directives in national legislation. Denmark also has a review body to which a dissatisfied party in a tender process can submit a complaint (Klagenævnet for Udbud).

In a broader context Denmark has a national law that makes it compulsory for public organisations with procurement volumes above 500,000 DKK (approximately 66,000 EUR) and up to the EU threshold values to publish their needs nationally. It is sufficient, for example, to publish such needs on the organisation's website.

SKI is a $\mathbf{1 0 0 \%}$ publicly-owned company falling under private law. The Danish Ministry of Finance owns $55 \%$ of the shares in SKI, while the remaining $45 \%$ are owned by the Association for Local Authorities of Denmark (Kommunernes Landsforening), which is the interest group and member authority of Danish municipalities.

\section{Operational Strategy and Objectives}

The strategy and objectives for the operations of SKI were latest reviewed and adjusted at the end of 2007, when SKI's Board of Directors approved a new strategy for SKI for the next five-year period, 20082012.

\section{SKI's mission statement:}

- SKI creates documented, increased returns of scale in public procurement by pooling volume, qualifications and system development for the benefit of SKI's customers.

- $\quad$ Through close co-operation with customers and suppliers, SKI secures attractive framework agreements.

- $\quad$ SKI's framework agreements facilitate the public sector purchase of needed solutions, products and services at the lowest possible price, while demonstrating environmental, energy-related and social responsibility. 
- $\quad$ SKI's earnings enable investment in new procurement initiatives that are prioritised in a commercial way.

\section{SKI's vision statement:}

- $\quad$ SKI strives to be a central player that develops public procurement and makes it more effective.

- $\quad$ SKI strives to inspire and support public organisations and their purchasing agents in achieving gains through efficient procurement and to help promote an effective public administration.

- $\quad$ Based on openness, equality and qualifications, SKI strives to be the natural and inspiring focus point for all players involved in public procurement.

- $\quad$ SKI must therefore be an innovative, effective and challenging workplace, which is able to attract and develop the best employees.

Based on the above mission and vision statements, SKI formulated the following list of long-term goals:

1) Growth

- $\quad$ SKI's framework agreement turnover must increase to 13 billion DKK by 2012.

- $\quad$ The turnover in municipalities must increase to $50 \%$ by 2012 .

- $\quad$ Growth and new initiatives must be self-financed. The average return before tax in the years 2008 to 2012 must be 1 million DKK per year.

2) Trust

- $\quad$ For each tender the co-ordinated turnover must be at least $25 \%$.

- $\quad$ For each tender a documentation of savings to be made must be accepted by customers.

- During 2008 a minimum of five partnerships between customers and SKI must be established, and this number must increase by two for each of the following years.

3) Qualifications

- A plan for the development of competencies must be established for each SKI employee.

- $\quad$ The change of staff (employees appointed) must not exceed $10 \%$ per year.

\section{Organisation and Finances}

The organisation, management structure and reporting lines of SKI (organisational chart attached) provide the following features:

SKI is roughly divided into four sections: Management and Staff, Procurement and Operations, Sales and Marketing, and Information Technology and Service, where:

a) Management and Staff comprises human relations, finance and legal sections.

b) Procurement and Operations is divided into an IT and telecommunications contract section, a goods and services contract section, and a contract management section.

c) Sales and Marketing is divided into a sales section and a marketing section.

d) Information Technology and Service is divided into an IT section and a services function. 
The top management consists of SKI'S CEO and a director, while there is an executive management level with another three managers. The middle-management level of SKI consists of an additional eight persons.

Currently the number of SKI staff exceeds $\mathbf{8 5}$ persons. Around $60 \%$ of the staff have formal education at a masters degree level, while most of the remaining staff have formal education corresponding to grammar-school level, which is often supplemented by a couple of years of further education.

SKI has established a formal working method called the "SKI process", which governs the day-to-day operations regarding tenders. The primary tasks of the 12 persons who are employed in SKI's two contract sections are to conduct EU tenders and establish framework agreements. The resulting contracts are then implemented by SKI's sales and marketing sections, in close co-operation with customers and procurement officials in the Danish public sector, while the day-to-day management of the framework agreement contracts including dealings with suppliers are handled by SKI's contract management section. Many concrete tasks are performed by groups comprised of individuals drawn from several SKI sections.

SKI has introduced electronic means in various parts of its operations. SKI conducts its EU tendering through an electronic system that it has partly developed itself. SKI started with electronic tendering in 1995, when it became obvious that the manual handling of the many pages of complex material of several bidders was a task that could no longer be dealt with in a traditional way. By the end of the 1990s SKI had established an electronic tendering system, which has been further developed over the years. SKI has also implemented an electronic dynamic purchasing system.

The contract conditions and other information regarding framework agreements can be found on SKI's website www.netindkob.dk, which is a password-protected site dedicated to SKI's customers in the public sector.

SKI prepares electronic catalogues of the goods and services that it provides through its framework agreements. These catalogues are only prepared if there is an expressed need for them by customers. The electronic catalogue is uploaded to the relevant e-commerce platforms in Denmark.

SKI is almost exclusively financed through a percentage of turnover (typically $1 \%$ - but on average around $\mathbf{0 . 8 2} \%$ ) on contracts with suppliers. This means that each supplier pays a small amount to SKI, corresponding to the framework agreement volume that the supplier concerned has generated through the contract. The percentages paid by suppliers accounts for $98 \%$ of SKI's revenue. Most of the remaining $2 \%$ of revenue is generated by a small annual fee that public organisations pay to SKI in order to be able to use SKI's framework agreements.

The turnover and profitability of SKI can be seen below in the headline figures and key ratios of the last couple of years. Note that SKI's goal is not to maximise profits but only to achieve a level of profitability that ensures sustainability and high-quality service capacity over time for owners and customers. 


\begin{tabular}{|c|c|c|c|}
\hline & 2007 & 2008 & 2009 \\
\hline \multicolumn{4}{|l|}{ Headline figures (1,000 DKK) } \\
\hline Net turnover & 81,400 & 94,736 & 110,007 \\
\hline Returns on primary operations & 2,663 & 8,570 & 7,205 \\
\hline Net financial posts & 114 & 226 & 190 \\
\hline Annual result & 2,058 & 6,485 & 5,444 \\
\hline Year's cash flow & 1,374 & 3,141 & 15,074 \\
\hline Net capital, end of year & 28,066 & 34,551 & 39,995 \\
\hline Combined assets & 45,100 & 54,748 & 63,232 \\
\hline Year's investment & 802 & 2,203 & 1,763 \\
\hline Number of staff & 57 & 60 & 74 \\
\hline \multicolumn{4}{|l|}{ Key ratios } \\
\hline Operating profit margin & $3 \%$ & $9 \%$ & $7 \%$ \\
\hline Profits from invested capital & $12 \%$ & $32 \%$ & $46 \%$ \\
\hline Invested capital (1,000 DKK) & 22,260 & 26,512 & 15,754 \\
\hline Gross margin & $3 \%$ & $7 \%$ & $5 \%$ \\
\hline Liquidity level & $229 \%$ & $242 \%$ & $247 \%$ \\
\hline Net capital share & $62 \%$ & $63 \%$ & $63 \%$ \\
\hline Net capital returns & $8 \%$ & $21 \%$ & $15 \%$ \\
\hline
\end{tabular}

\section{Products, Services and Market/Supplier Approach}

The following is a list of the general areas where SKI offers framework agreements:

- $\quad$ information technology;

- furniture;

- $\quad$ office equipment;

- energy;

- automobiles;

- $\quad$ spectacles;

- foodstuffs;

- $\quad$ catering centre equipment;

- electrical equipment;

- $\quad$ building materials;

- tools;

- timber; 
- $\quad$ work clothes;

- cleaning services;

- $\quad$ research and laboratory equipment;

- $\quad$ temporary staff, consulting engineers, and management consultancy.

Through input from procurement officials in the public sector and general market analysis, SKI selects a number of potential new framework agreement areas, which are analysed in depth in terms of their relevance. As SKI is self-financing, there is a general rule of thumb to the effect that SKI will only enter into a new framework agreement area if there is an expected yearly framework agreement turnover of at least 10 million EUR.

SKI naturally takes all standards into account, whether they be technical, environmental or otherwise. With regard to technical standards, SKI has throughout the years maintained close contact with the organisation Danish Standards, which is responsible for standardisation in Denmark. In the field of ecolabels, such as the Flower (EU) and the Swan (Nordic), SKI has likewise contributed to the standardisation work throughout the years.

Regarding delivery and payment policies, SKI uses common market standards and/or standards set by the central government.

Purchasing statistics constitute a weak link of most Central Purchasing Systems in the EU. When SKI exchanges experiences with European CPSs, relevant purchasing statistics are a shared problem. The Danish Statistical Bureau does calculate total public expenditure, but at a very aggregated level, which means that these figures are not very useful for the planning of efficient public purchasing. SKI obviously uses its own statistics generated from existing framework agreements, and SKI's customers are sometimes also able to help with relevant data. However, the supplier-side often has the most up-to-date statistics, which naturally is not the optimal situation.

The "market share" of SKI's turnover, compared with the overall procurement volume of the public sector represented, is not easily determined because of the general problem of determining the total public sector procurement volume. While some sources indicate around 300 billion DKK (40 billion EUR) as the total Danish procurement volume, other sources report a total volume of 150 billion DKK (20 billion EUR) within standardised products and services. SKI's framework agreements in 2009 totalled $\mathbf{1 3}$ billion DKK (1.7 billion EUR). The market potential for SKI's current portfolio of framework contracts is estimated to be 60 billion DKK (8 billion EUR). Therefore SKI's "market share" might only be around $\mathbf{2 0 \%}$. However, in specific areas - one example is telecommunications - SKI's market share is considerably higher.

The process for market and supplier analyses includes the following steps: SKI's employees responsible for the establishment of a framework agreement usually first go through a pre-analysis phase, where some of SKI's customers and suppliers are interviewed regarding the specific procurement area. If the pre-analysis shows that it would be feasible for SKI to establish a framework agreement, an actual market analysis is conducted. This analysis entails a more thorough investigation of the market, where an overview of both the demand and supply sides is established. Often the market analysis will contain statistical data from available sources and sometimes, for more specialised areas, external consultants will be used in connection with the market analysis. This analysis is put forward to SKI's top management level, which makes the final decision as to whether to go ahead with the framework agreement.

SKI has established a clear SME policy. First of all, if the EU definition of SMEs is applied (small as being fewer than 50 employees and medium-sized as fewer than 250 employees), more than $98 \%$ of Danish companies are small by definition. Therefore, SKI obviously must take into account the issue of SMEs. 
During the pre-analysis and market analysis phases, SKI considers the supplier structure for the relevant area. The role of SMEs is determined. Generally, SKI tries to make it as easy as possible for SMEs to submit their offers in response to a tender invitation launched by SKI within a particular framework agreement area. Naturally, the fairly complicated EU tender process is an obstacle for many small (and indeed large) companies. However, SKI occasionally organises seminars for potential bidders, where the procedures are discussed and SKI's electronic tendering system is presented. Fairly often, SKI organises its tender processes so that they are broken up into geographical lots, which increases the opportunities for SMEs to participate.

It is also important to stress that, while there is a common interest to help SMEs on the part of both SKI and the Danish public sector, the public sector also expects that the companies chosen to supply will be in a position to offer high stability and security along with their goods or services. Of course while SKI (or the public organisations themselves) cannot favour the large companies, the small companies cannot be favoured either. All potential suppliers must be treated equally.

\section{Internal Customer Relationships}

Notably, SKI caters for all sectors of the public sector: central, regional and local governments as well as semi-public companies. Practically all Danish public organisations in some way or another use SKI's framework agreements; yet it is important to stress that it is not obligatory for them to use any of SKI's framework agreements. 
A list of SKI's largest customers and their purchasing volumes is provided in the following table:

\begin{tabular}{|c|c|c|c|c|}
\hline Customer & 2007 (DKK) & 2008 (DKK) & 2009 (DKK) & $\begin{array}{l}\text { Total } 2007-2009 \\
\text { (DKK) }\end{array}$ \\
\hline Ministry of Defence & 822.722 .038 & 1.043 .664 .320 & 687.307 .327 & 2.553 .693 .685 \\
\hline $\begin{array}{l}\text { Universities - } \\
\text { common }\end{array}$ & 748.442 .385 & 778.881 .043 & 799.708.039 & 2.327.031.468 \\
\hline Ministry of Education & 601.428 .091 & 729.082 .817 & 983.005 .093 & 2.313.516.001 \\
\hline Ministry of Justice & 550.340 .696 & 403.807 .427 & 440.872 .570 & 1.395 .020 .693 \\
\hline $\begin{array}{l}\text { Capital Region of } \\
\text { Denmark }\end{array}$ & 184.425 .625 & 191.077.689 & 536.152 .403 & 911.655 .717 \\
\hline City of Copenhagen & 195.942 .137 & 309.128 .903 & 338.131 .662 & 843.202 .702 \\
\hline $\begin{array}{l}\text { Region of Southern } \\
\text { Denmark }\end{array}$ & 199.784.847 & 240.701 .683 & 399.746.078 & 840.232 .608 \\
\hline $\begin{array}{l}\text { Tax and Customs } \\
\text { Administration }\end{array}$ & 209.140.561 & 191.142.277 & 284.534 .890 & 684.817 .728 \\
\hline Ministry of Transport & 179.084 .613 & 224.888 .753 & 193.257 .427 & 597.230 .793 \\
\hline $\begin{array}{l}\text { Region of Central } \\
\text { Denmark }\end{array}$ & 160.713 .436 & 193.863.121 & 224.806 .591 & 579.383 .148 \\
\hline $\begin{array}{l}\text { Dong Energy Sales \& } \\
\text { Distribution A/S }\end{array}$ & 223.000 .180 & 226.998 .478 & 86.586 .969 & 536.585 .628 \\
\hline $\begin{array}{l}\text { Ministry of the } \\
\text { Interior and Health }\end{array}$ & 137.934.651 & 142.749 .058 & 254.827 .526 & 535.511 .235 \\
\hline Zealand Region & 190.341.707 & 189.885 .336 & 154.078 .435 & 534.305 .477 \\
\hline
\end{tabular}

As mentioned above, the use of SKI's services is voluntary. The rationale behind this general rule is the underlying political decision that SKI must exist on commercial terms. This means that SKI must establish framework agreements that are competitive and that are considered by public organisations as better than the agreements that they themselves could have established. SKI has had a few obligatory agreements, but they were established for the Ministry of Finance and were only obligatory for the central government. However, the ministry has now chosen to maintain this type of contract itself.

SKI has no formal means to prevent maverick purchasing (non-loyal behaviour) among its customers and can only rely on the attractiveness of the framework agreements. The lack of formal means is instead replaced by customer advisory boards for each tender process, comprised of public procurement officials from organisations that have large budgets in the area concerned. The tender process is then started in a partnership between SKI and the customer advisory board. Once the framework agreement has been established, all organisations in the public sector are able to use it. Over the years SKI has tried to obtain the approval of the members of the advisory board to use the resulting framework agreement prior to starting the tender process for the relevant agreement. This approval has proven to be very difficult to obtain, since most customers are unwilling to guarantee even a small turnover without knowing the result of the tender process. 
SKI has developed and rolled out a maturity model for public procurement in Denmark. The development model is based on the capability maturity model and is expected to lead to consistency of practice within Danish public procurement organizations and increase best practice transparency. Further, the model is expected to be used as a common frame of reference and communication tool to provide a clear picture of the strengths and challenges in the individual procurement organizations as well as within public procurement in Denmark.

SKI has no "internal customers" as such since it is an external organisation by nature, but clearly some customers are "closer to SKI" than others, such as those with which SKI has already established partnerships. Another example would be the members of SKI's customer advisory boards. SKI naturally maintains a closer communication with this type of customer. Communication with these customers is often on a day-to-day basis, with frequent e-mails and telephone calls being exchanged and meetings being held on a monthly basis. SKI even has employees who spend some working days in the offices of some partnership customers.

The commercial relationship with customers requires that all customers that wish to use SKI's framework agreements at the start of each year renew a subscription allowing them to use SKI. The only formal agreements - in the form of contracts - that SKI has with its customers are the partnership contracts that have been signed with 11 specific large customers.

Apart from the above, all other relationships between SKI and its customers are managed in a more voluntary and informal way, such as through e-mail, telephone calls, websites, newsletters and events.

Regarding co-ordinating activities with other public authorities, such as the competition authority, procurement regulatory and monitoring bodies, etc., SKI has throughout the years maintained informal contacts with the Danish Competition Authority, which is the primary regulatory body in Denmark. In an international context, SKI participates in the EU Public Purchasing Learning Lab, which provides SKI with invaluable input from other EU Member States.

\section{Procurement and Contracting}

The planning and preparation of the procurement process are always based on thorough market analyses, as mentioned above, which are also required by the customers. Procurement officials in the public sector require the analysis by SKI of specific areas in order to determine whether or not to go forward with a tender process. If a decision is made to start the tender process, a customer advisory board is established, comprised of some of the most engaged customers. The tender process is then established in a partnership between the advisory board and SKI, with SKI as the responsible party. The starting point for the type of framework agreements used is SKI's adherence to the EU rule of identifying at least three different suppliers for each framework agreement. It is often the case that many more suppliers are selected. It is especially important, now that it is possible to conduct mini-competitions, to have a sufficient number of suppliers. The contract period is typically between two and four years.

SKI almost consistently uses the restricted procedure, whereby SKI verifies whether potential bidders meet specific selection criteria. Publication rules are always identical to those set down by the EU directives.

The selection and award criteria also follow the rules of the EU directives. SKI uses a number of fairly standard selection criteria related to the financial, economic, technical and professional capacity necessary to carry out the contract. The award criteria used are always aimed at selecting the most economically advantageous offers, based on technical or qualitative merits in combination with economic merits. 
SKI uses an electronic tendering system. When framework agreements are established, suppliers are contractually obliged to deliver electronic catalogues containing information regarding their goods or services - if customers have expressly requested such information. These catalogues are maintained by SKI and are made available to customers on their preferred e-commerce sites. However, it is safe to say that public e-procurement in Denmark has not yet been fully developed.

SKI has held a few e-auctions over the years, and while the attention generated by these e-auctions was considerable, their long-term effects have been somewhat disappointing. Most of SKI's customers are not ready to commit themselves to whatever combination of supplier and product may win the auction, which is a prerequisite for participation in an e-auction. Most customers see mini-competitions/minitenders as a better alternative.

The organisation of mini-competitions/mini-tenders is nearly always a possibility under SKI's framework agreements. Indeed, some of SKI's framework agreements have the mini-competition as the only option. Many customers view mini-competitions as an attractive, although somewhat time-consuming, way of securing the right goods or services at the right prices. At the moment SKI is contemplating whether it should offer extra help to customers that want to conduct their own mini-competitions. Such assistance would be a service that SKI should be paid for, unless it was provided to a special customer, e.g. a partnership customer.

There are primarily two "call-offs" used in a SKI framework agreement context. Either a customer chooses the product/service that it considers to be the best suited to its needs - while naturally meeting the EU directive's formal procedures - or a mini-competition/mini-tender is implemented.

The contract management phase, involving routines for ordering, deliveries, invoicing, payments and statistics as well as contract dispute-settlement mechanisms, are more or less outlined in SKI's standard contract that is used for all framework agreements. Issues regarding ordering, deliveries, invoicing and payments are handled by the customer and the supplier between themselves and in accordance with the framework agreement. The supplier must provide SKI with statistical data concerning its total turnover under the framework agreement. This data also constitutes the information that SKI uses to bill suppliers for the percentage financing SKI's activities.

Complaints range from trivial customer and supplier complaints transmitted directly to SKI to official complaints submitted to the official Complaint Board regarding Tenders (Klagenævnet for Udbud) or to the Competition Authority (Konkurrencestyrelsen). SKI and its suppliers try to handle most of the trivial complaints amicably, while the more serious complaints often lead SKI to seek legal assistance. The past few years' experience had shown SKI that it was essential to have in-house legal competencies, and a lawyer specialised in public procurement has therefore been employed by SKI since 1 May 2010. Another lawyer will hopefully be recruited before the end of 2010.

The position of SMEs is generally acceptable if the EU definition is applied (see Section 4 above). However, if the definition is narrowed down to micro-enterprises, then very few SMEs participate in framework agreements. Some SMEs participate in highly specialised framework agreements (e.g. within management consultancies) or in agreements divided into geographical areas (e.g. cleaning services). SKI has many informal discussions with the trade associations that traditionally have SMEs among its members, and it is hoped that more SMEs will bid on SKI tenders in the future.

SKI undertakes its own benchmarking once a new framework agreement has been established in order to determine its competitiveness. However, this is not a simple task, as many customers do not have easy access to their own procurement data (either procurement volumes or specific prices). On the whole, SKI's increasing turnover over the past seven years is an indicator that SKI's framework agreements are competitive. 
SKI does have a few foreign suppliers. SKI has so far required all bids to be submitted in Danish, which is naturally seen as a major obstacle for foreign companies.

\section{Evaluation and Performance Measurement}

SKI has a person employed who is responsible for benchmarking all framework agreements against the prices obtained by members of the customer advisory board. However, this is not an easy task, and this is another area where there is room for improvement.

In view of SKI's fairly modest market share, analyses of market effects are not deemed necessary for most of SKI's framework agreements. In the areas where SKI has a substantial market share (e.g. telecommunications and information technology), SKI occasionally uses reports from consultancy services that monitor the market (e.g. IDC) or from national regulatory boards (e.g. National IT and Telecommunications Agency).

Customer surveys to determine the degree of customer satisfaction have not been conducted for several years. However, there are concrete plans to undertake such a survey later in 2010.

The main stakeholders - first of all, SKI's owners - have found the annual reporting provided in SKI's annual report, supplemented by ad hoc reporting at board meetings, to be adequate. The owners are of course well aware of the challenges that are faced when reporting on public procurement.

\section{Important Success and Risk Factors}

The key prerequisite that needs to be in place for the successful outcome of CPS operations is top management backing from all segments of the public sectors. This support is essential for the credibility of SKI.

The main risks in managing a CPS operation, which are summarised in SKI's annual report, are linked to the following capacities:

1. Customer relations: the ability to establish close and long-lasting relations with customers and to guarantee an appreciable profit from framework agreements in connection with the signing of new contracts;

2. Competition: the ability to ensure competitive terms for framework agreements and to provide customers with better conditions than they would have been able to achieve were they to tender their own contracts;

3. Personnel: the ability to attract, train and retain employees with the required competencies.

\section{Future Development}

The following list summarises the issues that SKI's CEO discussed at the meeting of the SKI Board of Directors as the basis for initiatives up until 2012:

1) Creation of a foundation for further gains from procurement by pooling and co-ordinating procurement volume and for closer involvement in customers' procurement;

2) Strengthened focus on local government;

3) Improved documentation of savings, by both product group and customer;

4) More dynamic financing of SKI activities; 
5) Partnerships with the leading and interested customers;

6) Easier use of SKI's framework agreements through further development of the content, connection and accessibility of contracts;

7) Strengthened activation of suppliers, locally as well as internationally;

8) "Packaging" of framework contracts, services and communication so as to enable SKI to offer coherent solutions and meet customers' political agenda, thereby securing managerial impact and support;

9) Securing a more qualified procurement debate through documentation and presentation of facts;

10) Investment in renewal. 


\section{Organisation Charts of SKI}

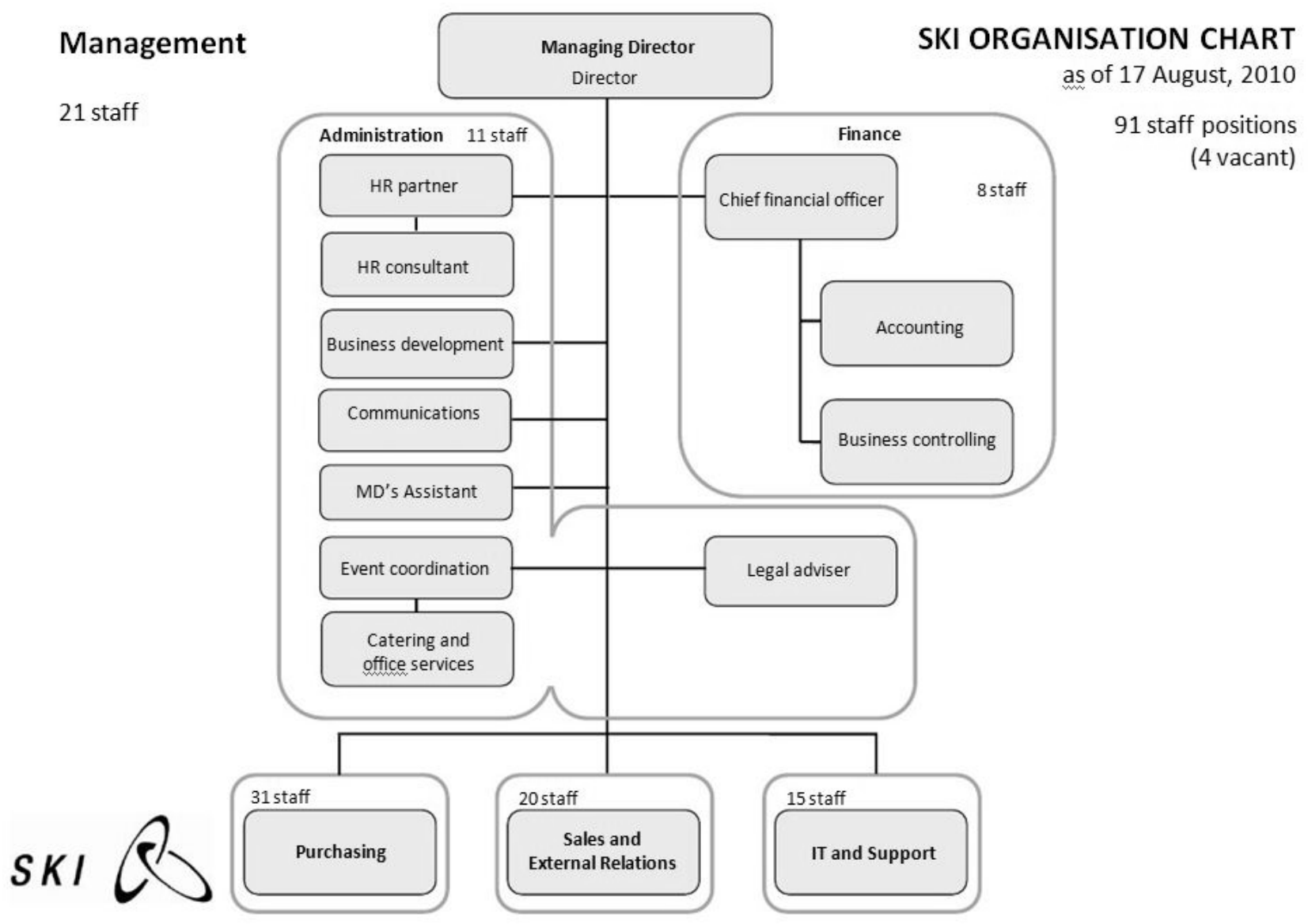




\section{Purchasing}

31 staff

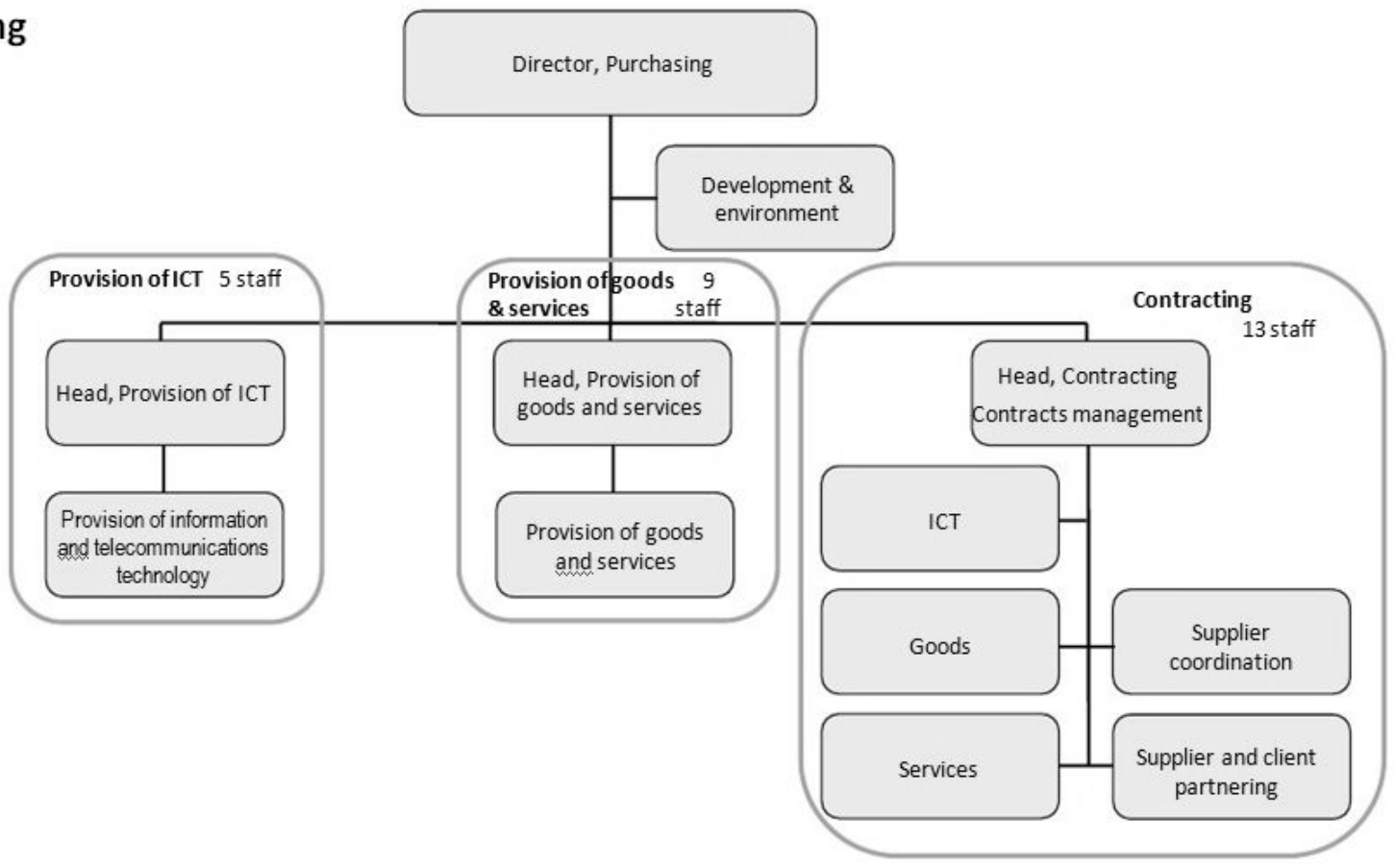

\section{Sales and External Relations}

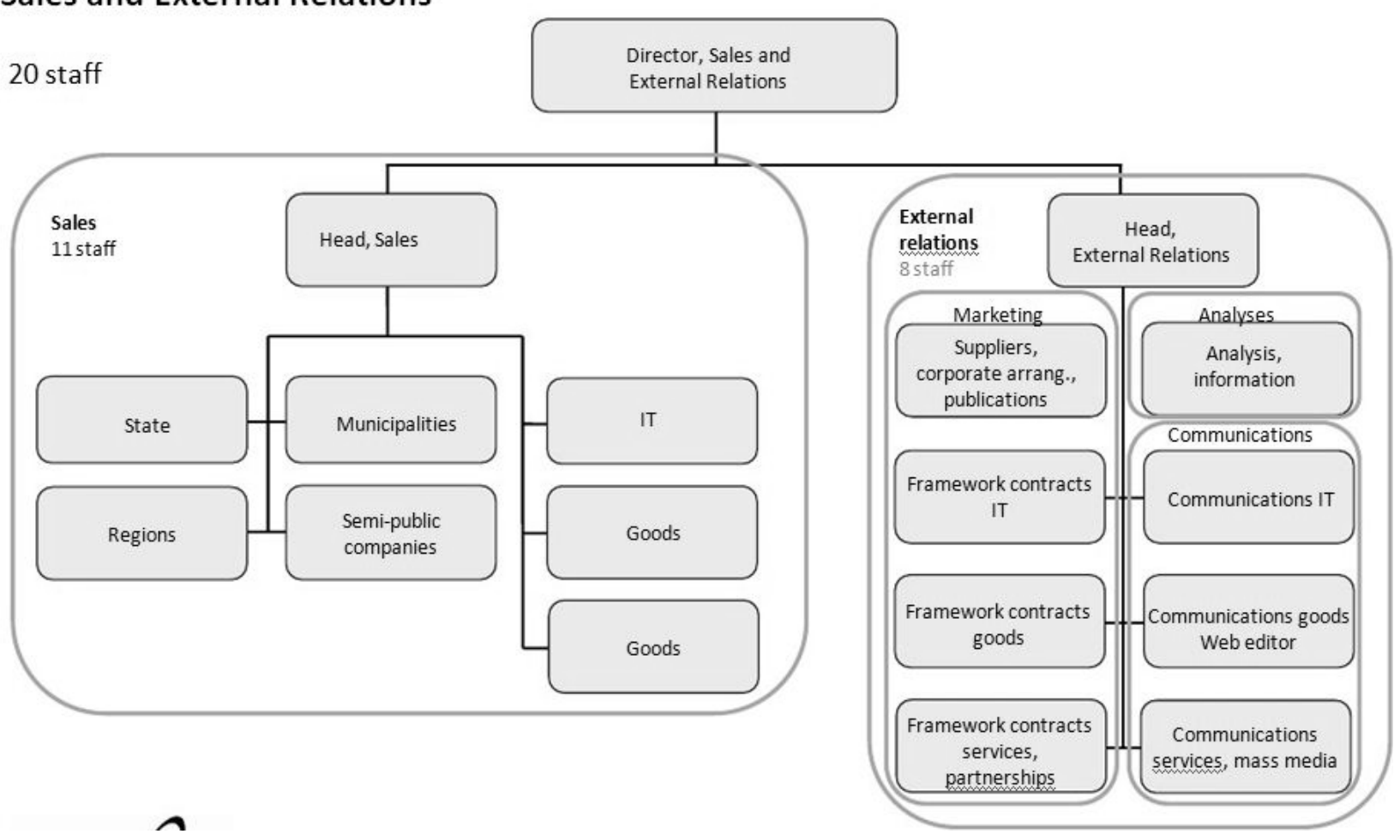


GOV/SIGMA(2010)3/REV2

\section{IT and Support}

15 staff

Director,

IT and Support

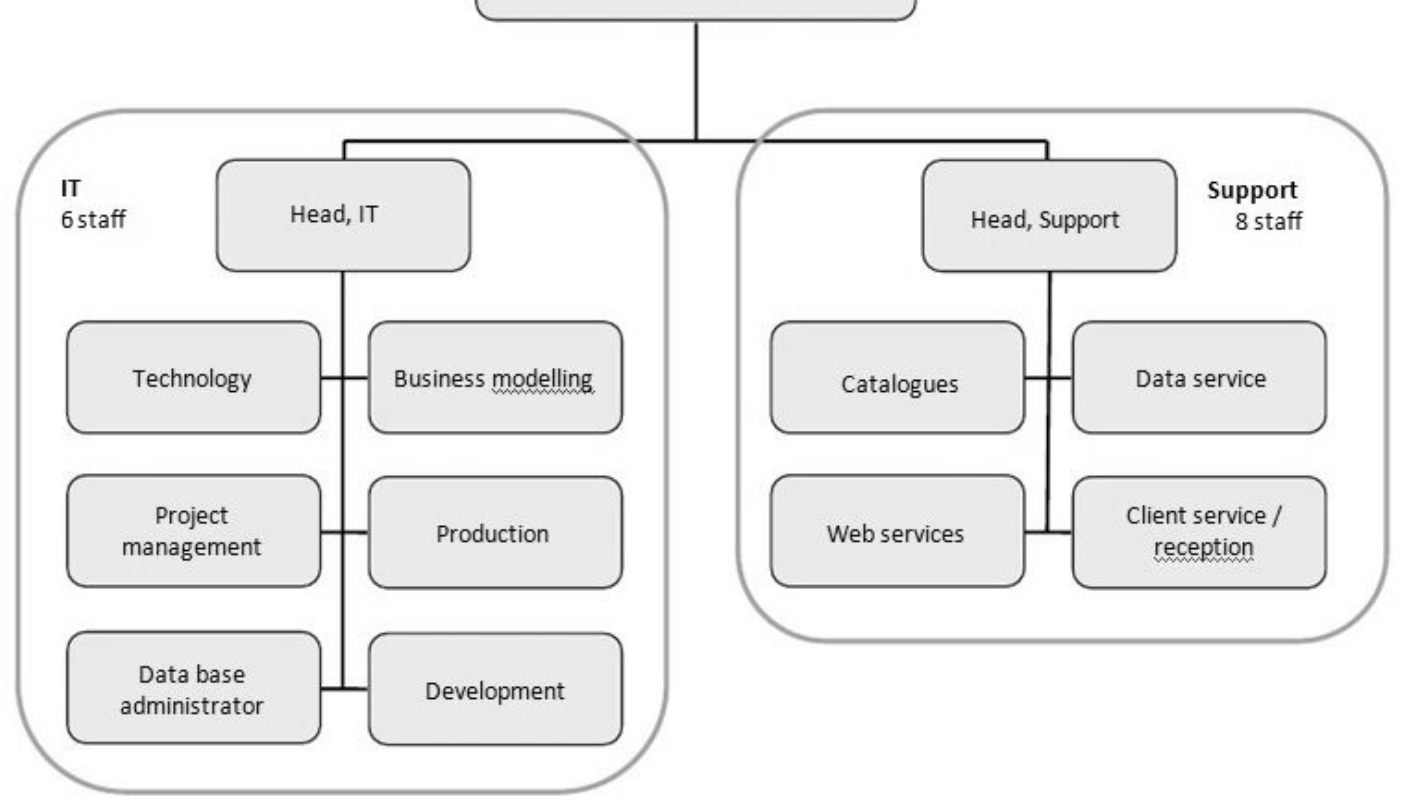




\section{ANNEX 2. FINLAND, HANSEL LTD}

\section{The Establishment of CPS - History and Rationale}

Hansel Ltd, the central procurement unit of the Finnish State, was established in its current form in 2003. Its previous operations (wholesale trade, etc.) were closed down during 2004, and the company's new activities were directed towards fulfilling the role of a central procurement unit in line with the European Union's procurement directives. Hansel was formed as a limited company under private law since it enables more flexibility in day-to-day activities and independent financing.

Hansel's new activities, which include the establishment and management of framework agreements, were determined with a view to supporting the implementation of the State Procurement Strategy.

Hansel is a non-profit organisation owned entirely by the State of Finland and operating under the control of the Ministry of Finance. Its task and role are defined in the Act on Hansel, the Public Procurement Act, and the State Procurement Strategy. The company's activities fall within the mandate of the Ministry of Finance, which is also responsible for its corporate governance. Hansel is governed by a board of directors comprised primarily of high-ranking officials from the state administration (e.g. Prime Minister's Office and Ministry of Finance).

\section{Operational Strategy and Objectives}

The objective of Hansel's operations is to produce savings for the Finnish Government by putting framework agreements for goods and services out to tender. Hansel also provides consultancy and development services for its customers.

The company's core functions involve running the tendering processes for procurement, handling the procurement contracts arising from these processes, and marketing those contracts. Hansel promotes high-quality procurement and the equitable, non-discriminatory treatment of suppliers in the tendering process.

\section{Organisation and Finances}

Hansel is led by the CEO Mr. Anssi Pihkala, assisted by the executive team comprised of the COO Mr. Reijo Alén, the CLO Mrs. Eija Kontuniemi, and the CFO Mrs. Kirsi Koivusaari.

Hansel's organisation is divided into three departments:

1) Legal Matters and Procurement Procedures

2) Services and Service Marketing

3) Finance and Administration

Hansel has three procurement sectors (situated in the Department of Services and Service Marketing):

1) ICT Procurement 
- $\quad$ contracts related to ICT hardware, software and services

2) Procurement of Administrative Services

- contracts related to financial administration, organisational and human resources development, travel and conference management

\section{3) Procurement of Materials and Technical Services}

- $\quad$ contracts related to material and facility services, vehicle and transport services, office and energy supply services

There are also units for Customer Service, Sales and Marketing, Procurement Procedures and Development, Legal Services, Finance and Administration, and Communication.

The number of personnel at the end of 2009 was 57 (56 at the end of the year 2008). In 2009, about 38\% of the personnel had a higher academic degree (39\% in 2008). The most common degrees are in the areas of business administration and law. Typical positions at Hansel are: Legal Counsel, Category Manager, Sourcing Consultant, Senior Specialist and Specialist.

Hansel's operations are financed by a service fee paid by the suppliers. The service fee is set at a maximum of $\mathbf{1 . 5 \%}$ of the turnover of the framework supplier, as invoiced under the framework agreement. The service fee is recorded as Hansel's turnover.

Hansel's turnover in 2009 was 7.8 million EUR (6.5 million EUR in 2008). The net profit was 1.3 million EUR (0.8 million EUR in 2008). The turnover consists mainly of the service fee. Hansel also has a minor income from consulting services (364,000 EUR in 2009, 136,000 EUR in 2008).

\begin{tabular}{|l|l|}
\hline Year & Turnover (Million EUR) \\
\hline 2009 & 7.8 \\
\hline 2008 & 6.5 \\
\hline 2007 & 8.0 \\
\hline 2006 & 5.5 \\
\hline 2005 & 3.6 \\
\hline
\end{tabular}

\section{Products, Services and Market/Supplier Approach}

Hansel maintains contracts in a wide range of areas. Hansel's agreements apply in particular to frequently recurring purchases made by government bodies, and the contracts are maintained in the business units of the company (see section 3 above). The contracts cover areas such as ICT hardware and software, organisational and human resources development, travel and conference management, vehicle and transport services, and office and energy supply services.

The process for determining the inclusion of services and products in the framework agreement portfolio follows the stages indicated below:

\section{Stage 1: Pre-study carried out by Category Manager (Hansel)}

1) Triggered by:
a) Customer or owner request;
b) Findings in customer spending;
c) Supplier initiative; 
d) Experience from the usage of existing framework agreements.

2) Pre-study report is compiled as an outcome of Stage 1.

\section{Stage 2: Go/No-go decision made by Hansel's Executive Team}

1) The decision is based on the pre-study report.

2) Decision-making criteria:

a) Finnish State's procurement volume of the product/service;

b) Number of procuring organisations in the Finnish central government.

c) Standardisation level of the product/service in the supplier market.

3) Go-decision triggers project planning for competitive tendering.

The Ministry of Finance, as a steering body of central government procurement operations, is regularly informed and consulted regarding Hansel's tendering plans.

During the tender process the common standards, technical and environmental aspects are carefully considered and followed. The decision as to their applicability to the tendered product/service in question is made on a case-by-case basis. In general, common product/service category-specific EU standards and requirements are followed (e.g. Energy Star certification). Environmental aspects and EU policies and the related recommendations are always followed when applicable. Guidelines presented in government reports are also taken into account in the project plans.

The purchases of the Finnish State are entered into a web-based accounting system (NETRA), which provides, for example, product/service category-specific summary reports of purchases. Hansel's contract suppliers report their framework agreement sales by product/service and by customer organisation on a monthly basis to Hansel's web-based reporting system (SUTI), which provides reliable statistical information on purchases through framework agreements in the central government context.

The overall procurement volume of the Finnish State in 2009 was about 4 billion EUR, of which about 1 billion EUR was considered to be within the potential range of the CPS. In 2009 the procurement volume through Hansel was 534 million EUR, and hence the theoretical "market share" of the CPS was 53\%.

The list of items to be clarified in the pre-study process has been documented. A formal and more detailed instructed process for carrying out market and supplier analyses is not yet in place. Analyses are most commonly based on supplier interviews and interviews with diverse associations and organisations representing enterprises and supplier markets as well as on market analyst information.

Hansel's general policy is that SMEs should have the opportunity to participate in tendering processes arranged by the company. In each tendering project plan consideration is given to the way in which the participation of SMEs in the competitive tendering can be assured. A recent study shows that more than $37 \%$ of Hansel's procurement volume (200 million EUR) was awarded to SMEs in 2009.

\section{Internal Customer Relationships}

Hansel's customers, defined in the act on Hansel, are the following:

1) Government agencies (central government, i.e. ministries and departments, regional and local state authorities); Parliament; Presidency, Council of State;

2) Unincorporated state enterprises (public service companies of the state); 
3) Off-budget funds;

4) Bodies governed by public law, which are controlled by the state (for example, universities and the Finnish Broadcasting Company);

5) European Union agencies in Finland.

Municipalities are not Hansel's customers. This means that health care and basic education, for example, are not covered by the CPS.

Purchases in 2009 through Hansel's framework agreements by branch of administration:

\begin{tabular}{|l|l|}
\hline Customers by branch of administration & Million EUR \\
\hline Ministry of Defence and its divisions & 94156806 \\
\hline Ministry of Education and its divisions & 87539508 \\
\hline Ministry of Transport and Communications and its divisions & 64332795 \\
\hline Ministry of the Interior and its divisions & 59283133 \\
\hline Ministry of Finance and its divisions & 58684049 \\
\hline Ministry of Employment and the Economy and its divisions & 36972251 \\
\hline Ministry of Justice and its divisions & 35361305 \\
\hline Ministry of Social Affairs and Health and its divisions & 30701623 \\
\hline Ministry of Agriculture and Forestry and its divisions & 22570903 \\
\hline Ministry for Foreign Affairs and its divisions & 11839681 \\
\hline Ministry of the Environment and its divisions & 11187090 \\
\hline Finnish Parliament & 10634208 \\
\hline Agencies of the European Union & 4022838 \\
\hline Council of State & 2574766 \\
\hline Office of the President of the Republic of Finland & 658356 \\
\hline Others & 3674272 \\
\hline $\begin{array}{l}\text { TOTAL SUM OF PURCHASES THROUGH } \\
\text { FRAMEWORK AGREEMENTS IN 2009 }\end{array}$ & $\mathbf{5 3 4 1 9 3 5 8 4}$ \\
\hline
\end{tabular}

The usage of framework agreements is primarily voluntary for Hansel's customers. The goal is to ensure that product/service quality and prices through framework agreements are competitive with the prices and quality provided by the customers' own purchase contracts. However, as an exception to this principle, the Ministry of Finance has stipulated that $\mathbf{1 5}$ of Hansel's $\mathbf{7 0}$ framework agreements are mandatory for Finnish central government entities. The procurement strategy of the Finnish State encourages state agencies to use joint procurement whenever possible.

In the case of maverick buying (non-loyal behaviour), no actions are taken by the central procurement unit. The State Inspection Agency also inspects government entities' procurement practices and points out all erroneous and illegal operations.

For each customer Hansel has an assigned Customer Manager. Customer Managers use a relationship marketing approach and means in customer interactions. Additionally, Hansel uses direct marketing efforts, such as marketing campaigns and events as well as e-mail and web-based means (Internet and extranet sites) to promote the usage of its framework agreements by its customers.

Before procuring products and services through a framework agreement, customers must join the framework arrangement by means of a written notification, in either web form or paper copy. By doing so, the customer organisation commits to the terms and conditions of the framework agreement. 
Experts from Hansel participate regularly in various committees and working groups dealing with public procurement issues (for example, preparation of legislation, state procurement strategies, action plan for sustainable public procurement, state ICT strategy and action plan, and state recommendations on contractual issues, data safety, etc.).

\section{Procurement and Contracting}

Hansel's tender competitions are prepared and accomplished in projects. Common project methods and organisation models are used. The project group usually consists of three members (procurement, legal, and commercial/technical experts). In larger projects there is usually also a steering group. Project plans and essential steps of the project are introduced and decided by Hansel's executive team.

The project model is used in all tender competitions. The model defines:

- $\quad$ the responsibilities of the group members (documentation, etc.);

- $\quad$ steps of the tender competition and the actions in practice;

- $\quad$ customer activities during the preparation of the tender competition (working groups, provision of information);

- decision points and decision-makers.

Detailed instructions for tender competitions are provided in internal work instructions.

Technical dialogue is usually used in order to prepare technical specifications and other tender documentation.

Hansel has $\mathbf{7 0}$ framework agreements. Both single-supplier framework agreements and multi-supplier framework agreements are used.

Individual contracts based on a multi-supplier framework agreement are awarded using a minicompetition or "ranking" method. The method for choosing between the various suppliers during the contract period is always laid down in the tender documentation of the framework agreement and in the contract between Hansel and suppliers.

When using a "ranking" method, customers first contact the supplier whose tender for the award of the framework agreement was considered to be the best, and only turn to the second supplier if the first one is not capable or interested in providing the goods or services in question. "Dynamic ranking" is also used. For such framework agreements, the ranking of the suppliers changes during the contract period. The criterion for these changes is usually the price. The method and the criteria are always laid down in the invitation to tender when establishing the framework agreement and in the contracts between Hansel and suppliers.

Normally the open procedure is used. For complicated procurement the negotiated procedure is sometimes used. A prior information notice is usually published. A contract notice is always published. In Finland notices are sent to the information channel HILMA www.hankintailmoitukset.fi), where they are published simultaneously with the publication in TED.

The award criterion for awarding a framework agreement is always the most economical advantageous tender. The weight of price is usually about $\mathbf{6 0 - 8 0 \%}$. Many different qualitative criteria linked to the subject of the contract are used (for example, delivery time, coverage of services, environmental aspects, efficiency and technical performance). Usually Hansel tries to limit the number of criteria in order to make the comparison of the tenders as simple and efficient as possible. The quality aspects are also 
guaranteed by minimum performance criteria when defining the subject of the contract and in contract clauses.

Electronic procurement methods are usually not used in tender competitions. At the moment there are no provisions for electronic auctions and a dynamic purchasing system in the Finnish legislation. Relevant articles of the EU procurement directives will be implemented approximately in 2011. Electronic means of communication (e-mail) are used in tender competitions. However, procurement decisions are usually delivered by hand to the recipients or sent by mail. The negligence of the standstill period is sanctioned. In order to minimise risks, electronic communication is not used for delivering procurement decisions.

Electronic methods are used in mini-competitions. Hansel has a specific tool for mini-competitions related to vehicles, charter bus services and removal services. Hansel is also developing electronic tools for other framework agreements where mini-competitions are used. Electronic communication is commonly used throughout the process in mini-competitions.

The Finnish State Treasury is setting up an electronic Purchasing Management System (TILHA) for central government agencies. TILHA will be fully in use by the end of the year 2011.

TILHA's main features are:

- $\quad$ Electronic process for procurement proposals and approvals;

- $\quad$ e-catalogues of suppliers (Hansel's framework suppliers/other government suppliers);

- $\quad$ Direct e-orders (from government agency suppliers);

- $\quad$ Acceptance of the delivery;

- $\quad$ e-invoices (from supplier to government agency, automatic payment of accepted invoices, automatic transfers to the bookkeeping system);

- Mini-competition and awarding tool.

Mini-competitions are arranged by Hansel's customers. Hansel's experts provide support to customers when needed. Hansel also provides model documents (invitation to tender, tender, tender comparison document, decision) for customers. Special guides and model documents are tailored to each framework agreement.

In mini-competition a written invitation to tender is sent to all suppliers of the framework agreement. The subject of the contract is defined in the invitation to tender as well as the evaluation criteria and the relative weighting of the criteria. Suppliers submit their tenders, and the contract is awarded to the supplier that has submitted the best tender.

Customers and suppliers may, when necessary, agree on matters related to the delivery of products in a customer-specific agreement, which applies in addition to the terms of the framework agreement. The terms of the customer-specific agreement cannot deviate substantially from the terms of the framework agreement.

The call-off systems differ in the various framework agreements. Usually orders are made by using the supplier's electronic ordering system or by e-mail, telephone, fax or post. Electronic systems are commonly used.

Examples of the various ordering systems are as follows:

- $\quad$ Flights: ordering channels of travel agencies;

- $\quad$ ICT equipment: supplier's web-shop; 
- Telecommunication services: written order/customer-specific contract;

- $\quad$ Electricity: written order/customer-specific contract.

The TILHA system will provide an efficient channel for ordering in the future. The call-off system is always described in the tender documentation of the framework agreement, in framework contracts and in customer guidance.

Contract management in terms of ordering, deliveries, invoicing and payments are agreed in detail in the framework agreement. The terms differ in the various types of products and services. The terms of dispute settlement are usually similar in all framework agreements. In a multi-supplier framework agreement, the terms are the same for all of the suppliers of the framework agreement.

There are wide possibilities for complaint in the Finnish public procurement system, and it is likely that the implementation of the EU remedies directive will increase the number of complaints (the new legislation came into force on 1 June 2010). A standstill period of 21 days applies to all procurement above the EU threshold. According to the new law, a 21-day voluntary standstill period will also apply to contracts above the EU threshold that are based on framework agreements. The new law also makes it possible to complain in relation to mini-competitions and other decisions based on framework agreements.

The first instance for a complaint is the Market Court. The complaint suspends the procurement (i.e. it is not possible to sign the procurement contract prior to the judgment of the court). The second instance for a complaint is the Supreme Administrative Court. There were 151 cases pending in the Supreme Administrative Court at the end of 2009. The handling time for a case in the Supreme Administrative Court can exceed two years.

\section{Complaints to the Market Court}

\begin{tabular}{|l|l|l|}
\hline Year & Cases (solved) & Period of lis pendens \\
\hline 2009 & 617 & 9.1 months \\
\hline 2008 & 515 & 15 months \\
\hline
\end{tabular}

In Finland the main obstacle for SMEs to access public procurement is probably the lack of information and knowledge. Joint procurement usually also hinders the opportunities for SMEs to participate. Hansel has paid special attention to this issue. The position of SMEs is always taken into consideration in Hansel's tender competitions. The project plans of tender competitions are required to contain an analysis of the situation of SMEs.

Hansel has close contacts with business-related organisations (e.g. the Federation of Finnish Enterprises and the Confederation of Finnish Industries). Sometimes organisations representing entrepreneurs in certain business fields are consulted when planning a tender competition. For example, a tender competition on translation and interpretation was conducted in close co-operation with the Finnish Association of Translators and Interpreters.

Contracts are often divided into lots in order to enhance competition and to facilitate the participation of small enterprises. For example, the procurement of hotel services and of conference services was divided into several areal lots in order to enable small enterprises to participate. The procurement of ICT consultancy services was also divided into several areas of expertise, which allowed small specialised companies to also participate. In that particular tender competition, special attention was also paid to the technical and capacity requirements (without setting too strict demands). That framework agreement has been very successful, and the customers have been satisfied with the quality of the suppliers. 
SMEs are encouraged to participate in tender competitions by forming groups of companies. Subcontracting is also always possible.

Usually there is adequate competition for a successful tender process. However, the level of competition is not satisfactory, for example, for gas, domestic and foreign flights and for refill services for tools. There are also some signs of insufficient competition in the areas of fuels and telecommunication services.

Direct cross-border tenders in tender competitions are not common. In order to have foreign tenders, foreign companies are personally contacted and informed about the tender competition. However, many branch offices of foreign companies or Finnish companies owned by foreign companies are suppliers in Hansel's framework agreements. The establishment of a subsidiary is the current way of entering the market in Finland.

\section{Evaluation and Performance Measurement}

Hansel bases its analysis of operational savings on an academic model. A study, focusing on the savings that Hanselhad made on behalf of the state, was carried out in 2008 at the Helsinki School of Economics (Katri Karjalainen, Tuomo Kivioja, Sanna Pellava, Yhteishankintojen kustannusvaikutus, B-94).

This study, requested by the Ministry of Finance, shows that centralised purchasing can bring an estimated savings of $\mathbf{2 0 . 5 \%}$ compared to decentralised purchasing. These savings result from a combination of purchasing prices and tendering costs. By using the model of the study, savings in 2009 were approximately 185 million EUR and estimated savings in 2010 amount to 197 million EUR. A realistic potential for savings at Hansel is 236 million EUR. Hansel has undertaken further analysis on this subject, based on the above-mentioned study.

\begin{tabular}{|l|l|r|r|r|r|}
\hline \multicolumn{2}{|l|}{$\begin{array}{r}\text { Hansel customers } \\
\text { Hansel }\end{array}$} & 2006 & 2009 & $\begin{array}{l}\text { l. } \\
\text { (estimate) }\end{array}$ & Realistic goal \\
\hline potential: & centralised, MEUR & 850 & 904 & 854 & 854 \\
\cline { 2 - 6 } & decentralised, MEUR & 1144 & 1217 & 1149 & 1149 \\
\hline Savings \% (Karjalainen \& al., 2008) & $25,7 \%$ & $25,7 \%$ & $25,7 \%$ & $25,7 \%$ \\
\hline Purchase volume, centralised, MEUR & 281 & 534 & 570 & 683 \\
\hline Usage rate, \% & $33 \%$ & $59 \%$ & $67 \%$ & $80 \%$ \\
\hline Volume, decentralised model, MEUR & 378 & 719 & 767 & 920 \\
\hline Savings, \% & $8 \%$ & $15 \%$ & $17 \%$ & $21 \%$ \\
\hline$\approx$ Annual savings, MEUR & $\mathbf{9 7}$ & $\mathbf{1 8 5}$ & 197 & 236 \\
\hline
\end{tabular}

A customer satisfaction survey is undertaken annually. The development of customer satisfaction has been positive. 


\begin{tabular}{|l|l|l|l|}
\hline $\begin{array}{l}\text { Customer satisfaction } \\
\text { "I am satisfied with the services of Hansel." }\end{array}$ & $01 / 2008$ & $01 / 2009$ & $01 / 2010$ \\
\hline Agree fully & $30.6 \%$ & $35.2 \%$ & $40.9 \%$ \\
\hline Agree in part & $53.5 \%$ & $52.3 \%$ & $50.0 \%$ \\
\hline Percentage of positive answers & $84.1 \%$ & $87.5 \%$ & $90.9 \%$ \\
\hline
\end{tabular}

Hansel reports regularly to the Ministry of Finance on its activities. Hansel also publishes an annual report and a sustainability report. The company also organises regular Advisory Board meetings (its members represent various ministries).

Management reports are prepared monthly at Hansel and submitted to the Board of Directors and to Hansel personnel. Customers and suppliers have access to a limited database.

\section{Important Success and Risk Factors}

Close co-operation with the owner is one of the key factors in the success of the CPS. It is essential that, in addition to the owner, customers and suppliers are also committed to the operations of the CPS. In other words, the customers and suppliers should have trust in the system and rely on the business opportunities that it offers.

It is important to maintain the high level of commercial and legal expertise in order to guarantee the quality of the operations and services of the CPS.

From a legal standpoint, it is important to follow carefully the public procurement rules in tender competitions so that customers can be assured that legal obligations are fulfilled. It is also essential that framework agreements provide legal and commercial safety to customers and suppliers. The development and use of electronic methods are essential in order to enhance the efficiency of activities.

The first main risk in managing a CPS operation is the failure to fulfil the key demands described above.

Other important risks may occur when public procurement legislation overrules the economical advantages of the procurement operation and makes the CPS operation difficult and expensive for customers to use. In Finland the complaints system generates risks, as complaints are common occurrences and are tending to increase in number. A complaint always suspends a contract, which disrupts the use of the framework agreement. The complaints system also presents severe financial risks. The new remedies system, which allows the possibility to also complain on call-offs (mini-competitions) under framework agreements, may potentially reduce the future use of framework agreements.

The tight and very detailed public procurement rules and the (mis)use of the slow complaints system cause many problems. Economic operators do not always have an adequate knowledge of public procurement rules or do not possess the practical skills required to prepare successful tenders. This situation leads to various problems in tender competitions (disqualification of tenderers or tenders, complaints, etc.). The rules concerning tenders based on framework agreements are very complicated and ambiguous. The development of simple and efficient ways for the use of framework agreements is one of Hansel's major challenges.

\section{Future Development}

One of the main goals for the future is to raise the degree of utilisation of Hansel's framework agreements. Currently the percentage is $\mathbf{5 3 \%}$, but it is estimated that the total "market share" of Hansel could reach about 70-75\% (700 - 750 million EUR). Besides raising the volume of current framework 


\section{GOV/SIGMA(2010)3/REV2}

agreements, it is critical to simplify the use of framework agreements and to find new product areas for joint procurement.

It is apparent that the demand for procurement consultancy services will increase. Hansel is responding to this demand and will offer to its customers more legal and other expert services in the future.

One of the major issues in the future will be to develop new and efficient methods for joint procurement, tender procedures and the utilization of framework agreements. These methods will most likely include electronic purchasing methods (e.g. dynamic purchasing systems). It is also important to further develop the use of electronic tools in all activities (reporting, e-invoicing, electronic communication).

Altogether, Hansel will develop its activities and make further efforts to increase savings and enhance productivity in state procurement, which is Hansel's overall aim. 


\section{ANNEX 3. FRANCE, UNION DES GROUPEMENTS D'ACHATS PUBLICS (UGAP) AND SERVICE DES ACHATS DE L'ETAT (SAE)}

\section{The Establishment of CPS - History and Rationale}

The Union des groupements d'achats publics - UGAP (Union of Public Purchasing Groups) was established by the Ministry of Education in 1949 as a central purchasing unit for goods and school furniture. In 1985, it obtained a legal status as a public body having an industrial and commercial character, with legal personality, jointly and fully controlled by the Ministry of Economy and Finance and the Ministry of Education. With time, UGAP, which deals only with supplies and services, has progressively widened its purchases to include new areas: medical equipment for hospitals, vehicles, hardware, software, stationery and ink cartridges, services to buildings (cleaning, security, removal...) etc.

Furthermore, a new entity, the Service des achats de l'Etat - SAE (State Procurement Office), was set up by Decree $n^{\circ}$ 2009-300 of 17 March 2009. Its mission is to define and implement state procurement policy for common purchases (office furniture, hardware, software, and services connected with telecommunications facilities and services, transport services, building maintenance, non-specialised vehicles, fuel, printing equipment and services, energy and financial services). For such purchases, the SAE awards framework agreements and procurement contracts or entrusts UGAP or another state administration with the task of awarding such agreements and contracts. More generally, the SAE's mission is to co-ordinate the common purchases of the state (amounting to approximately $10 \mathrm{M}$ EUR per year) and to professionalise state procurement officers.

The statute of UGAP is defined by Decree $n^{\circ} 85-801$ of 30 July 1985 and by article 9 of the Code des marchés publics (Public Procurement Code). It falls under the definition of a centralised purchasing body in accordance with Directive 2004/18/EC.

The statute of the SAE is defined by Decree $n^{\circ}$ 2009-300 of 17 March 2009. When the SAE awards procurement contracts or framework agreements, it is a central purchasing body with respect to Directive 2004/18/EC, and it is thereby obliged to respect the relevant provisions of the Code des marchés publics stemming from this directive.

Although it is a state-owned body with legal personality having an industrial and commercial character within the meaning of French law, UGAP is a body governed by public law within the meaning of EU law. As a result, all of its procurement contracts are submitted to the provisions of the Code des marchés publics (article 17 of Decree $n^{\circ} 85-801$ ).

The SAE is a state administration located within the Ministry of the Budget.

\section{Operational Strategy and Objectives}

UGAP acts strictly speaking as a central purchasing body. It buys products or services, usually through framework agreements and subsequent multi- purchase orders contracts, in order to resell them to procuring entities. It does not act as a "referencing centre" awarding framework agreements to which 
procuring entities could refer in order to directly buy products or services from the selected supplier or provider of services.

The first task of the SAE is to co-ordinate common state purchases and make sure that they are made under the most economically advantageous conditions, in compliance with sustainable development objectives, and with the aim of favouring the widest possible access to public procurement of small and medium-sized enterprises (SMEs). With these objectives in view, the SAE analyses the economic market for each group of purchases, standardises needs, and mutualises procurement procedures at the appropriate level (local, regional or national), depending on the nature of both the offer and the demand. It has been given the objective of saving $10 \%$ during the period 2009-2011 on the value of common purchases.

\section{Organisation and Finances}

The board of directors of UGAP comprises 18 persons: six are appointed by the Prime Minister to represent the Ministers of Finance (2), Health (1), Education (1) ,Defense (1) and Interior (1); six are qualified persons, also appointed by a decree of the Prime Minister; and six are elected UGAP employee representatives. The chairman of UGAP (CEO) is appointed by a decree of the President of the Republic; he/she is generally chosen (but this is not mandatory) from among the six qualified persons.

The SAE has a Purchasing Committee (Comité des achats) and a Steering Council (Conseil d'orientation). The Purchasing Committee, which comprises about 30 procurement specialists and the heads of procurement of each ministry, develops the purchasing strategies and more generally sets out proposals aimed at improving the methods and efficiency of public procurement. The Steering Council comprises Members of Parliament and representatives of the Ministers of Economy, Budget, Defence, Interior, and Sustainable Development. It supervises the activity of the Purchasing Committee. The Director of the SAE implements the orientations set by the Steering Council and is accountable for its results.

Number of staff, qualifications and typical positions

STAFF 22

\begin{tabular}{|l|c|}
\hline Permanent employees & $\begin{array}{c}\text { Number of employees } \\
\text { (EQTP 1/10/2010) }\end{array}$ \\
\hline IT & 59 \\
\hline Marketing & 75 \\
\hline Commercial network & 504 \\
\hline Law & 14 \\
\hline Purchasing and logistics & 131 \\
\hline Accounting and support & 121 \\
\hline TOTAL &
\end{tabular}

UGAP's funding is provided exclusively from the gross margin resulting from the sales realised to public bodies. UGAP does not receive any subsidies and does not have any additional activities.

The SAE is funded by the state budget. 
Yearly activity of UGAP (purchase orders receives from public entities)

\begin{tabular}{|l|r|}
\hline Year & Orders (MEUR) \\
\hline 2003 & $\mathbf{4 8 5}$ \\
\hline 2004 & 666 \\
\hline 2005 & $\mathbf{8 5 5}$ \\
\hline 2006 & $\mathbf{9 7 5}$ \\
\hline 2007 & 1142 \\
\hline 2008 & 1159 \\
\hline 2009 & 1575 \\
\hline
\end{tabular}

UGAP is intended to contribute to the efficiency of public procurement; accordingly its profitability must be minimal and any "excess profitability is returned to public entities through gross margin reductions the year after".

\section{Products, Services and Market/Supplier Approach}

The products and services sold by UGAP can be split into six groups: IT equipment, medical equipment, furniture, vehicles, respiratory masks, and services.

\begin{tabular}{|l|c|c|c|c|c|c|c|}
\hline \multicolumn{7}{|c|}{ UGAP ORDERS (MEUR) } \\
\hline Department & $\mathbf{2 0 0 3}$ & $\mathbf{2 0 0 4}$ & $\mathbf{2 0 0 5}$ & $\mathbf{2 0 0 6}$ & $\mathbf{2 0 0 7}$ & $\mathbf{2 0 0 8}$ & $\mathbf{2 0 0 9}$ \\
\hline IT & 73.6 & 169.8 & 155.9 & 163.2 & 208.8 & 254 & 304 \\
\hline $\begin{array}{l}\text { Medical } \\
\text { equipment }\end{array}$ & 70.3 & 99.7 & 143.2 & 164 & 216.1 & 239.6 & 279.3 \\
\hline Furniture & 97.3 & 108 & 130.7 & 137.5 & 154.8 & 146.6 & 152.3 \\
\hline Vehicles & 218.1 & 239.9 & 289.4 & 336.5 & 357.2 & 330.1 & 453.3 \\
\hline $\begin{array}{l}\text { Respiratory } \\
\text { masks }\end{array}$ & & & 74.4 & 93.3 & 96.4 & 19.6 & 196.1 \\
\hline Services & 25.3 & 48.9 & 62.2 & 81.3 & 109.2 & 169.6 & 190.6 \\
\hline Total & 484.6 & 666.3 & 855.8 & 975.8 & 1142.5 & 1159.5 & $\mathbf{1 5 7 5 . 6}$ \\
\hline
\end{tabular}

UGAP identifies the products and services to be proposed to public entities by analysing their needs as well as the evolution of the offer. It can also set up ad hoc working groups, including representatives of public entities, in order to better identify any evolution of the needs or the offer. In compliance with the EU Directives and with the Code des Marchés publics, requirements relating to sustainable development are introduced into the technical specifications whenever it is possible and relevant. Around one-third of the products mentioned in the UGAP Catalogue refers to eco-labels or parts thereof.

UGAP's work is broken down as follows:

- Analysis of historical data on final user purchases

- Analysis of innovative product trends

- Mass surveys of final users' needs

- $\quad$ Express requests of final users 
The SAE endeavours to harmonise the characteristics of the goods or services to be purchased by state administrations. With this aim in view, it defines the needs by referring to EU standards and by avoiding any over-qualification. Requirements relating to sustainable development are introduced into the technical specifications whenever it is possible and relevant.

The SAE has a Purchasing Committee (Comité des achats), which meets once a month. This committee is comprised of the high-level officers in charge of procurement in each ministry. The key task of the committee is to determine for each good or service the common characteristics that are acceptable for all of the administrations concerned, the best level of aggregation (local, regional and national), and the best type of contract (a classical procurement contract, a framework agreement with one contractor, or a framework agreement with several contractors that are periodically in competition).

UGAP and the SAE are fully aware that the grouping of purchases can exclude SMEs from the public procurement market. However, this negative impact can be prevented by means of technical or geographical allotment. For example, if all of the medical equipment for hospitals were to be purchased through only a single contract or framework agreement, most SMEs, since they have specialised activities, would be unable to make an offer and would therefore be excluded from competition. If the needs are divided into lots corresponding to families of products for which companies are in competition (and into types of products meeting similar needs), specialised SMEs would be able to compete in the lots corresponding to their activity.

Moreover, instead of having to prepare as many requests to participate and tenders as the number of procedures initiated by individual procuring entities, which is time-consuming and expensive, SMEs have an opportunity, thanks to the central purchasing bodies, to do business with procuring entities with which they would not normally have any business. In addition, any SME can also join with one or several other SMEs with the aim of submitting more competitive tenders. By analysing the economic structure of the offer for each family of goods and services, UGAP and the SAE make sure that the structure of their contracts or framework agreements do not exclude SMEs from public procurement; such exclusion would be contrary to the SMEs' interests but also to the interests of the procuring entities.

\section{Internal Customer Relationships}

\section{Public sectors/procuring entities covered}

UGAP covers state administrations, local authorities, and bodies governed by public law (public hospitals, social housing offices, public agencies, and some private entities or associations entrusted with a public service mission).

The SAE is competent only for the common goods and services purchased by state administrations (ministries as well as regional and local branches of ministries). However, the agencies or bodies governed by public law under the supervision of the state (for instance, public universities) may decide to take part in the implementation of the state's procurement policy as defined by the SAE.

The use of UGAP's services is not mandatory. The use of the SAE's services is mandatory for state administrations but only for common goods and services, as listed in a by-law issued by the Minister of the Budget, and voluntary for agencies or bodies governed by public law under the supervision of the state.

\section{Procurement and Contracting}

As concerns UGAP, most of the time, framework agreements are concluded with one contractor. 
Procurement procedures commonly used:

- Open procedure

$83 \%$

- Restricted procedure

$2 \%$

- Negotiated procedure with prior publication

$7 \%$

- Negotiated procedure without prior publication

$8 \%$

Award criteria commonly used:

- Common goods:

lowest price

- Complex goods as well as services :

most economically advantageous tender

Approximately $\mathbf{9 5 \%}$ of tendering files are available through electronic means of communication on the platform AchatPublic. In 2009, for 428 lots placed in competition, 1284 tenders were received, of which $5 \%$ electronically. In addition, $90 \%$ of orders are sent electronically to the suppliers. These orders result in electronic invoices in more than $40 \%$ of procedures.

The SAE uses electronic reverse auctions only for hardware. It considers that such auctions can be organised only for goods for which all of the characteristics in the tender documents can be defined electronically.

\section{Market features}

\begin{tabular}{|c|c|c|c|c|c|c|}
\hline Sector of purchase & $\begin{array}{l}\text { Total } \\
\text { number } \\
\text { of } \\
\text { suppliers } \\
\text { (1) }\end{array}$ & $\begin{array}{l}\text { Number } \\
\text { of } \\
\text { SME } \\
\text { suppliers } \\
\text { (2) }\end{array}$ & $\begin{array}{c}\% \\
\text { of } \\
\text { SME } \\
\text { suppliers }\end{array}$ & $\begin{array}{l}\text { Total } \\
\text { amount of } \\
\text { purchases } \\
\text { (thousand } \\
\text { EUR net) }\end{array}$ & $\begin{array}{l}\text { Amount of } \\
\text { SME } \\
\text { purchases } \\
\text { (thousand } \\
\text { EUR net) }\end{array}$ & $\begin{array}{c}\% \\
\text { of } \\
\text { SME } \\
\text { purchases }\end{array}$ \\
\hline $\begin{array}{l}\text { Furniture, General } \\
\text { equipment, Logistics }\end{array}$ & 239 & 198 & $82.8 \%$ & $126,687 €$ & $86,692 €$ & $68.4 \%$ \\
\hline Medical equipment & 129 & 93 & $72.1 \%$ & $195,608 €$ & $69,025 €$ & $35.3 \%$ \\
\hline IT - Telecommunications & 34 & 10 & $29.4 \%$ & $186,068 €$ & $17,201 €$ & $9.2 \%$ \\
\hline Services and fuel products & 22 & 3 & $13.6 \%$ & $101,342 €$ & $4,374 €$ & $4.3 \%$ \\
\hline Vehicles & 42 & 22 & $52.4 \%$ & $341,712 €$ & $51,429 €$ & $15.1 \%$ \\
\hline Respiratory masks (FFP2) & 6 & 4 & $66.7 \%$ & $93,303 €$ & $69,755 €$ & $74.8 \%$ \\
\hline Total UGAP & 472 & 330 & $69.9 \%$ & $1,044,720 €$ & $298,476 €$ & $28.6 \%$ \\
\hline
\end{tabular}

Of course, there is no intention to exclude foreign suppliers or to favour French suppliers over other suppliers. In fact, most foreign suppliers interested in public contracts to be awarded by French procuring entities carry out their activities in France through commercial networks comprised of subsidiary or concessionary companies or franchises. In such cases (for instance, for vehicles or computers), even if the goods purchased have been manufactured in one or several foreign countries, the contract awarded by the procuring entity is registered in statistics as a contract awarded to a French company (the local or regional subsidiary, concession or franchise). 


\section{Evaluation and Performance Measurement}

Operational savings appear to be difficult to calculate or estimate. For UGAP, only the final procuring entity is in a position to estimate these savings, but on condition that they concern the same products with the same quality of associated services. UGAP considers that procuring entities are taking advantage of the centralisation of their purchases since UGAP turnover has increased in recent years, but an indepth analysis would be necessary to determine the nature of this advantage (only lower prices, saving of time, less administrative work?).

For the SAE, it is definitely possible for state administrations to save money through the centralisation of their purchasing activities, but the main advantage is the professionalisation of procurement officers: better procurement results from the fact that needs are better defined in contracts, which in turn are awarded after wider competition or better negotiation. Centralisation is often useful, but not in all cases. However, it is true that centralisation makes professionalisation easier for small public procuring entities, as it is a way of limiting their costs of transaction while benefitting from the services of more competent purchasing officers.

\section{Important Success and Risk Factors}

The first key factor for success is to gain the support of users. If this support is lacking, users may consider that "it was better before" or "less expensive".

The second factor is to obtain a maximum competitive intensity to the tenders and to that purpose:

- understand the objectives of the industry and have a good knowledge of their cost accounting;

- $\quad$ provide them with predictability (the model of multi purchase order contract is by far the one that fits the best this objective) and potential growth;

- $\quad$ provide them with administrative cost savings through dematerialisation (one single entity to bill) and optimization of working capital needs (one single place for recovery of accounts receivable);

- $\quad$ not limit public contracting to its legal aspects, but take into consideration economic aspects as well, which means defining the needs without any over-qualification, monitoring the fulfilment of the contract, saving money and measuring the gains that have been made. The key point is to be credible. 


\section{ANNEX 4. HUNGARY, KSZF (CENTRAL SERVICES DIRECTORATE GENERAL)}

\section{The Establishment of CPS - History and Rationale}

The introduction of the Public Procurement Act (PPA) as well the current centralised public procurement system date back to 1995. Previously, two significant actors conducted centralised purchasing, namely the Ministry of Defence (MoD) and the Ministry of Interior (Mol).

After the introduction of the PPA, the government faced two challenges:

- $\quad$ the lack of professionalism to effectively conduct procurement procedures and activities;

- $\quad$ the requirement to prove the efficiency and effectiveness of the procurement system in general.

To meet these challenges, a centralised system was established by a government decree, which introduced mandatory, collaborative procurement in specific, predetermined categories between central government entities financed by the central budget and under the control of the central government. The general areas of centralised public procurement activities are listed in the government decree, while further details are provided by a ministerial guideline (State Normativ).

Initially, centralised purchasing was shared between three central procurement entities, namely the Prime Minister's Office (PMO), which was in charge of ICT contracts, the MoD of fuel contracts, and the Mol of contracts for photocopy machines and fleet management. In addition, the National Health Insurance was responsible for contracts concerning medical equipment, etc.

In the late 1990s a re-organisation took place, resulting in the establishment of a single central purchasing organisation within an independent, semi-professional structure solely owned and controlled by the PMO. In $2003 \mathrm{KSzF}$ (Central Services Directorate General), a state-controlled body with economic independence, was established by Government Decree 2722003 (XII.24.) The control of KSzF is represented by the Minister of the Prime Minister's Office.

The PPA establishes two kinds of collaborative public procurement tools: (i) for central government entities (KSzF), and (ii) for local governments. The central system is regulated by the government decree establishing KSzF, which is the contracting agency for centralised public procurement. The local system is regulated more in depth by the PPA, leaving less room for detailed regulation by local governments.

KSzF is a service provider for central government entities, for the majority of ministries, and for the PMO as facility manager of the infrastructure.

\section{Operational Strategy and Objectives}

The services provided by KSzF through the establishment of attractive framework agreements that are large enough in volume and value for the defined period of time (for a minimum of one year and typically for four years) should provide or generate savings and reduced transaction costs for the users of these framework agreements. 


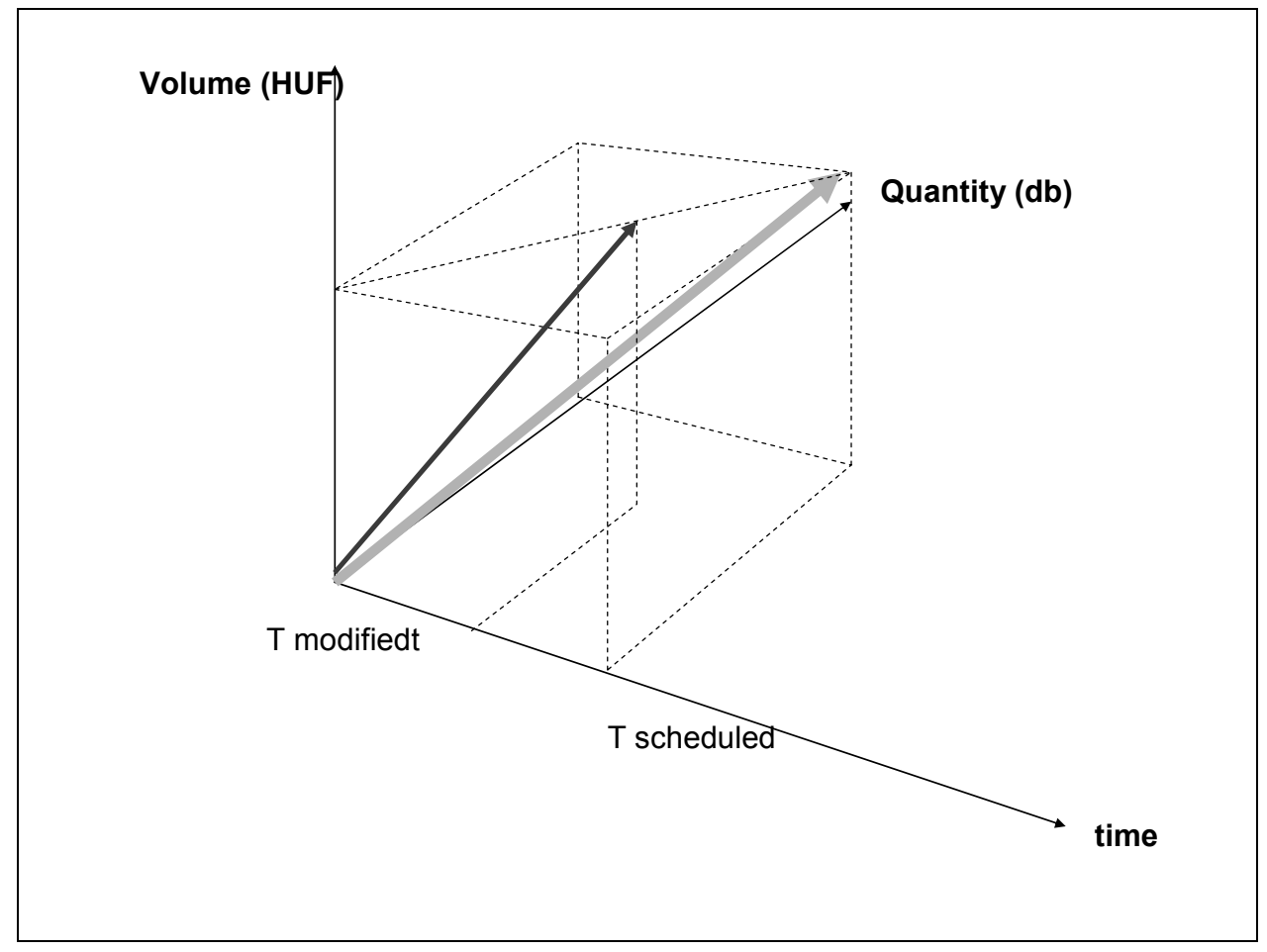

$\mathrm{KSzF}$ is to study market trends, carry out market analyses, and update the "State Normativ", before launching new procedures or at least once a year.

KSzF should further evaluate contract statistics, identify on an annual basis the procurement needs of the represented institutions, and forecast future procurement volumes, contract values, and the most appropriate period for a specific framework agreement within a particular area of its activity.

Tender planning and actual preparation of documentation are to be concluded as a combination of traditional and electronic document management processes.

Electronic aspects are in particular related to the creation of KSzF's future catalogue for a specific category based on a compilation of the main catalogues available on the supply market.

The success of the central system for framework agreements depends highly on the quality of the planning of the procurement process and the extent of good co-operation between the centralised functions (performed by KSzF) and the decentralised functions (performed by the beneficiaries) during the tendering process and in the consecutive contract management phase.

\section{Organisation and Finances}

The operational and organisational structure of $\mathrm{KSzF}$ consists of two layers:

- Layer one: "front-office" services include centralised public procurement services, supply and ITC services, and asset management;

- Layer two: "back-office" services include financial and account management services, human resources management services, and legal advisory and legislative control services.

$\mathrm{KSzF}$ is managed by a general manager, who is appointed by the Minister of the PMO. On a daily level the $\mathrm{KSzF}$ manager co-operates with the appointed Secretary of State of the PMO. 
The main front-office services are organised in directorates. Consequently, public procurement services are organised under the Public Procurement Directorate, which is further subdivided into the following departments:

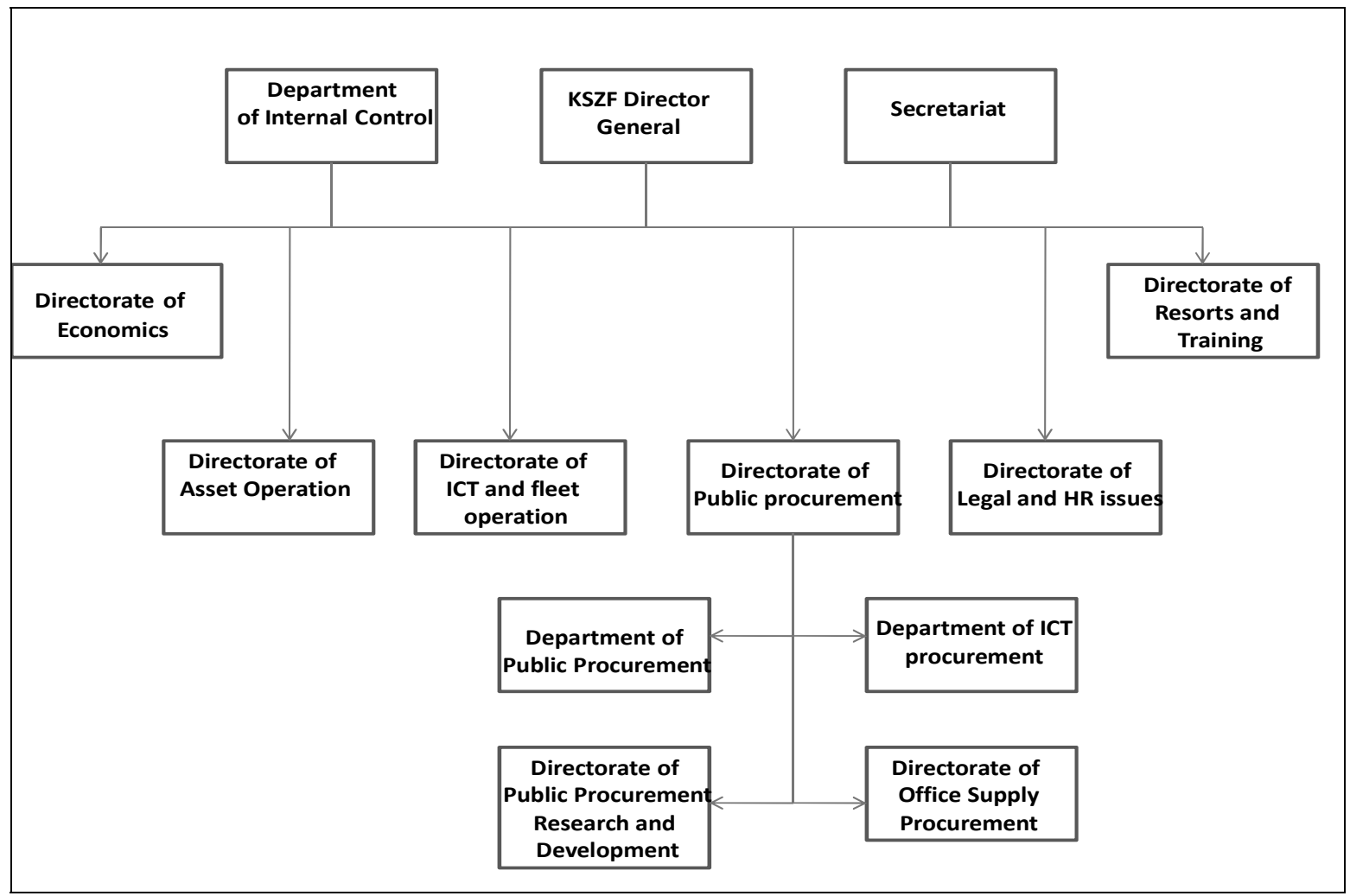

- $\quad$ Centralised public procurement service departments:

- $\quad$ ITC-profile centralised public procurement services

- Office supply-profile centralised procurement services

- $\quad$ Public procurement services for KSzF and for the PMO:

- General public procurement services

\section{- Department for Public Procurement Research and Development}

The Legal Department co-operates closely with the public procurement service departments, as there is a legal obligation to assign a legal expert for each and every public procurement procedure.

The services of the Public Procurement Research and Development Department are as follows:

- $\quad$ Centralised public procurement services have been backed by electronic support since 2003, at the beginning by an intranet (internal) system and since 2004 by an Internet-based contract management system that supports transactions between suppliers and customers/users in the post award phase of the public procurement process.

- Electronic support means in practice the operation of the ITC infrastructure, in particular the operation of the core software application to internal and external users (referred to as the "portal"). 
Both of the above services are provided as hosted facility management services.

$\mathrm{KSzF}$ is financed from two main sources: first of all, through allocations within the PMO budget structure and, secondly, by charging procuring entities with a fee - which does not exceed $\mathbf{2 \%}$ of the value of the purchases made under the framework agreements signed with and managed by KSzF. Furthermore, some revenues are provided by support projects and other supply services.

The total number of staff in the Public Procurement Directorate amounts to $\mathbf{2 6}$ people, including the directorate's management, the heads of the four departments, and technical experts and economists.

The organisation of centralised procedures for a specific category of products and services is the responsibility of the department allocated to the particular market and product segment and is managed by a small team of experts. These experts are expected to have a thorough knowledge of the market, the products and contracting techniques.

A further important task of the expert team is the regular update of the State Normativ resulting from the changes in the technology and characteristics of the product (and catalogue) categories. This update is a precondition for the initiation of any new procurement process, together with the confirmation by the representative of the Minister of the PMO.

Further details concerning procurement should be developed by a working group consisting of procurement, legal, financial and market experts of the KSzF and, importantly, experts assigned by the collaborating partner institutions.

The General Director of KSzF - as the person signing contracts (framework agreements and framework contracts) - appoints an evaluation committee that confirms the tender documentation and evaluation criteria developed by the working group and is responsible for the opening and evaluation of tenders. The tender committee prepares a recommendation to the General Director regarding the award decision.

Following publication of the award decision, the responsible expert finalises the contract documentation and uploads the electronic catalogue and all other contract-related data to the "Portal" (the web-based application by means of which KSzF communicates with the general public).

Once the contracts have been signed and become effective, the responsible expert is in charge of the management of the framework agreements as well as the catalogue management.

The purchasing partner institutions can now download the contract documentation, search for the relevant products or product classes, and place their orders (a basket engine is used to prepare orders and support decision-making activity). The order that is in the "transaction process" needs to be confirmed by the selected supplier. The transaction process continues with the confirmation of delivery, including the issuing of the invoice, and terminates with the payment transaction.

Transaction data is monitored by the responsible expert, who prepares monitoring reports with information on contract performance. This expert is also responsible for the initiation of any new procedure in due time before the contracted value or volume (or contract deadline) under the respective framework agreement has been reached. (All framework agreements within an agreed deadline have a maximum quantity or amount, which cannot be exceeded.)

Electronic systems are available in the planning phase of the procurement process and in the implementation of existing contracts. 


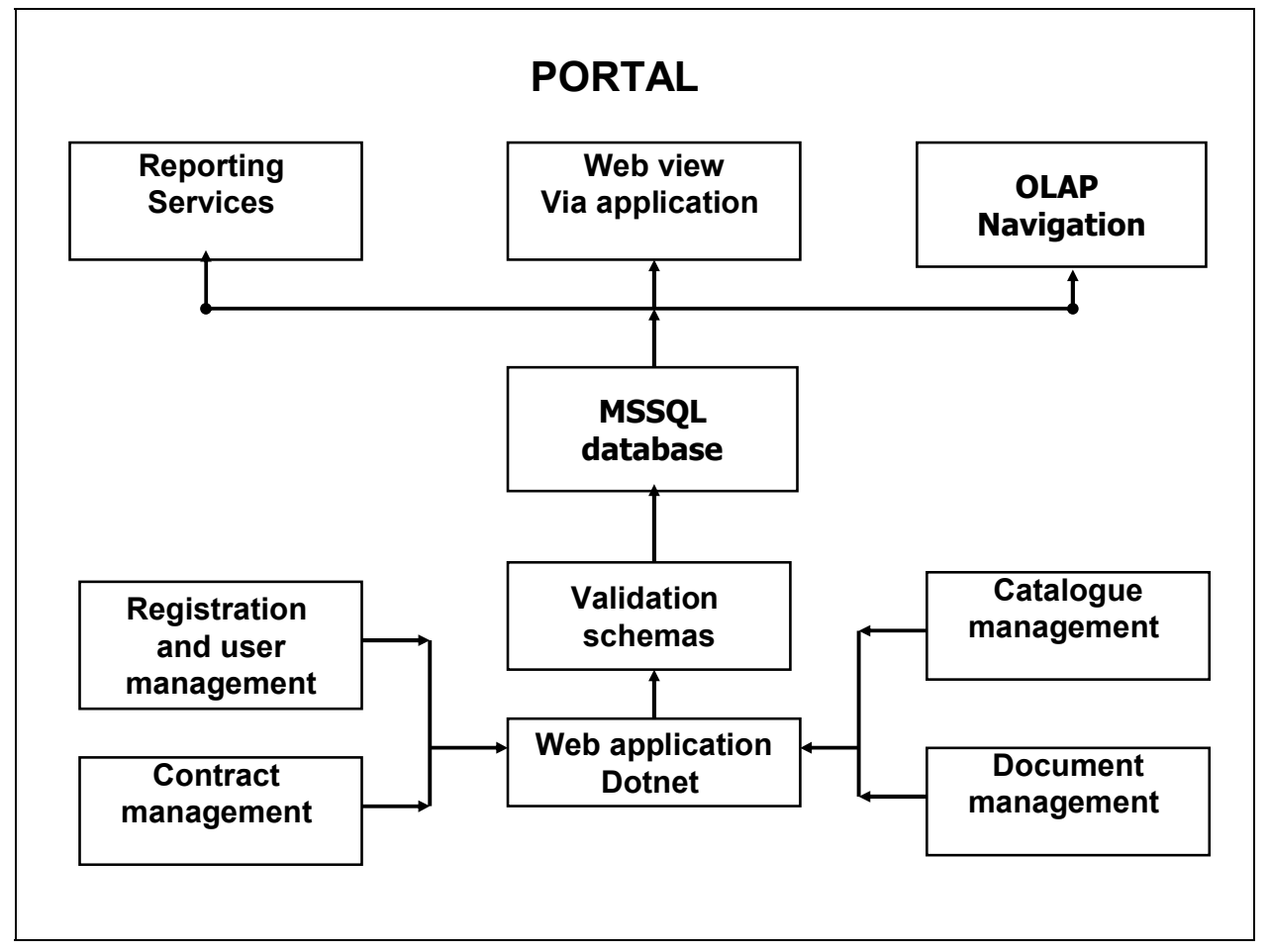

The application - besides the usual web-based and CRM services - manages the electronic cataloguerelated operations (pre-award and post-award) and the performance of the contract (typically large frameworks connecting approximately 2000 customers with 10 suppliers) in repeated purchasing cycles by supporting the call-offs made by customers. The main functionality of the application is regarded as a "contract management" system.

As mentioned above, the operations of KSzF are financed mainly by the budget and by a fee paid by the beneficiaries (institutions, procuring entities). The rate of the fees is set at a maximum of $\mathbf{2 \%}$ in order to cover the expenditures incurred by KSzF for the preparation and running of procurement procedures, the management of the contracts, and the costs related to back-office and infrastructure operations. KSzF is a non-profit organisation.

In 2008 the National Audit Office evaluated the use of the centralised public procurement fees by KSzF and provided the following charts in its report:

\begin{tabular}{|c|c|}
\hline Year & Fees (million HUF net) \\
\hline 2000 & 29.197 \\
\hline 2001 & 46.834 \\
\hline 2002 & 66.069 \\
\hline 2003 & 56.568 \\
\hline 2004 & 58.525 \\
\hline 2005 & 51.904 \\
\hline 2006 & 53.171 \\
\hline 2007 & 59.347 \\
\hline
\end{tabular}


Volume of contracts performed under the framework of centralised public procurement during the period $2005-2009$

(Thousand HUF net)

\begin{tabular}{|l|r|r|r|r|r|}
\hline \multicolumn{1}{|c|}{ Market segment } & \multicolumn{1}{c|}{$\mathbf{2 0 0 5}$} & \multicolumn{1}{c|}{$\mathbf{2 0 0 6}$} & \multicolumn{1}{c|}{$\mathbf{2 0 0 7}$} & \multicolumn{1}{c|}{$\mathbf{2 0 0 8}$} & \multicolumn{1}{c|}{$\mathbf{2 0 0 9}$} \\
\hline Info-communication & 28075512 & 27527583 & 33553267 & 45635247 & 48154255 \\
\hline Telecommunications & 3775385 & 2767775 & 2458851 & 2129525 & 1316956 \\
\hline Office equipment & 1279346 & 2173792 & 1756333 & 1502196 & 1229573 \\
\hline e-government services & & & & 1245 & 6295 \\
\hline Office furniture & 3140312 & 2820495 & 3224084 & 1972167 & 2318607 \\
\hline $\begin{array}{l}\text { Paper and office } \\
\text { supplies }\end{array}$ & 2904228 & 3007498 & 3139992 & 3595260 & 1494766 \\
\hline Vehicles & 2679542 & 1818355 & 1656368 & 957028 & 1882784 \\
\hline Fuel & 8506318 & 10037400 & 10126918 & 14317794 & 9935274 \\
\hline Medical supplies & 1544020 & 1985793 & 1829069 & 2224266 & 2809400 \\
\hline Travel services & & $1032 \mathbf{2 0 7}$ & $1604 \mathbf{7 4 4}$ & 2182066 & 2390969 \\
\hline Total & $\mathbf{5 1 9 0 4 6 6 3}$ & $\mathbf{5 3 1 7 0 ~ 8 9 8}$ & $\mathbf{5 9 3 4 9 6 2 6}$ & $\mathbf{7 4 5 1 6 7 9 4}$ & $\mathbf{7 1 6 0 6 3 0 3}$ \\
\hline
\end{tabular}

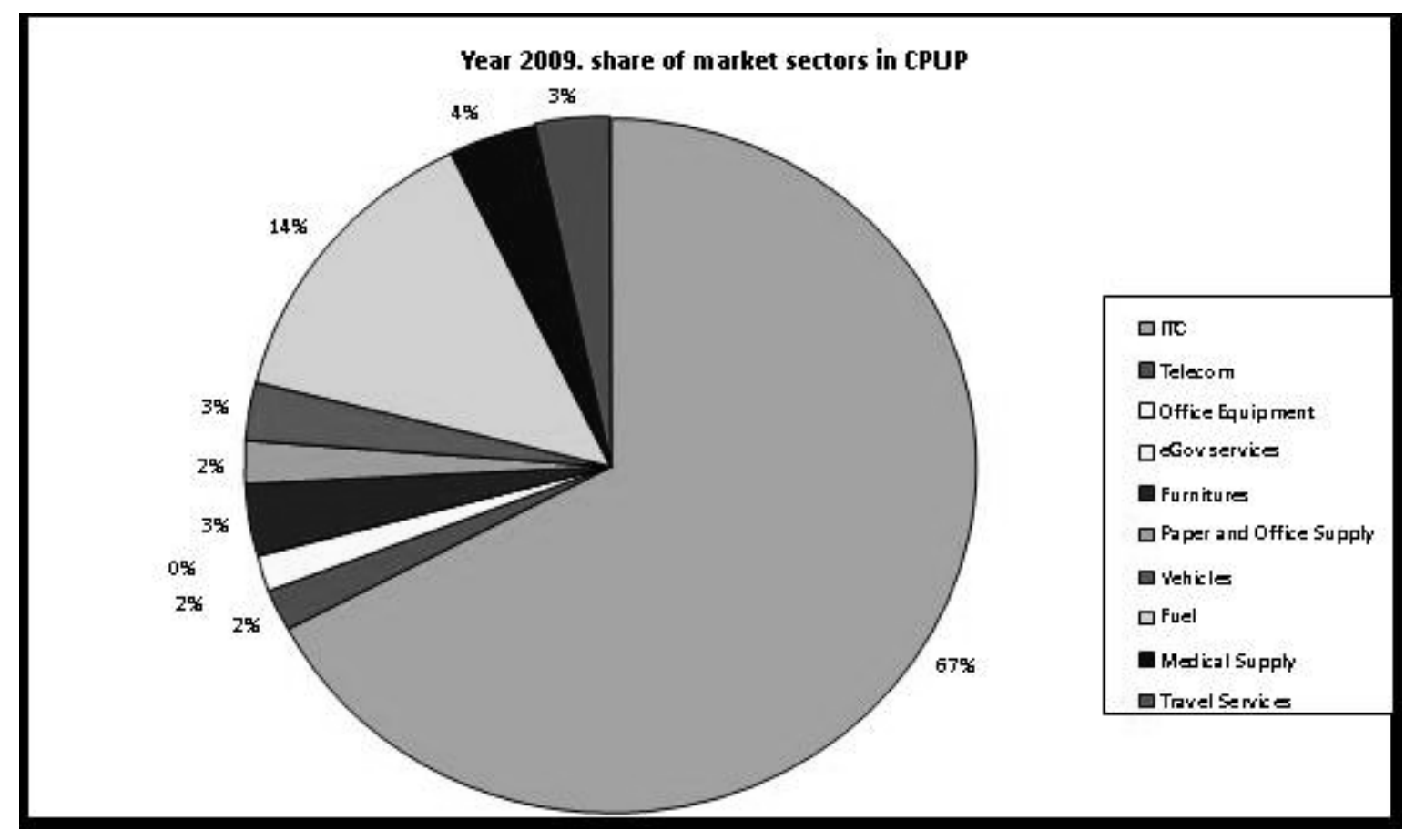




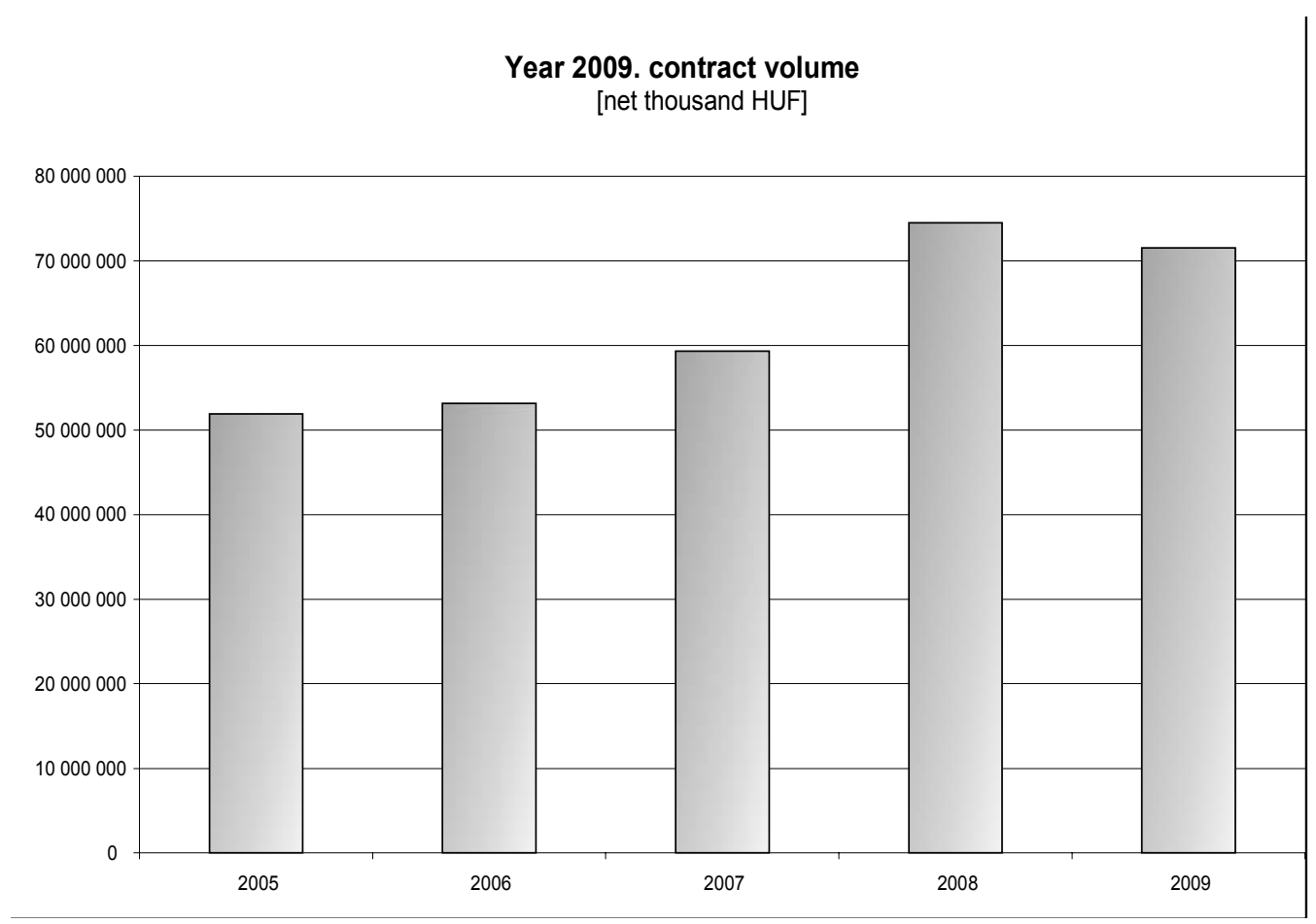

\section{Products, Services and Market/Supplier Approach}

The products and services subject to centralised public procurement are defined by the ministerial guideline (State Normativ). The guideline includes a description of the methodology used for the update and management of the system. At present the categories are defined in terms of functional requirements to be met by the parameters of the products offered by economic operators. The most significant parameters are included in the normative standards and may be set for evaluation purposes. Function-carrying parameters are defined by a "value analysis" methodology. Revisions and updates of the normative standards must be provided on schedule and in due time before a new procurement process is launched or as changes in a product's life cycle is forecasted by market trends.

The development of catalogues is supported by KSzF's own electronic system, referred to as the "catalogue factory".

Products and services to be included in the framework agreement system should have a high and stable demand over time and should be readily available on a competitive basis in the market. Consequently, a variety of products should exist, and it should be possible, in a harmonised manner, to describe, classify and "catalogue" them in relation to each other and in compliance with related standards.

Delivery services may vary to the extent that the customers assume these tasks themselves. There is a set distance within which delivery services are not supposed to be charged (50 km or within town perimeters).

Any statistics produced are based on transaction data. Transaction data are being collected as part of the contract management process in ready-made formats, covering various dimensions of data, and then linked to a central database, set up as follows:

- customer

- supplier 
- time, date

- contract, procedure, lot

- category

- product

- price

The "market share" of central purchasing services in the national public procurement market is $\mathbf{7 - 8 \%}$ which makes KSzF one of the key public sector buyers (in the top ten of procuring entities).

The process for market and supplier analyses is defined by a dynamic and attribute-based classification system, which defines categories as "statistic" entities. Product or catalogue categories are positioned in a hierarchy, which enables the matching of new and old categories.

There is no explicit SME policy since the majority of economic operators in the Hungarian market fall within the SME category. The framework contracts that are awarded generally require nationwide coverage for the supply of goods and services. For this reason, tenderers frequently submit their offers in the form of "consortiums", thereby allowing small or rather "micro" enterprises to act as sub-contractors formulating supply-clusters.

\section{Internal Customer Relationships}

Public sectors/procuring entities covered by the Central Purchasing System (CPS) include on a mandatory basis central government entities and entities covered by the National Health Insurance (hospitals). The basic factor in the classification of partners is the budget source and the way in which the government exercises control over the use of the budget.

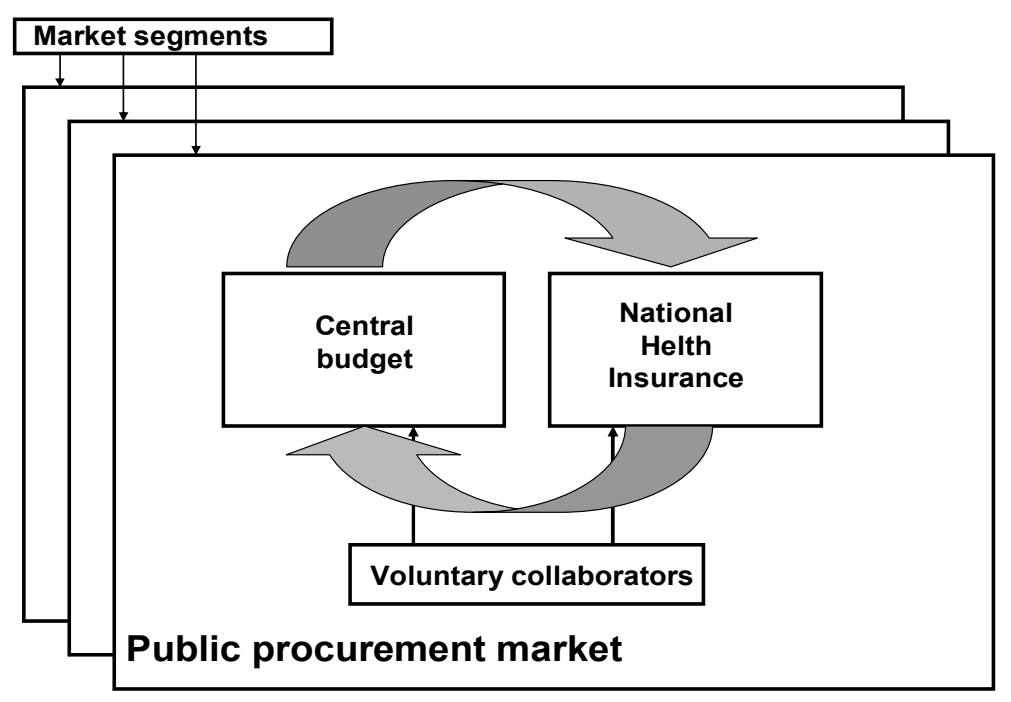

Excluded from the CPS are universities, local governments, state-owned companies, and concession service-providers. These groups of entities are eligible for voluntary collaboration with the CPS.

Main customers are ministries with large annual budgets and with purchasing volumes that are proportional to the overall budgets. 


\begin{tabular}{|c|c|}
\hline Customer & Net volume \\
\hline Hungarian Tax Agency & 8932295091.51 \\
\hline National Health Insurance & 2940737544.26 \\
\hline National Treasury & 2550228473.34 \\
\hline Agricultural Administration Office & 2467535206.16 \\
\hline Central Services Directorate General & 2453766314.86 \\
\hline Hungarian Post Shareholding Company & 2044351125.05 \\
\hline Administration Office of Social Issues & 1975347341.72 \\
\hline National Telecommunications Office & 1906098349.26 \\
\hline $\begin{array}{l}\text { National Road Management Office Shareholding } \\
\text { Company }\end{array}$ & 1572427924.42 \\
\hline $\begin{array}{l}\text { Prime Minister's Office Electronic Government } \\
\text { Centre }\end{array}$ & 1432776746.62 \\
\hline Top 10 Total & 28275564117.18 \\
\hline TOTAL & 78015576106.13 \\
\hline Supplier & Net volume \\
\hline $\begin{array}{l}\text { MOL National Oil and Gas Industrial Shareholding } \\
\text { Company }\end{array}$ & 9938789807.57 \\
\hline $\begin{array}{l}\text { Delta ICT Trading and Service Provider } \\
\text { Shareholding Company }\end{array}$ & 7191715660.09 \\
\hline KFKI System Integration Shareholding Company & 3405401964.22 \\
\hline $\begin{array}{l}\text { EURO ONE Computer Technical Shareholding } \\
\text { Company }\end{array}$ & 3390219751.88 \\
\hline $\begin{array}{l}\text { Inter-Computer-Informatics Computer Technical } \\
\text { and Trading Shareholding Company }\end{array}$ & 3254708322.31 \\
\hline Hewlett-Packard Informatics Ltd. & 3013523964.00 \\
\hline $\begin{array}{l}\text { RacioNet Computer Technical and Trading } \\
\text { Shareholding Company }\end{array}$ & 2632978907.34 \\
\hline $\begin{array}{l}\text { Answare Computer Technical Network Service } \\
\text { Provider Ltd. }\end{array}$ & 2340954010.00 \\
\hline $\begin{array}{l}\text { WSH Computer Technical and Training Service } \\
\text { Provider Ltd. }\end{array}$ & 2000248557.43 \\
\hline Nádor System House and Office Automation Ltd. & 1959521277.87 \\
\hline Top 10 Total & 39128062222.71 \\
\hline TOTAL & 78015576106.13 \\
\hline
\end{tabular}

As mentioned above, the central purchasing system is obligatory for central government entities and voluntary for other public sector entities. Voluntary collaborators are welcome to join the system. Prior to their enrolment they have to register in the system and indicate and confirm their procurement volume 
forecast. Those collaborators accepted are only allowed to carry out procurement up to the volume that has been confirmed within the system.

\section{Procurement and Contracting}

Planning procedures actually mean the composition of the Central Contracting Agency (CCA) master catalogue, which is based on the harmonised catalogues of the suppliers that have been selected for framework agreements. The planning steps along the contract layers are as follows:

- $\quad$ Tender procedure

- $\quad$ LOT (independent bids under the tender)

- Group of framework agreements

- Individual framework agreements

- Framework contracts or individual contracts

- $\quad$ Delivery units

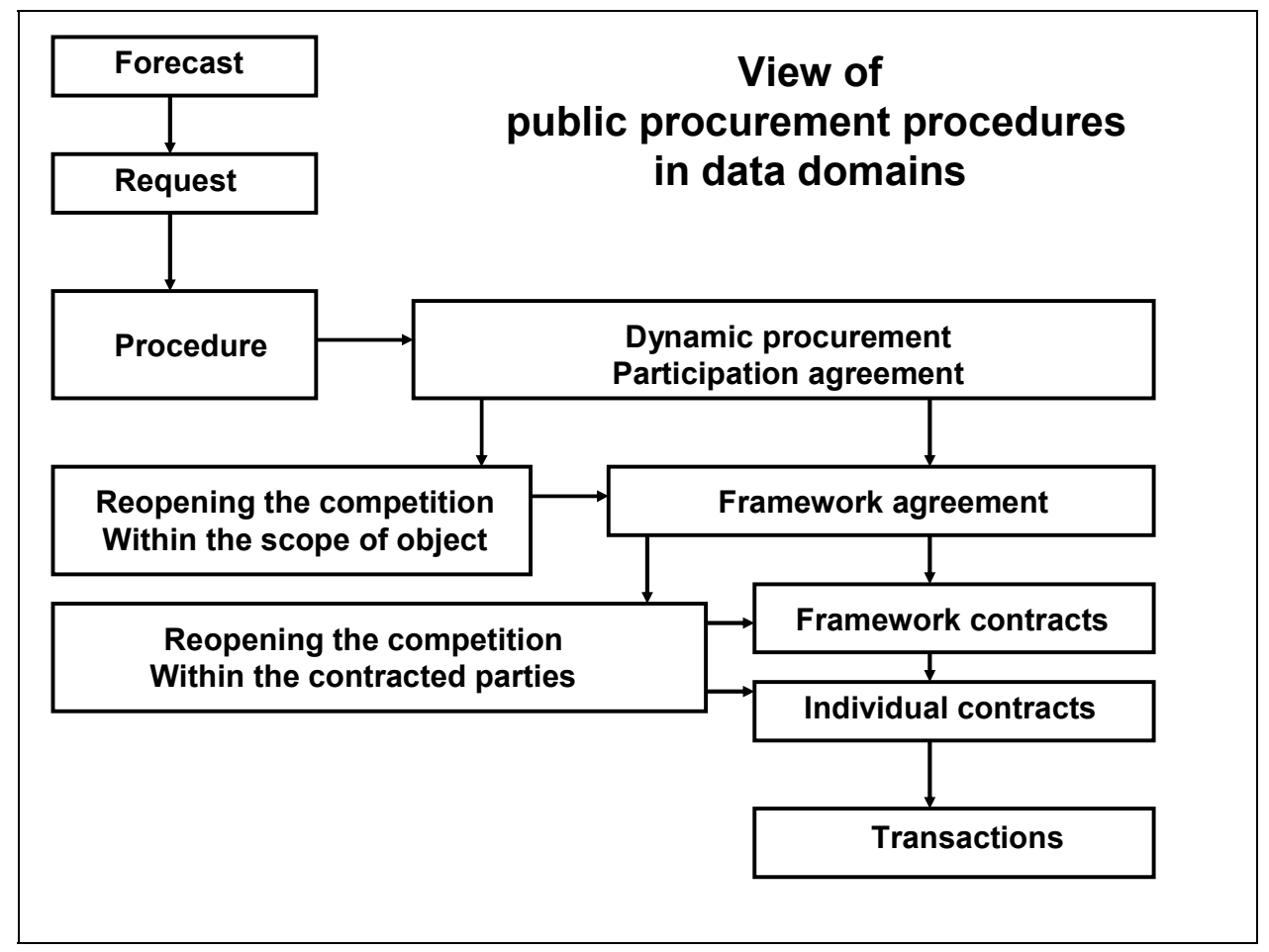

$\mathrm{KSzF}$ uses multiple framework agreements. The typical number of individual framework agreements varies between 3 and 10. Main contractors in individual contracts generally form a consortium of three to five economic operators. Main contractors in a consortium usually have 10-20 subcontractors for nationwide services.

The evaluation pattern of framework agreement-based procedures takes into consideration the share of activities along the phases between CCA (centralised level) and identical beneficiary contracting agencies (CA) (decentralised level).

The process for the establishment of the delivery contract in the second stage of the framework agreement may vary as follows. 


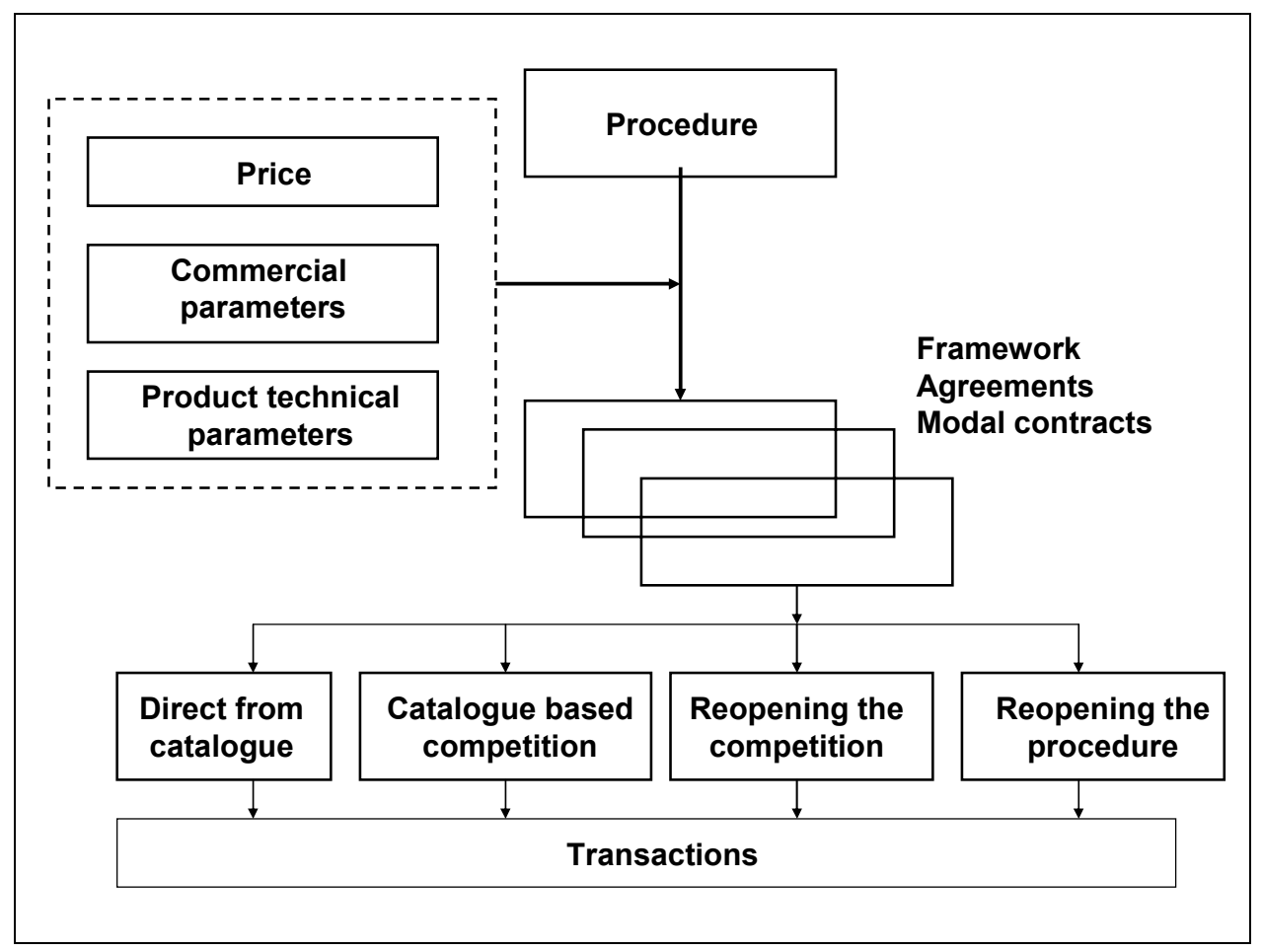

$\mathrm{KSzF}$ applies the open procedure in the majority of cases to set up the framework agreements. The negotiated procedure is rarely used. Electronic auctions can be used in both the first and second stages of framework agreements. In open procedures the use of e-auctions is mandatory, as stipulated in the government decree on centralised public procurement.

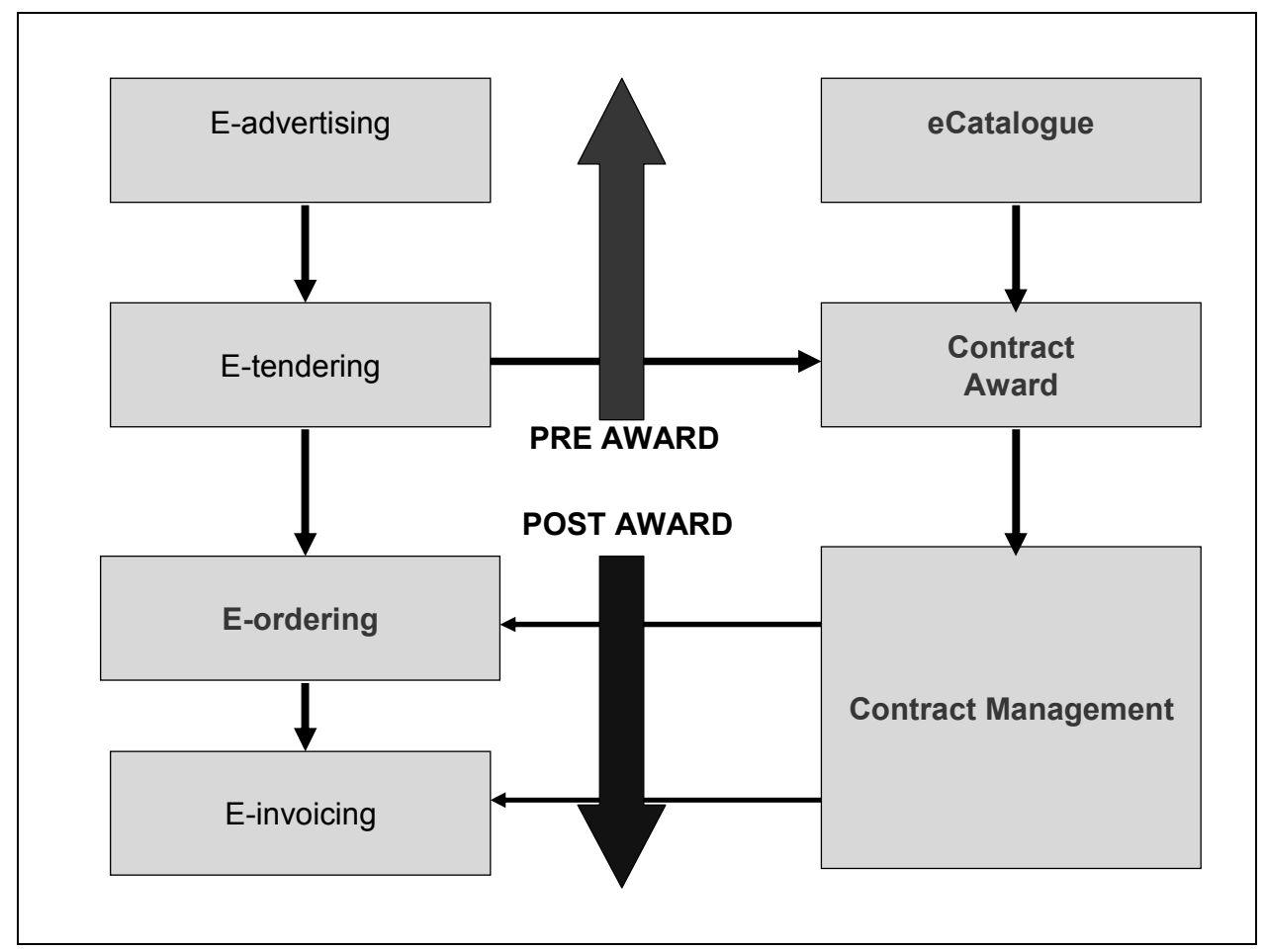


Following the technical evaluation, those products determined to be "acceptable" by KSzF are ranked in the order of price in the first stage of the award of framework agreements. To facilitate the evaluation of complex offers (huge supply catalogues), KSZF uses "model configurations" of a pre-defined set of products and "model contracts" tailored to general business cases. These models should always be used by procuring entities when they are "buying from the catalogue". Award criteria can be either the lowest price or the economically most advantageous tender.

As mentioned above, electronic support for the tendering procedure, contract planning and contract management is used.

As e-auctions are one of the services that are "standardised" in the State Normativ, KSzF provides framework agreements for providers of e-auction services to be used by the beneficiary institutions as "outsourced" services.

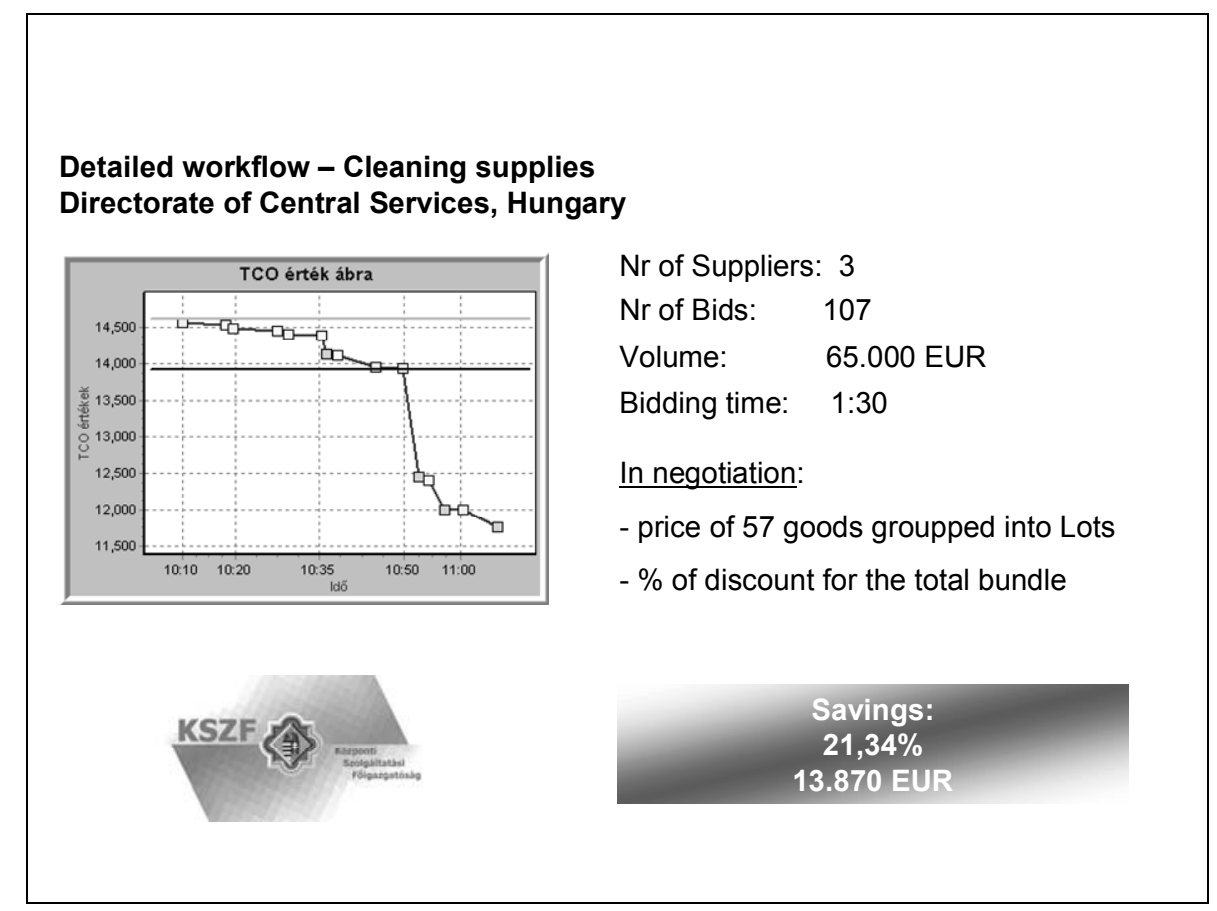

The use of e-auctions might drastically reduce the usual time consumption required to complete public procurement procedures. 


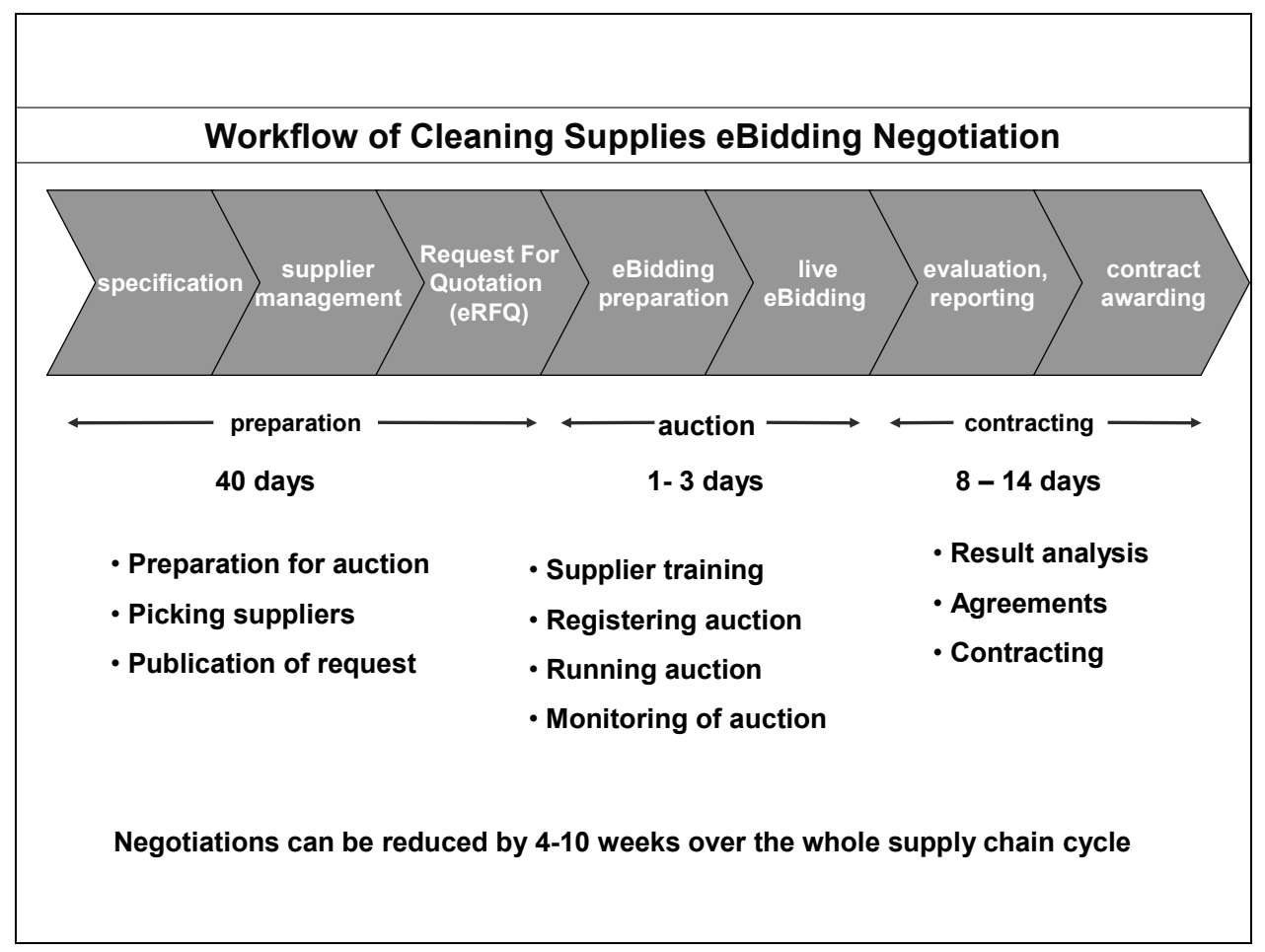

Complaints and standstill obligations are handled in accordance with the Public Procurement Act (PPA) by the Arbitration Board of the Public Procurement Council.

The competitive situation is generally satisfactory for the award of framework agreements.

\section{Evaluation and Performance Measurement}

The savings made under framework agreements are calculated and displayed by means of a comparison of the prices agreed and the normal market prices published by the framework supplier. The price lists in the catalogue of a particular supplier includes a "public price" list and a guaranteed discount rate. Basically, these figures are to be taken into account when KSzF advertises the "results" of the procurement procedure's effectiveness.

No particular measures are being taken to analyse the potential market effects of the CPS, although there are worries that the CPS might create a monopolistic situation in specific segments of the market, augment the risk of formation of cartels, and increase the occurrence of corruption.

No regular customer satisfaction surveys are undertaken in order to measure the performance of the CPS, and no benchmarking indicators are determined. The web portal supporting the CPS activity has a "forum" (and a corresponding FAQ section) where registered, logged-in users may ask questions, add notes, send compliances and receive answers either directly or for public view in the FAQ section. No anonymous notes and comments are processed.

\section{Important Success and Risk Factors}

The key prerequisites that need to be in place for the successful outcome of CPS operations are the followings: 
a) The government decree on centralised public procurement allows for minor deviations from the provisions of the Public Procurement Act (PPA). Such deviations could lead to unclear situations in the event of complaint procedures.

b) The category management of CPS is regulated in a ministerial guideline. The use of electronic catalogues, as stipulated by this guideline, compared with the use of electronic catalogues developed by industrial or cross-sector standards, places an extra workload on economic operators. This situation generates resistance to the use of e-catalogues on the supplier side.

c) Although there is a specific government decree stipulating the use of electronic actions to perform actions set out in the PPA, there is no clear business model for the use of electronic procurement, and in particular no model for the use of standardised e-commerce services available on the market. Electronic support in the post-award phase should be prepared in a relatively short period of time between the date of the contract award and the date of signing and publishing the contract. The processing of data concerning content-rich contracts could cause delays or affect the quality of support.

The main risks in managing a CPS operation are the followings:

a) Delays in the update of "State Normativ" of the guideline for category management;

b) An unsuccessful centralised tendering procedure could create an uncertain situation in the supply of entities with valid, ongoing contracts in the system;

c) If the validity of a particular contract (framework agreement) is too short, there is a risk that there will not be enough time to prepare and carry out the subsequent procedure to establish the consecutive contracts in specific categories;

d) If - by chance - the purchase of goods under a particular contract is not proportional to the elapsed time of validity of the contract (in an extreme case, if customers are not at all buying the products available under the contract, so that contract performance is "too slow"), KSZF would not receive sufficient fees to compensate for the cost of setting up and managing the contract.

The main problems or obstacles in managing a successful CPS operation today are:

a) Collection of requirements: Entities under the regime of the centralised public procurement system are obliged to forward annually their procurement plans in due time - by mid-April, as stipulated in the PPA. Since contracts in the centralised public procurement system may terminate at different times, procuring entities also have to sign or update their procurement requirements quarterly, as required by the government decree on centralised public procurement. There might be a particular period during which KSZF requires data, but where there happens to be no confirmed budget. The use of statistical calculations to forecast procurement requirements is not encouraged by the legal system.

b) Aggregation phenomena of centralised procurement requirements is not in line with day-to-day experience: The aggregation of plans provided in detail with rough forecasts of procurement requirements could create uncertain situations.

c) Management of the procurement performance of customers in line with their forecast indications of requirements: Procuring entities might place orders that more or less exceed the amount indicated in the Framework Agreement. Such behaviour could result in an uncertain fulfilment of the contract or a "slow" performance of the contract, which altogether makes the planning and management of contracts problematic. 
d) Management of the enrolment of voluntary collaborators: Voluntary collaborators may join the system with the prior confirmation of KSzF. This confirmation means that the official in charge of the management of the particular contract checks the threshold level of the contract volume or value and, if there is enough leeway, may suggest the confirmation of the request. This kind of collaboration should fit into the EU's regime for below the threshold level, but it leaves doubts concerning the extent to which the EU's above-threshold tender rules are followed.

e) Making electronic versions "authentic": KSzF electronic support covers mainly the post-award phase of public procurement, which terminates with invoicing and payment. Unfortunately, the financial regulation that is applied government-wide does not enable the use of electronic invoices. The placed order and the contract are indispensable elements of the invoice documentation, but since the "official" invoice must be in printed form all of the other original documents (orders, delivery documents, and the relevant contract) should also exist in printed form. Therefore, electronic documents created in the supporting application cannot be used as authentic electronic documents.

f) Partner identification and authentication: In relation to the use of electronic documents, the identification and authentication of the users of the electronic supporting system should be regulated. Definitions of actions and of acceptable ways and modes of authentication should be clearly stated (Electronic Data Interchange - EDI - scenario, e-signature).

\section{Future Development}

Since KSzF participates in the PEPPOL (Pan-European Public Procurement Online) project, the main concern is to align KSzF activities with PEPPOL's strategic plan. PEPPOL's strategic plan is being developed on the basis of a service-oriented business architecture model, with defined technology for the creation of structured electronic documents (UBL XML). The communication of these documents is being defined by CEN BII standards, with further customisation in PEPPOL workshops. Since KSZF is a member of the PEPPOL project - it is currently participating in the activities of two horizontal working groups - the harmonisation of electronic document technology and communication should be aligned with those of the PEPPOL project. Since the approach to business profiles in the PEPPOL project slightly differs from that of KSZF's present application, both the business architecture and the process should be modified to a certain extent. To perform that task, KSzF needs to modify or develop the following business functions:.

- $\quad$ The business model;

- The business architecture;

- $\quad$ The financial model;

- $\quad$ Standardisation of services;

- $\quad$ Enlarged scope of services and partners involved;

- Initialisation of the update of the related government decree;

- Harmonisation of core activities with EU trends;

- Introduction of benchmarking and SOA-based operations.

The main concern for the development strategy is focused on SOA (Service-Oriented Architecture), not exclusively for the ITC infrastructure but for the business infrastructure as well. 
Business Architecture

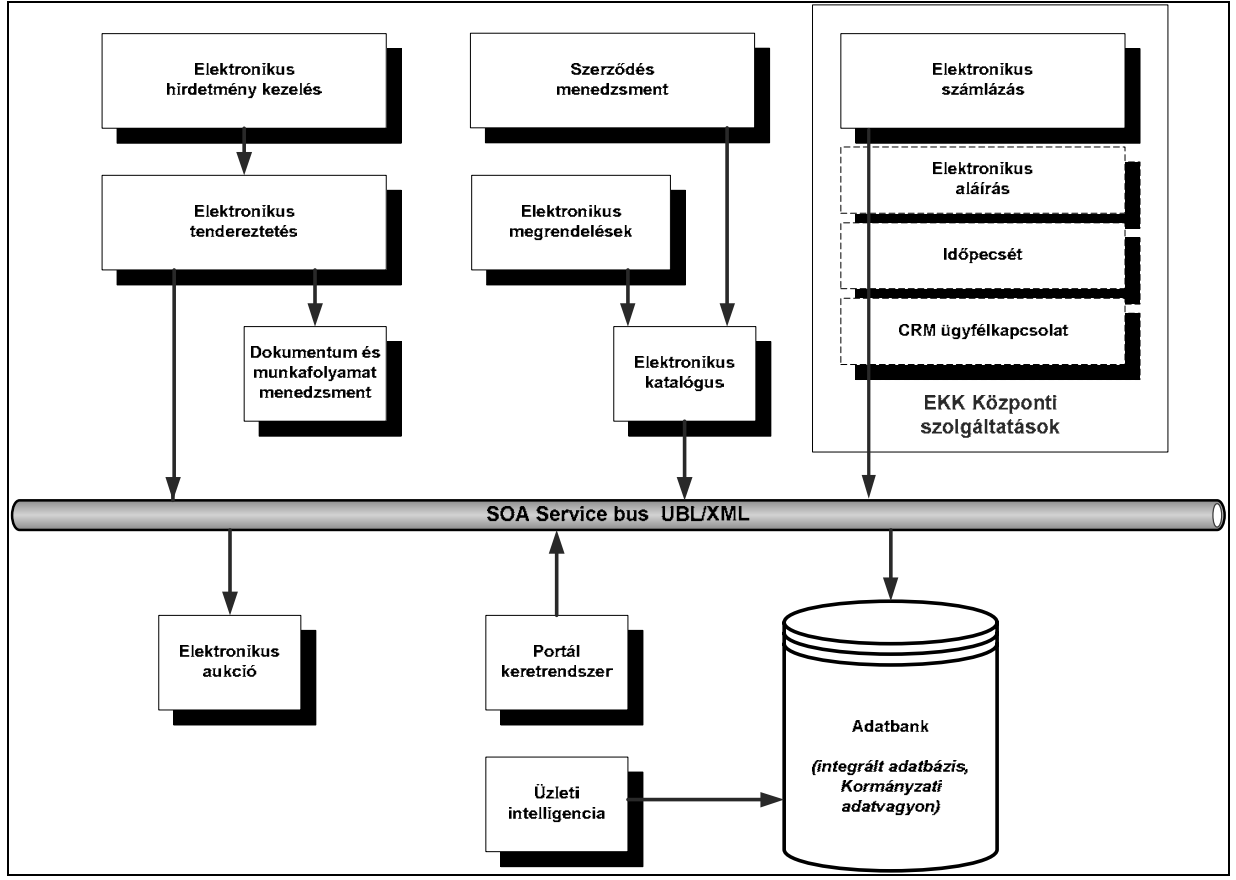

ITC Architecture

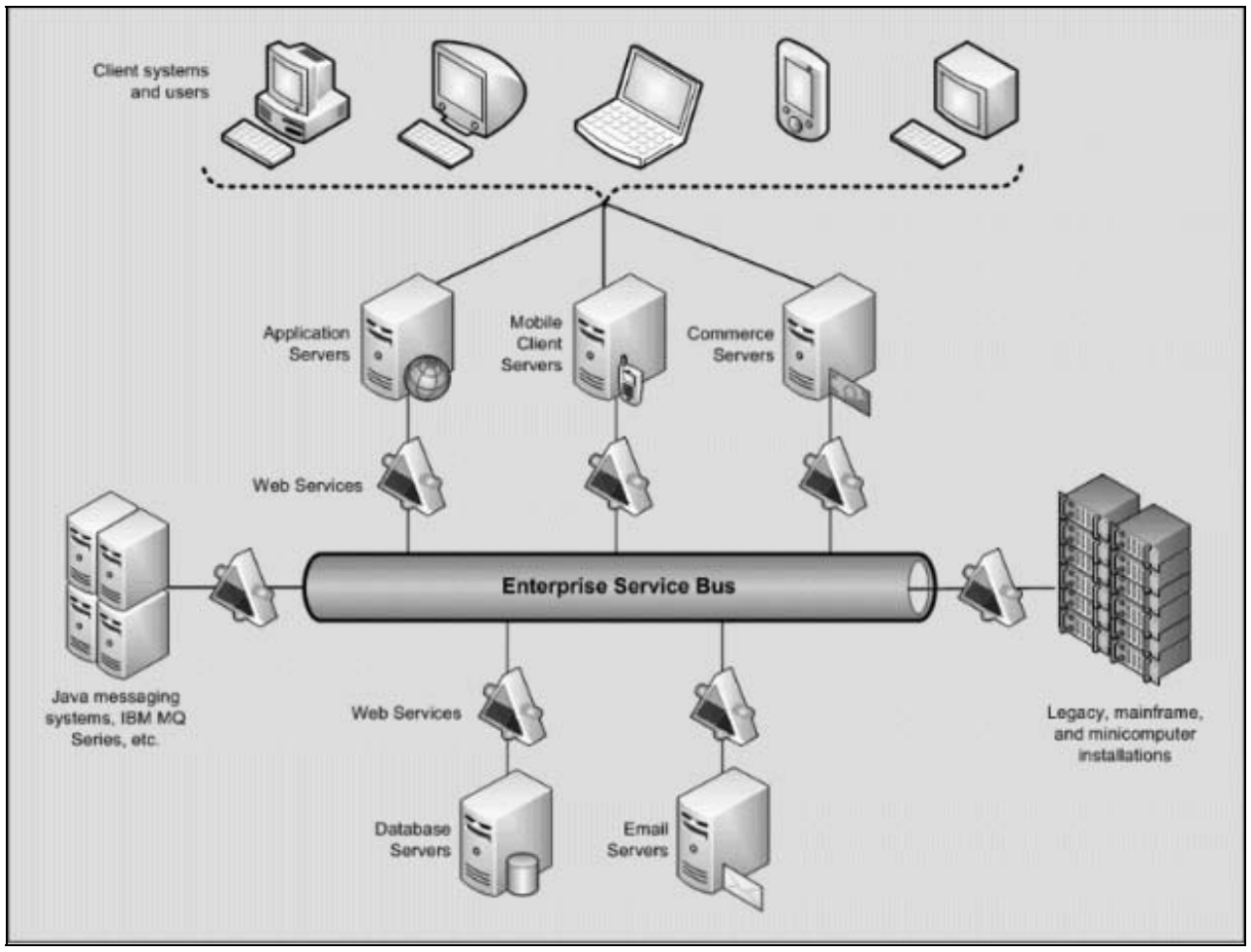




\section{ANNEX 5. ITALY, CONSIP S.P.A}

\section{The Establishment of CPS - History and Rationale}

Consip S.p.A. - whose original name was CON.S.I.P., acronym for Concessionaria Servizi Informativi Pubblici - operates exclusively on behalf of the state, with the aim of engaging in information technology, consultancy and support of public administration activities.

The company was established in the course of 1998 as an operative tool to radically change information technology management in what was then the Ministry of the Treasury, the Budget and Economic Planning. Specifically, Legislative Decree No. 414 of 19 November 1997 entrusted Consip with the state administration's information technology activity in the areas of finance and accounting. Later, with the Minister of the Treasury Decrees of 22 December 1997 and 17 June 1998, the company was given the task of managing and developing the information technology services of the same ministry.

Following the same logic of a continuing effort to use information technologies in supporting change, the 2000 Budget Law identified Consip as the service structure for the provision of goods and services on behalf of public administrations. The Budget Laws of the following years defined the regulations to be abided by the company in the implementation in what has become the Programme for the Rationalisation of Public Expenditure in Goods and Services ("the Programme") .

The organisational structure of Consip reflects the company's orientation towards clients, services and projects through the support of common and centralised functions. The organisational chart is consistent with a functional model and meets two crucial requirements:

The concentration of similar competences within the same work groups, allowing for a better integration of resources and avoiding inefficiency and dispersion of work and efforts;

The reduction of hierarchical levels, thereby facilitating horizontal interaction and increasing the delegation of responsibilities to individuals.

The Italian Parliament designed the "Programme to Rationalise Public Spending on Goods and Services" in the $\mathbf{2 0 0 0}$ Budget Law, which is the regulatory instrument for the Programme ${ }_{2}$ and gave to the Ministry of Economy and Finance the responsibility for developing and managing the Programme. Consip was identified as the service structure for the provision of goods and services on behalf of public administrations.

The Budget Laws of the following years defined the regulations by which the company had to abide in the implementation of the Programme.

Other relevant regulatory instruments are: D.P.R. n. 101/2002 (President's Decree) and, as Italy is an EU Member State, Directive 2004/18/EC, which was transposed in the Italian Code for Public Contracts (Codice degli appalti, D.Lgs. 12/04/2006, n. 163)

Consip is a joint-stock company that is entirely and directly the property of the Ministry of Economy and Finance.

\section{Operational Strategy and Objectives}

The main objectives of Consip are as follows:

- $\quad$ Streamlining of procurement processes; 
- $\quad$ Aggregation of demand through the use of framework agreements, mostly with fixed terms and conditions (also known as frame contracts);

- Identification of innovative areas for the rationalisation of expenditure and the promotion of innovative e-procurement tools;

- Implementation of "tailored" projects on behalf of individual public administrations.

\section{Organisation and Finances}

In order to meet complex challenges, Consip has devised for itself an organisation that is focused on users and oriented towards services and projects. The organisation has been developed to ensure:

- Focus on the growth of professional competences, on the correct allocation of resources to projects and services, and on corporate organisation and processes;

- Emphasis on relations with users and on project development;

- Development of specific competences within the company's line structures, both to increase the speed, effectiveness and flexibility of response to specific user requirements and to focus attention and internal resource efforts on the needs and priorities of each department;

- An appropriate focus, through the integration of know-how, on the comprehensive coherence of initiatives in terms of planning, quality standards, modalities for the acquisition of goods and services, project monitoring, and compatibility of application and technological structures.

The operational model of the organisation has recently moved from a divisional to a functional model. The value chain, composed of planning and control, business management, innovation and development phases - which previously crossed every corporate division vertically - now follows a horizontal path across all corporate business areas.

The Public Procurement Division (DAPA) implements Consip's procurement strategies.

(organisational chart below)

Approximately 140 people work in DAPA. A few comments can be made on the organisational chart of DAPA, which reflects Consip's working methods:

- $\quad$ Five units deal with sets of goods and services, interacting often with the supply market in order to obtain a state-of-the-art picture of the relevant markets.

- The unit "e-Procurement Strategies" develops innovative e-procurement solutions (e.g. new functionalities of the ministry's procurement platform).

- One (large) unit is in charge of gathering suggestions/comments from public administrations and exploring with them the best e-procurement solutions.

- The unit "Programming and Monitoring" performs two main tasks: i) gathering of evidence concerning the nature and value of the public sector's demand for a set of goods and services; and ii) supervision of Consip's efforts in monitoring the extent to which selected contractors for frame contracts deliver quality standards that are in line with technical specifications.

The working methods and day-to-day operations of Consip are governed by two basic guidelines. On the one hand, its methods and operations reflect the continuous pursuit of corporate effectiveness and efficiency, based mainly on the competence, responsibility and co-operation of its personnel rather than 
on mere compliance with organisational instructions. On the other hand, they ensure a clear process that guarantees the achievement of corporate goals in as transparent a way as possible. In the case of the tender process, every single step is documented and supported by the required tools, starting from the definition of the tender strategy and up until the completion of the process.

Consip's electronic procurement system relies mainly on three different tools:

- The Frame Contracts System. This tool consists of competitively awarded "frame contracts" according to which contractors undertake to accept orders from public administrations - at established conditions and prices - up to a predetermined monetary amount or quantity of goods or, in any case, until the expiry date of the frame contract. Administrations send their orders for supplies (by fax or online) directly to the contractors. All public administrations can make use of frame contracts, undertaking purchases for amounts that may even be above the EU threshold, without having to resort to a tender. According to the provisions of the 2007 Budget Law, state administrations (excluding schools and universities) are mandated to use frame contracts for particular categories of goods that are specified every year in a decree issued by the Ministry of Economy and Finance (mandatory frame contracts).

- The Electronic Marketplace of the Public Administration (MEPA). This tool is designed to support purchases below the EU threshold and to encourage the participation of small and medium-sized enterprises in the purchasing programme. The MEPA is an authentic electronic marketplace found on the Consip website (www.acquistinretepa.it), where authorised suppliers can offer their goods and services directly online. Public administrations that are registered with MEPA can consult the catalogues for offers and make purchase orders or offer requests directly online. In order to conclude transactions, both the administrations and the companies must have a digital signature (and of course a computer and an Internet connection). MEPA is designed to complement the Frame Contracts System and is suitable for the purchase of goods and services that are not suitable for purchase through that system due to their particular features or to the type of needs that they aim to satisfy (e.g. frequent, fragmented purchases, in small quantities, with specific service options).

- $\quad$ e-tenders. This tool should not be confused with "e-auctions" as defined by Directive 2004/18/EC. E-tenders constitute a paper-free, competitive tendering process, and they are normally used for awarding contracts concerning products with technical specifications that are objectively measurable. E-tenders are often used to fulfil specific (i.e. tailored) procurement needs of public administrations.

The financing of Consip's operations is secured through a three-year framework agreement with the Ministry of Economy and Finance. The ministry provides the financial resources that are required for corporate activity in two parts: (i) a fixed amount; and (ii) a variable amount that is tied to the achievements of jointly-defined objectives of the Programme for the Rationalisation of Public Expenditure in Goods and Services. 
The turnover in 2009 related to public procurement activities and to the overall profitability level was as follows:

\begin{tabular}{|l|c|c|}
\hline & Turnover & Profitability \\
\hline 2009 & 45 million EUR & $(*)$ \\
\hline
\end{tabular}

$(*)$ It would be inappropriate to use standard measures of profitability for Consip, since any profit is immediately transformed into reserves. Other measures of financial and economic performance have been designed, such as the amount of savings in euros generated by the Programme for each euro invested in the Program by the ministry.

\section{Products, Services and Market/Supplier Approach}

Products and services covered by the CPS are in the following areas:

- Health care (e.g. ambulances, diagnostic equipment, services for managing health care equipment);

- $\quad$ Fuel (for heating and transport) and electricity;

- $\quad$ Office goods/equipment (printers, photocopiers, PCs, servers, software);

- $\quad$ Transportation (car purchase and rental);

- $\quad$ Facility management (for offices, hospitals);

- Telecommunications (networks, mobile phones, landline phones, telephone exchanges);

- $\quad$ Furniture (for offices, schools, universities);

- Insurance and financial services (credit cards);

- $\quad$ Food (foodstuffs, meal tickets).

Before issuing any calls for tender and, more generally, before initiating any centralised purchasing process, Consip engages in in-depth demand and supply analyses. Demand analysis is conducted by gathering information from public agencies (through interviews, phone calls, questionnaires, etc.). The supply market analysis is conducted by organising regular and structured meetings with individual suppliers and with associations of suppliers.

The centralised purchasing process, including the secondary phases and the units involved in the procurement process, is summarised below.

One distinguishing feature of Consip's procurement processes, besides the "teamwork" approach at each stage, is the presence of an internal economics consulting unit, the Research Unit (RU), which itself is part of a larger research and development unit.

The decision to create an RU in 2003 was rooted in the view that public procurement ought not to be considered as a set of rule-bound and multiple sign-off procedures. Basically, Consip rejected the idea that, in order to correctly implement public procurement processes, it was sufficient to just "stick to the rules".

Indeed, neither primary nor secondary legislation will ever instruct a procurement officer, among other things, concerning the way in which he/she should:

- $\quad$ split a national contract into multiple lots; 
- $\quad$ set a scoring rule;

- $\quad$ allocate technical and financial weightings;

- design appropriate quality incentives in a contract;

- $\quad$ minimise the risk of collusion among participating firms;

- design the architecture of an incomplete framework agreement, balancing competition between the first (conclusion) and the second (call-off) stages.

The topics above are some of the economic dimensions of procurement processes that are carefully analysed by the Research Unit. Moreover, the Research Unit conducts internationally recognised theoretical and empirical research in public procurement and plays an active role in international networks, such as IPPC and IPSERA, besides co-ordinating the activities of the EU Public Procurement Learning Lab. Moreover, RU staff are frequently invited as lecturers in postgraduate programmes in public procurement.

Environmental aspects are a key element in the Programme for the Rationalisation of Public Expenditure in Goods and Services. In recent years, the number of initiatives in compliance with Green Public Procurement (GPP) standards has considerably increased.

Key eco-objectives are:

- Efficiency and savings in the use of resources, especially energy, thus reducing CO2 emissions;

- $\quad$ Reduction in the use of hazardous substances and prevention of diseases;

- Quantitative reduction in waste products.

After years of commitment to sustainability, in 2008 Consip created an area dedicated to Green Public Procurement (GPP).

The GPP area has three main tasks:

- $\quad$ Support for market and demand analyses and the subsequent definition of purchasing strategy;

- $\quad$ Definition of the main criteria to be specified in tender documentation as basic criteria or supplierrewarding criteria;

- Support for the communication of green initiatives and the organisation of educational events.

The GPP area uses two main methodologies to define green product policies.

The common starting point is the research of any environmental standard (EU or international) referring to that specific product/service. If the product/service under consideration has been awarded an Ecolabel, it falls under the provisions of article 68 of legislative decree no.163/2006, which means that in its definition of environmental standards, Consip is legally allowed to use the criteria (all or part of the criteria) contained in the Ecolabel.

Once the criteria have been determined, it is necessary to assess whether the market is ready to fulfil the requirements that have been set. The rationale behind this assessment can be found in article 68 of legislative decree no.163/2006, which sets forth the duty to guarantee equal access to all tenderers, without creating unjustified obstacles to fair competition. Moreover, in accordance with the principle of non-discrimination, unless justified by the contract, technical specifications included in product labels are 
not to refer to a specific manufacturing or processing scheme or to trademarks, patents, type, origin or to a specific production that would result in preventing, restricting or distorting competition.

After this stage of assessment, some or all of the criteria contained in the Ecolabel are included in the tender.

If the product/service does not carry an Ecolabel, the methodology of LCA (Life Cycle Assessment) is applied. This investigation aims to identify the product's/service's critical parts (among the critical stages) during the life cycle. Once the critical stages have been identified, there is further research on standards and means of proof directly related to that specific aspect. Market analysis is the final stage.

The "market share" of Consip compared with the overall procurement volume of the public sector in 2009 is indicated in the following table:

\begin{tabular}{|l|c|c|}
\hline \multicolumn{2}{|c|}{ Year 2009 - figures in billion EUR } & Value (\%) \\
\hline $\begin{array}{l}\text { A) Overall public expenditure for goods and } \\
\text { services }\end{array}$ & 133 & - \\
\hline $\begin{array}{l}\text { B) Public expenditure that could have been } \\
\text { managed through the "Programme" }\end{array}$ & 36 & $\mathbf{2 7 . 1 \%}$ (B/A) \\
\hline $\begin{array}{l}\text { C) Overall public expenditure in goods/services } \\
\text { that are also covered by Consip's procurement } \\
\text { processes }\end{array}$ & 11.09 & $\mathbf{1 0 . 1 \%}$ (D/B) \\
\hline $\begin{array}{l}\text { D) Public expenditure directly passing through } \\
\text { Consip's e-procurement system }\end{array}$ & 3.62 & \\
\hline
\end{tabular}

The processes for market demand and supply analyses are as follows:

\section{Market demand analysis}

The key objectives of the "demand analysis" function within the Programme can be summarised as follows:

- Assess the interest of public administration bodies in the items surveyed and estimate the qualitative and quantitative aspects of the demand, with a focus on those administrations that are required to use Consip;

- Define the most appropriate e-procurement tools in order to gather together baskets of goods and services and accordingly define mixed/complementary supplies;

- Support the planning of initiatives (minimum/maximum amounts, technical features and distribution of supplies, continuity of the supply, etc.), while bearing in mind potential synergies within the network system.

Since procurement techniques are highly diversified, the analysis of the demand uses a broad spectrum of tools and inquiry sources/methods. 


\section{Market supply analysis}

The supply market is analysed by means of ad hoc market analyses and direct interviews with suppliers, consumer associations, industrial unions, etc.

The SME policy is based on the fact that Italy hosts the highest proportion of SMEs in Europe (19\%), although the average size of an Italian company - 3.19 employees - is well below the EU-27 average. Although the average value of frame contracts turns out to be too high for SMEs to participate, Consip's procurement strategy tends to split large contracts into several lots so as to reconcile two potentially conflicting forces. On the one hand, the higher the number of lots, the more likely that smaller firms will be willing to bid for some of the lots; on the other hand, the degree of competition may decrease for other lots.

Consip also defines technical and economic requirements so as to make it easier for smaller firms to join together to form bidding consortia.

Furthermore, in 2003 Consip set up the electronic marketplace for goods and services (MEPA), which has enabled a wider participation of SMEs (see Section 3 above).

Since 2004 Consip has been strengthening its co-operation with suppliers' institutional representatives by setting up Supplier Training Desks (STDs) within the territorial offices of enterprise associations. STDs provide training and assistance to local enterprises, mainly SMEs, on the use of electronic procurement tools.

The main goals of the SME policy are as follows:

- $\quad$ Enhance SMEs' awareness of IT tools and strengthen their ability to use them;

- Increase the participation of SMEs in Consip's activities, especially at local and regional levels, and support them in the use of e-procurement tools;

- Provide training on the use of the e-marketplace and on the opportunities it offers ("multiplication effect");

- $\quad$ Support SMEs during their first use of the e-marketplace (registration with the platform, ecatalogue creations, reply to a request for quotation).

\section{Internal Customer Relationships}

All public agencies at central and local levels are covered by Consip's operations, comprised as follows:

- Central state level: ministries and their territorial/local offices, state-owned companies, welfare institutions;

- Local administrations in regions, provinces and municipalities;

- Health institutions: hospitals, public health organisations;

- Universities. 
Main customers and their purchasing volumes (in million EUR):

\begin{tabular}{|l|c|c|c|c|}
\hline & $\begin{array}{c}\text { Local } \\
\text { Government }\end{array}$ & Central Government & Health Sector & Universities \\
\hline $\begin{array}{l}\text { Non-specific goods/services } \\
\text { (foodstuffs, restaurant } \\
\text { vouchers, car rentals, clothing) }\end{array}$ & 157 & 213 & 52 & 15 \\
\hline Electricity, fuel, fuel cards & 241 & 292 & 220 & 46 \\
\hline Services for buildings & 76 & 31 & 59 & 13 \\
\hline Goods/services for health care & 0 & 0 & 9 & 0 \\
\hline $\begin{array}{l}\text { IT equipment } \\
\text { Telecommunication services }\end{array}$ & 59 & 21 & 9 & 14 \\
\hline $\begin{array}{l}\text { Overall value of purchases } \\
\text { (million EUR) }\end{array}$ & $\mathbf{5 4 9}$ & $\mathbf{6 0 6}$ & $\mathbf{3 8 9}$ & $\mathbf{9 0}$ \\
\hline
\end{tabular}

On the issue of voluntary or obligatory use of Consip's services, the following rules have applied to date:

- The central government is mandated to use Consip's frame contracts according to a list that is drafted each year by the Ministry of Economy and Finance. The central government is also mandated to use the e-marketplace for purchases of a value that is below the EU threshold.

- Other public agencies are free to use Consip's frame contracts, if they so wish. If they do not choose to do so, however, they are obliged to "meet-or-beat" the "value-for-money" target achieved through Consip's frame contracts.

- $\quad$ Consip's strategy for communication and interaction with customers is implemented by means of a professional representative referred to as the "account manager" (AM).

The AM's tasks are mainly to:

establish a continuous exchange of information with users, identifying requirements and special needs;

- $\quad$ promote Consip's services: frame contracts, e-marketplace, projects;

- $\quad$ advise and support users' in the change management process;

- $\quad$ identify new initiatives and development opportunities;

- $\quad$ monitor "users' perception" of Consip's services.

The commercial relationship between Consip and customers is managed by means of "customer relation management tools", which comprise the following:

- $\quad$ Contacts database, containing information about users;

- Users' request management, which is an "end-to-end" process starting from various inputs: letter, fax, e-mail, call centre inquiry;

- Data Warehouse analysis and reporting;

- Marketing tools: e-mail campaigns, newsletters, toolkit.

Co-ordinated activities with other public agencies take place mainly with the Antitrust Authorities (AGCM) and the IT Authority for the Italian Public Administration (CNIPA). Every "new" procurement process (that is, relating to a good/service that has never been the object of a frame contract) and any new "edition" of a repetitive procurement process that has been modified in those aspects most likely to 
affect the level of competition (e.g. the number of lots) are sent to AGCM for a "non-binding evaluation". This means that Consip is not legally forced to heed the recommendations provided in AGCM's evaluation, but it nevertheless generally complies with those recommendations.

All of Consip's procurement strategies relating to IT goods/services are sent to CNIPA, with the same level of commitment to its recommendations as described above with AGCM.

\section{Procurement and Contracting}

Consip relies mostly on framework agreements (also referred to as frame contracts) with fixed terms and one economic operator. Consip is planning to adopt framework agreements where not all terms are fixed and where there is more than one economic operator (defined by the EC directive as framework agreements strictu sensu).

Virtually all procurement procedures are open tenders. Consip abides strictly by Italian rules for the publication of the notification of tenders by means of:

- $\quad$ GUUE (Official Journal of the European Union);

- $\quad$ GURI (Official Journal of the Italian Republic);

- $\quad$ ads in Italian and other European newspapers;

- website of the Programme: www.acquistinretepa.it.

The two main economic selection criteria are i) accumulated turnover in the past two years; and ii) accumulated "specific" turnover (that is, the fraction of the overall turnover that has been generated by activities related to those to be performed under the procurement contract).

Award criteria are either i) the lowest price (approximately $10 \%$ of tenders) and ii) the economically most advantageous tender (approximately 90\%).

The use of mini-competitions under framework agreements is limited. So far only one such framework agreement (strictu sensu) has been concluded for "server computers." At the call-off stage in a minicompetition, procuring entities are able to further specify some technical aspects (thus awarding additional technical points) and to ask for new financial offers (both for items that have already been subject to competition in the first stage and for some others).

Although Consip is not highly involved in the contract management phase (it is to be recalled that Consip awards frame contracts, with the contracting parties acting as the selected supplier and the procuring entity), it does provide help-desk services to those public agencies purchasing through Consip's system. It also supervises quality inspections by specialised firms to check whether quality standards have been maintained by contractors.

No evidence of anti-competitive behaviour has been gathered in the past few years, and the Antitrust Authorities (AGCM) have not started any formal investigation concerning competitive tendering procedures managed by Consip.

\section{Evaluation and Performance Measurement}

The analyses of prices and operational savings of Consip are carried out in the following manner:

The Italian National Statistics Institute (ISTAT) is the third party that annually has the task of surveying, estimating and endorsing the average purchasing "unit price" by public agencies that do not use Consip's 
system, and this average price is also normalised in such a way as to be comparable to the unit prices under Consip's frame contracts. More precisely, every year ISTAT takes the following steps:

1) Performs a survey to collect the prices of goods and services purchased by public agencies for which active frame contracts exist;

2) Normalises data regarding several kinds of products, including their terms and conditions of purchase, with a view to comparing them with "similar although not identical" products and their prices for which frame contracts are active;

3) Estimates the average "unit price" of each good/service purchased by public agencies and compares it with the unit price of a similar good/service available under a frame contract.

The analyses of market effects (in particular on SMEs), supplier structures and the competitive situation are carried out in the following manner:

1) "Product managers" in Consip's Public Procurement Division (DAPA) continuously monitor market trends (active firms, market shares, etc.), mainly by relying on official statistics and interviews/meetings with economic operators.

2) The impact of procurement strategies on the potential level of participation - and consequently on competition - is conducted with the Research Unit by using a bundle of economic/statistical indexes ("pessimistic" and "optimistic" indexes).

A customer satisfaction survey (according to the ECSI methodology) of public buyers using Consip's Programme is conducted every year by a third party (generally, an Italian university). The outcome of the customer satisfaction survey provides relevant information that contributes to the elaboration of Consip's strategic plan.

Consip's broad methodological approach can be summarised as follows:

"Active" customers - namely, those public buyers using Consip's e-procurement tools (frame contracts and the electronic marketplace) - are monitored by means of the statistical method referred to as FI.DO. (Fldelizzazione della Domanda - Demand Loyalisation). This tool has been developed by the company Pragma. In addition, "quadrant analysis - priority mappings" are used: starting from satisfaction indexes, the relative weight of any single factor used in taking a decision (or affecting satisfaction) is taken into account.

"Inactive" clients - namely, those public buyers that have not used Consip's e-procurement tools (frame contracts and the electronic marketplace) - during the previous year are surveyed by means of qualitative and quantitative analyses in order to identify the reasons for their decision to no longer use Consip's e-procurement solutions, with a view to identifying solutions for retrieving such buyers.

Reporting requirements are met by the elaboration of an official annual report, which is normally sent to all interested parties. Consip also drafts a "tailored" report for the Italian Parliament in which all main business activities are described.

\section{Important Success and Risk Factors}

\section{Success factors}

- Perception among public buyers as a "problem-solver" rather than an "expenditure controlling agency"; 
- $\quad$ Focus on the governance of complex procurement processes;

- $\quad$ Proven portfolio of complementary e-procurement solutions (e.g. design frame contracts should not compete with e-catalogues);

- Focus on both organisational change in the public sector and adoption of innovative IT solutions;

- Careful analyses of both the demand and supply sides;

- $\quad$ Promotion of SME participation in the procurement marketplace;

- $\quad$ Support by all relevant stakeholders.

\section{Risk factors}

- $\quad$ Perception by public authorities as a threat (to their autonomy) rather than an opportunity;

- General perception of centralisation as a policy orientation that hampers the participation of SMEs in the procurement market (even though the share of purchases made through Consip's framework agreements represents a tiny fraction of the overall expenditure by central and local public authorities);

- Difficulty to exert an influence on the purchasing models of public authorities (i.e. centralisation does not guarantee that public authorities will react by adopting a "new" organisational model).

\section{Future Development}

- $\quad$ Prove (that is, by providing concrete/measurable evidence) to main stakeholders that Consip is able to add more "value" to the national system rather than to provide mere "savings"), such as process innovation, social impact at a local level, higher level of integrity of public procurement processes, and higher level of trust of economic operators in the overall system of public procurement;

- Consolidate leadership in terms of "integrated know-how" (technological, legal and economic) in the field of public procurement;

- Consolidate its role as forerunner in the implementation of innovative solutions in public procurement (after the transposition of Directive 2004/18/EC into the Italian Code of Public Contracts, Consip designed and awarded the first framework agreement strictu sensu with several economic operators in Italy), for example by possibly undertaking the first "experiment" in Italy of a dynamic purchasing system, to be implemented by late 2011 . 